Chemical Technology

Division

Chemical Technology

Division

Chemical Technology Division

Chemical Technology Division

Chemical Technology

\title{
Recovery of Entrained CSSX Solvent from Caustic Aqueous Raffinate Using Coalescers
}

Division

Chemical Technology

Division

Chemical Technology

Division

Chemical Technology

by C. Pereira, H. A. Arafat, J. R. Falkenberg, M. C. Regalbuto, and G. F. Vandegrift

Division

Chemical Technology

Division

Chemical Technology

Division

Chemical Technology

Division

Chemical Technology

Division

Chemical Technology

Division

Chemical Technology

Division

Chemical Technology

Division

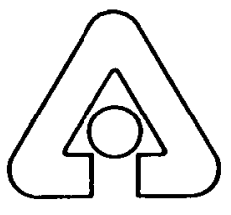

Argonne National Laboratory, Argonne, Illinois 60439

operated by The University of Chicago

for the United States Department of Energy under Contract W-31-109-Eng-38

Chemical Technology

Division

Chemical Technology

Division

Chemical Technology

Division

Chemical Technology

Division 
Argonne National Laboratory, with facilities in the states of Illinois and Idaho, is owned by the United States Government and operated by The University of Chicago under the provisions of a contract with the Department of Energy.

\begin{tabular}{l} 
DISCLAIMER \\
This report was prepared as an account of work sponsored by an agency of \\
the United States Government. Neither the United States Government nor \\
any agency thereof, nor The University of Chicago, nor any of their \\
employees or officers, makes any warranty, express or implied, or assumes \\
any legal liability or responsibility for the accuracy, completeness, or \\
usefulness of any information, apparatus, product, or process disclosed, or \\
represents that its use would not infringe privately owned rights. Reference \\
herein to any specific commercial product, process, or service by trade name, \\
trademark, manufacturer, or otherwise, does not necessarily constitute or \\
imply its endorsement, recommendation, or favoring by the United States \\
Government or any agency thereof. The views and opinions of document \\
authors expressed herein do not necessarily state or reflect those of the \\
United States Government or any agency thereof, Argonne National \\
Laboratory, or The University of Chicago. \\
\hline
\end{tabular}

Available electronically at http://www.doe.gov/bridge

Available for a processing fee to U.S. Department of Energy and its contractors, in paper, from:

U.S. Department of Energy

Office of Scientific and Technical Information

P.O. Box 62

Oak Ridge, TN 37831-0062

phone: (865) 576-8401

fax: (865) 576-5728

email: reports@adonis.osti.gov 
ANL-02/34

Argonne National Laboratory

Chemical Technology Division

9700 South Cass Avenue

Argonne, IL 60439

\section{RECOVERY OF ENTRAINED CSSX SOLVENT FROM CAUSTIC AQUEOUS RAFFINATE USING COALESCERS}

Candido Pereira, Hassan A. Arafat, John R. Falkenberg, Monica C. Regalbuto, and George F. Vandegrift

November 2002 
ABSTRACT

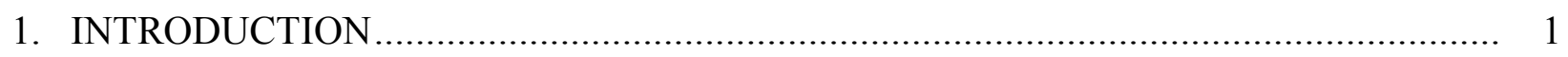

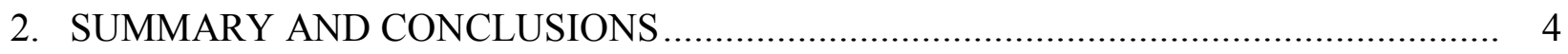

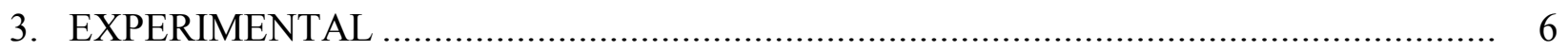

3.1 PHYSICAL PROPERTIES MEASUREMENT FOR OPTIMIZED SOLVENT FULL-COMPONENT SIMULANT …........................................................... 6

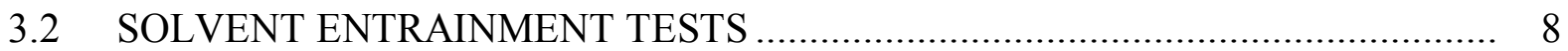

3.3 COALESCER MEDIA INTEGRITY ………................................................. 9

3.4 LABORATORY-SCALE COALESCER TESTS …......................................... 10

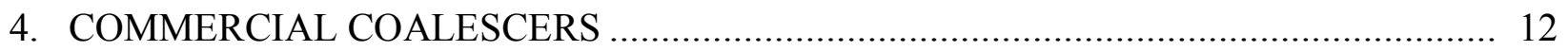

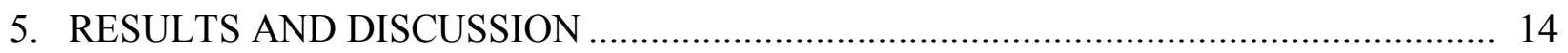

$5.1 \quad$ PHYSICAL PROPERTIES MEASUREMENTS ........................................... 14

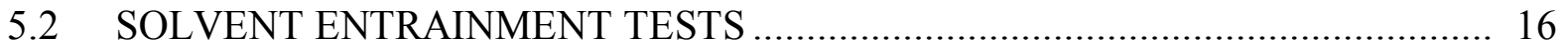

5.3 WEBER NUMBER EVALUATION .............................................................. 19

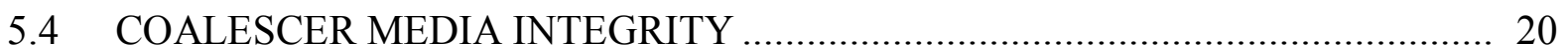

5.5 LABORATORY-SCALE COALESCER TESTS ............................................... 23

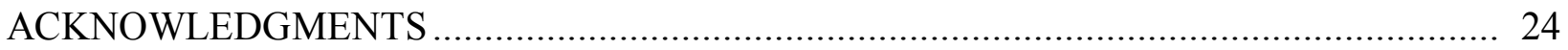

REFERENCES …

APPENDIX A. CHEMICAL ANALYSIS OF SIMULANT FROM ENTRAINMENT TESTS FOR BOBCALIXC6 AND CS-7SB CONTENT ................................ 27

APPENDIX B. CHEMICAL ANALYSIS OF SIMULANT FROM ENTRAINMENT TESTS FOR ISOPAR ${ }^{\circledR}$ L CONTENT …................................................... 29

APPENDIX C. DROPLET SIZE DISTRIBUTIONS AND DATA FOR ENTRAINMENT TESTS................................................................... 30

APPENDIX D. SUMMARY OF PHYSICAL PROPERTY DATA …………….................. 42

APPENDIX E. COALESCER VENDOR CONTACTS AND MEDIA SAMPLES ................ 45 


\section{FIGURES}

1. Flowsheet for CSSX Process Proof-of-Concept Tests with Solvent Recycle

2. Flowsheet for Solvent Entrainment Test

3. Laboratory-Scale Coalescer .

4. Experimental Setup for Laboratory-Scale Coalescer Tests ....

5. Variation in Density as a Function of Temperature for the Full-Component Simulant and Deionized Water....

6. Viscosity of Solvent vs. Temperature.

7. Viscosity of Full- and Four-Component Simulants vs. Temperature.

8. Effect of Temperature on Interfacial Tension between Full SRS Simulant and

CSSX Solvent

9. Droplet Size Distributions for Entrainment Test Raffinate Samples

10. Droplet Size Distributions for Two Entrainment Test Raffinate Samples and Blank SRS Waste Simulant after Standing for 12 Days

11. Weber Number as a Function of Droplet Size and Velocity at $25^{\circ} \mathrm{C}$ 20

12. Effect of Temperature on Weber Number 20

C.1. Droplet Size Distribution and Data for First Entrainment Test Sample. 30

C.2. Droplet Size Distribution and Data for Second Entrainment Test Sample. 32

C.3. Droplet Size Distribution and Data for Third Entrainment Test Sample 34

C.4. Droplet Size Distribution and Data for Fourth Entrainment Test Sample....................... 36

C.5. Droplet Size Distribution and Data for Blank SRS Waste Simulant ............................ 38

C.6. Droplet Size Distribution and Data for Blank Four-Component Simulant .................... 40

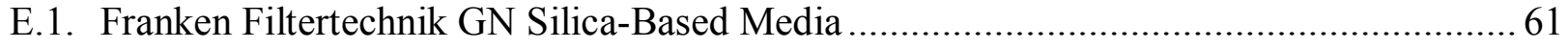

E.2. Franken Filtertechnik MF Stainless Steel Media ..................................................... 61 
FIGURES (continued)

E.3. Frank Filtertechnik MN Stainless Steel Media 62

E.4. Koch Otto-York 316SS Mesh Sample, Stainless Steel Mesh..................................... 62

E.5. Koch Ott-York 316SS/TEF Mesh Sample, Stainless Steel and Fluoropolymer Mesh ...... 63

E.6. Mercer International Sample 1, Stainless Steel Mesh .............................................. 63

E.7. Mercer International Sample 2, Stainless Steel Coupon .......................................... 63

E.8. McTighe Industries Sample A, Polymer Mesh Mixture........................................... 64

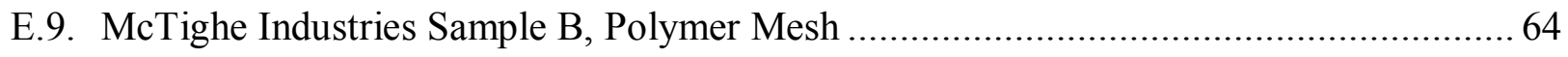

E.10. McTighe Industries Sample C, Polymer Mesh .................................................. 64

E.11. McTighe Industries Sample D, Polymer Mesh .................................................. 65

E.12. McTighe Industries Sample E, Polymer Coupons ............................................ 65

E.13. McTighe Industries Sample F, Polymer Coupons.................................................. 66

E.14. Filter Innovations Polymer Spheres .............................................................. 66 


\section{TABLES}

\section{$\underline{\text { Page }}$}

1. Full-Component SRS Waste Simulant Composition for a 30-L Batch ............................ 7

2. Commercial Coalescer Options ................................................................................. 12

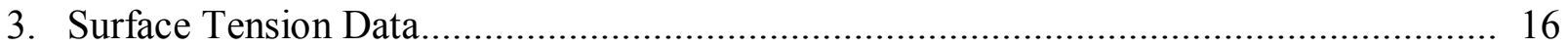

4. Chemical Analysis of Solvent Entrainment Samples .................................................. 17

5. Media Compatibility Tests....................................................................................... 22

6. Results of Tests with Laboratory-Scale Coalescer........................................................ 23

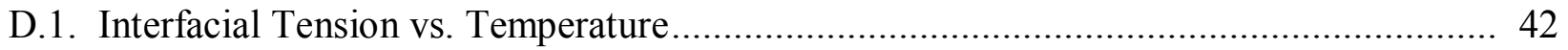

D.2. Surface Tension at Ambient Temperature …….......................................................... 42

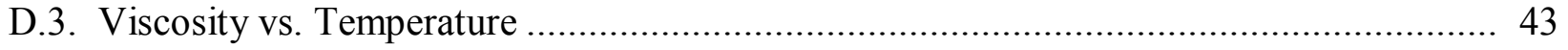

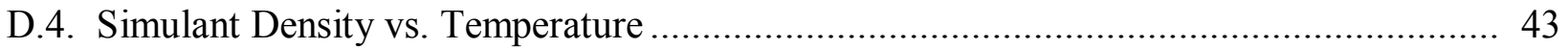

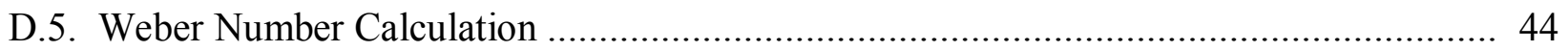

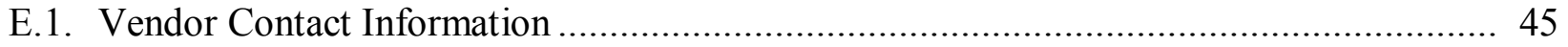




\title{
RECOVERY OF ENTRAINED CSSX SOLVENT FROM CAUSTIC AQUEOUS RAFFINATE USING COALESCERS
}

\author{
Candido Pereira, Hassan A. Arafat, John R. Falkenberg, Monica C. Regalbuto, and \\ George F. Vandegrift
}

\begin{abstract}
A solvent was developed at Oak Ridge National laboratory (ORNL) for a caustic-side solvent extraction (CSSX) process that removes cesium from Savannah River Site (SRS) tank waste. After treatment, a small fraction of the solvent is entrained in the caustic raffinate at a level of 100-300 ppm, well above the solubilities for the various solvent components. Recovery of this solvent can produce a potential cost saving in excess of $\$ 5 \mathrm{M}$ per annum based on a processing rate of $20 \mathrm{gpm}$. In this study we examined the issues associated with the use of a coalescer for solvent recovery and measured the physical properties of the solvent and simulant. The density, surface, and interfacial tension, and viscosity of the optimized solvent and a fullcomponent SRS waste simulant were determined as a function of temperature. The entrainment of the solvent components in the SRS waste simulant during the operation of a four-stage 4-cm contactor unit was quantified based on chemical and volumetric analysis. The chemical stabilities of several candidate commercial coalescing media in the caustic simulant were examined. Stainless steel media showed little degradation over a 30-day test; polymer media tended to be coated by the organic. A laboratory-scale coalescer was operated in tandem with a four stage 4-cm contactor unit. Results indicate that a $90 \%$ recovery of the entrained solvent can be achieved using a commercial coalescer equipped with appropriate media and at appropriate operating conditions. Finally, several commercial coalescer options are discussed.
\end{abstract}

\section{INTRODUCTION}

Approximately 34 million gallons of high-level radioactive waste are currently stored in underground tanks at the Savannah River Site (SRS) near Aiken, South Carolina [LEVENSON 2000]. A process developed at Oak Ridge National Laboratory (ORNL), in collaboration with Argonne National Laboratory (ANL) and SRS, was selected to remove cesium-137 $\left({ }^{137} \mathrm{Cs}\right)$ from the waste prior to immobilizing the waste in low-level grout. The treatment technology, which is a caustic-side solvent extraction (CSSX) process, will utilize a multistage centrifugal contactor to extract ${ }^{137} \mathrm{Cs}$ from the waste [LEONARD 2000]. The solvent consists of four components: (1) an extractant, calix[4]arene-bis(tert-octylbenzo-crown-6), designated BOBCalixC6, which is a calixarene crown that is very specific for cesium extraction; (2) a modifier, 1-(2,2,3,3,tetrafluoropropoxy)-3-(4-sec-butylphenoxy)-2-propanol, also called Cs-7SB, which is an alkyl aryl polyether that keeps the extractant dissolved in the solvent and increases its ability to extract cesium in the extraction section; (3) a suppressant, tri- $n$-octylamine (TOA), which suppresses the effects of organic impurities to ensure that the cesium can be back-extracted from the solvent in the strip section; and (4) a diluent, Isopar ${ }^{\mathbb{B}} \mathrm{L}$, which is a mixture of branched-chain 
hydrocarbons. The optimized solvent composition is $0.007 \underline{\mathrm{M}}$ BOBCalixC6, $0.75 \underline{\mathrm{M}} \mathrm{Cs}-7 \mathrm{SB}$, and $0.003 \mathrm{M}$ TOA in Isopar ${ }^{\mathbb{R}} \mathrm{L}$. The flowsheet for the CSSX process proof-of-concept test, performed at ANL in FY01 using the optimized solvent, is shown in Figure 1 [LEONARD 2000]. In the extraction section (stages 1 through 15 in Fig. 1), cesium is extracted from the alkaline waste feed by the CSSX solvent. Then, as the organic solvent flows through the scrub section (stages 16 and 17), entrained alkaline aqueous solution and weakly extracted potassium are removed from the solvent. In the strip section (stages 18 through 32), cesium is stripped from the CSSX solvent into dilute nitric acid.

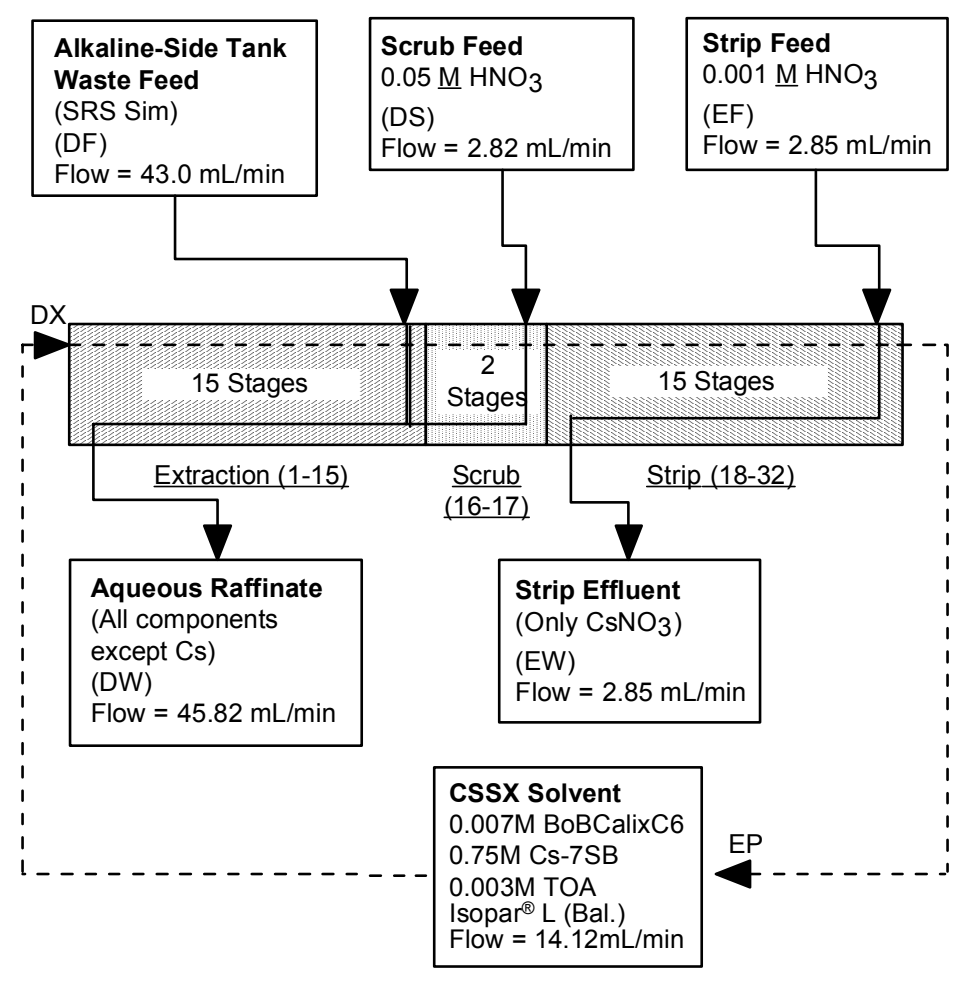

Fig. 1. Flowsheet for CSSX Process Proof-of-Concept Test with Solvent Recycle

Since the cost of the CSSX solvent is high, even small losses in the aqueous effluents can be expensive. Recent cost estimates for the BOBCalixC6, Cs-7SB, and Isopar ${ }^{\circledR} \mathrm{L}$ are $\$ 150 / \mathrm{g}$, $\$ 1.5 / \mathrm{g}$, and $\$ 5 / \mathrm{gal}$, respectively [ARAFAT 2002A]. Based on these estimates, the cost of original solvent was approximately \$1900/L [ARAFAT 2002A]. With the new, optimized solvent the cost is somewhat less, approximately $\$ 1600 / \mathrm{L}$. During the CSSX process, the solvent is transferred to the aqueous phase via two mechanisms: partitioning (dissolution) and entrainment. Solvent loss through partitioning is dependent on the distribution ratios (i.e., D values) of the solvent components between the organic and aqueous phases. The $\mathrm{D}$ values for the Cs-7SB and BOBcalixC6 were estimated to be greater than 50,000 and 12,500 respectively, suggesting that solvent loss will arise predominantly from entrainment. 
The recovery of entrained solvent should lead to a significant cost savings. As discussed in [ARAFAT 2002B], solvent entrainment accounts for most (>85\%) of the solvent lost in the extraction section. In that report, solvent entrainment was found to average $121 \mathrm{ppm}$ at steady operation for tests with the four-component simulant and an earlier solvent composition containing $0.010 \mathrm{M}$ BoBCalixC6, 0.5M Cs75B, and 0.001 M TOA. In this study, tests were conducted with a full-component simulant [PETERSON 2000] and the optimized solvent [KLATT 2001].

A number of options have been considered for recovery of the entrained solvent. Physical separations using decanters, centrifuges, and coalescers were discussed in an earlier work, where the decanter was the only option among these three that was tested [ARAFAT 2002B]. Chemical separation by contacting the aqueous phase with organic diluent Isopar ${ }^{\circledR} \mathrm{L}$ was also studied previously [ARAFAT 2002A]. Physical separation with a decanter proved inefficient, but calculations showed that a coalescer or centrifuge was feasible. Chemical separation achieved recovery of $>90 \%$ of the entrained solvent components; however, further processing was refined to remove the excess diluent and adjust the extractant and modifier concentrations to those of the feed in addition to removing entrained organic diluent from the processed aqueous solution. In this report we examine the use of a coalescer to achieve the desired separation. In a coalescer, the aqueous effluent contacts a physical medium that causes the entrained solvent droplets to agglomerate or coalesce until they become large enough to collect on the surface of the aqueous phase, allowing for a separation to be achieved. The advantage over a decanter is the smaller size of the unit and the higher throughput. Since the coalescer is static, maintenance is minimal and energy requirements are much lower than for a centrifuge.

Several factors that affect the design of the coalescer were examined. Physical properties of the simulant and solvent that play a role in the design of a coalescer, including the density, viscosity, and interfacial tension, were measured as a function of temperature. The entrainment of the CSSX solvent in the SRS waste simulant was measured by contacting the simulant and solvent in a four-stage $4-\mathrm{cm}$ contactor unit. The stabilities of several candidate coalescing media in the caustic simulant were tested. Finally a laboratory-scale coalescer was demonstrated to effect the separation of the organic and aqueous phases in the raffinate from a contactor. The results indicate that a coalescer, under appropriate operating conditions and with suitable media, can effectively recover entrained solvent. 


\section{SUMMARY AND CONCLUSIONS}

The high cost of the solvent and the significant entrainment losses suggest that recovery of the entrained solvent should lead to significant process savings. A coalescer is being considered for collecting and separating entrained CSSX solvent from the caustic raffinate. In order to test the viability of a coalescer and to size a commercial unit, we conducted experimental work to (1) measure the physical properties of the solvent and simulant that are required to size the coalescer and select an appropriate media, (2) determine the durability of various media materials when contacted with solvent and simulant, (3) extend the entrainment measurements to include SRS waste simulant and CSSX solvent, (4) examine the effectiveness of a laboratory-scale coalescer under process conditions, and (5) consider several available commercial coalescers.

A coalescer can be used to recover the entrained solvent. The coalescer consists of a large cylindrical vessel that houses mesh-like media. Suspended solvent droplets adhere to the media and agglomerate over time. At a critical size, the inertial forces of the flowing simulant overcome the adhesive forces between the droplet and the mesh causing it to break free. The increased buoyancy of the enlarged droplets causes them to flow to the surface of the aqueous phase, where they coalesce further to form a layer that can be effectively separated from the aqueous phase.

We measured several physical properties of the simulant and solvent that play a role in the design of a coalescer. Density, viscosity, and surface tension were determined as a function of temperature. The interfacial tension between the two liquids was also measured. Temperature was found to have a strong effect on the viscosity of the solvent, which varied from $5.3 \mathrm{cP}$ at $12^{\circ} \mathrm{C}$ to $2.2 \mathrm{cP}$ at $46^{\circ} \mathrm{C}$. The viscosity of the simulant also varied with temperature, ranging from $4.6 \mathrm{cP}$ at $11^{\circ} \mathrm{C}$ to $2.0 \mathrm{cP}$ at $45^{\circ} \mathrm{C}$. Interfacial tension and density did not vary strongly with temperature. The density of the simulant at $25^{\circ} \mathrm{C}$ was $1.26 \mathrm{~g} / \mathrm{mL}$; the surface tension was 59.7 dynes $/ \mathrm{cm}$. The surface tension of the solvent at $25^{\circ} \mathrm{C}$ was 24.3 dynes $/ \mathrm{cm}$. The interfacial tension between the SRS simulant and the CSSX solvent varied from 16.4 to 17.0 dyne $/ \mathrm{cm}$.

Entrainment was measured in the aqueous raffinate by contacting the simulant and solvent in a four-stage 4-cm contactor unit. Solvent entrainment was higher than previous results for the four-component solvent and the older simulant composition; on the order of $300 \mathrm{ppm}$ of solvent was entrained in the simulant based on analysis of the aqueous phase for BOBcalixC6 and modifier content. Entrainment was also measured as part of the tests with a laboratory-scale coalescer. I $\mathrm{n}$ one test, the quantity of solvent collected was consistent with an entrained solvent content of $\sim 350 \mathrm{ppm}$, in the same range as the results obtained by chemical analysis.

The organic component of the raffinate produced by a four-stage 4-cm contactor unit with SRS simulant and CSSX solvent as the feed was successfully separated from the aqueous component with a laboratory-scale coalescer equipped with mesh-like media. The aqueous product from the coalescer was selectively and continually drained from the coalescer while the organic accumulated within the vessel. At the end of the test, the coalescer was completely drained. Over one six-hour test with a Franken Filtertechnik MN media, $8 \mathrm{~mL}$ of organic phase 
was collected from $22.5 \mathrm{~L}$ of raffinate, corresponding to $90+\%$ recovery of the entrained solvent based on the entrainment test results. In tests with a coarser media and at higher flow rates, significantly less solvent was recovered, corresponding to 15 to $30 \%$ at the $300 \mathrm{ppm}$ entrainment level, indicating that media selection and operating conditions may significantly affect performance. However, variability in contactor operation may also have resulted in much lower entrainment and therefore higher recovery.

The tests conducted to date with the laboratory-scale coalescer indicate that a coalescer, under appropriate operating conditions and with suitable media, can be used to efficiently recover entrained solvent. There also appears to be some variability in the levels of entrainment from the test. Additional tests will have to be conducted to determine the optimal operating conditions and to select the best media because of the apparent variability. There was no visible change to the stainless steel media used in the tests with the laboratory-scale coalescer. A similar study of the recovery efficiency can readily be done for a centrifuge. 


\section{EXPERIMENTAL}

Physical properties were measured as a function of temperature. Chemical analysis of the solvent entrained in the simulant was performed at SRTC, and the BOBCalixC6, Cs-7SB, and Isopar $^{\circledR} \mathrm{L}$ diluent concentrations in the raffinate were measured. Conclusions related to solvent entrainment were based on the accuracy of these chemical analyses and additional measurements made using a laboratory-scale coalescer. Studies were conducted with the same four-stage, 4-cm contactor system used for the entrainment studies at the same organic to aqueous (O:A) ratio, 0.3 , but the flow rates were adjusted to match the operating range of the coalescer.

\subsection{PHYSICAL PROPERTIES MEASUREMENT FOR OPTIMIZED SOLVENT AND FULL-COMPONENT SIMULANT}

The solvent used for these tests was obtained from ORNL. The composition was that of the optimized solvent containing $0.007 \mathrm{M}$ BOBcalixC6 extractant, $0.75 \mathrm{M}$ Cs-7SB modifier, and $0.003 \mathrm{M}$ TOA in Isopar ${ }^{\mathbb{R}} \mathrm{L}$. In all of the tests the solvent was used as received.

Both four-component and full-component SRS waste simulants were used in the physical properties measurements. The four-component simulant contained $2 \mathrm{M} \mathrm{NaOH}, 2 \mathrm{M} \mathrm{NaNO}$, $0.5 \mathrm{M} \mathrm{Al}\left(\mathrm{NO}_{3}\right)_{3}$, and $0.5 \mathrm{M} \mathrm{NaNO}$ in deionized water. The full-component simulant without radionuclides was formulated in-house following the procedure provided by SRS [PETERSON 2000]. The composition is given in Table 1. The full-component simulant is not stable. Although the SRS simulant was filtered after it was prepared, a precipitate continued to form as the simulant was stored. The precipitate was not analyzed. In these tests, wherever the fullcomponent simulant was used, care was taken to exclude the precipitate by sampling only from the supernate at the top of the simulant storage vessel

Density Measurement: The density of the full-component simulant was measured as a function of temperature. A clean, dry $25-\mathrm{mL}$ volumetric flask was weighed. Slightly more than $25 \mathrm{~mL}$ of the simulant was added to the flask. The flask was immersed in a controlledtemperature bath until the solution attained the desired temperature. A pipette was used to adjust the simulant volume in the flask to $25 \mathrm{~mL}$. The simulant and flask were then weighed and the temperature was measured. Three samples were done at each temperature. 


\section{Table 1. Full-Component SRS Waste Simulant Composition for a 30-L Batch}

\begin{tabular}{|c|c|}
\hline Component & Quantity \\
\hline $\mathrm{NaOH}$ & $3.57 \mathrm{~kg}$ \\
\hline $\mathrm{Al}\left(\mathrm{NO}_{3}\right)_{3} .9 \mathrm{H} 2 \mathrm{O}$ & $3.16 \mathrm{~kg}$ \\
\hline $\mathrm{NaNO}_{3}$ & $3.01 \mathrm{~kg}$ \\
\hline $\mathrm{NaNO}_{2}$ & $1.04 \mathrm{~kg}$ \\
\hline $\mathrm{NaSO}_{4}$ & $0.6 \mathrm{~kg}$ \\
\hline $\mathrm{NaCO}_{3} \cdot \mathrm{H}_{2} \mathrm{O}$ & $0.56 \mathrm{~kg}$ \\
\hline $\mathrm{NaSiO}_{3} .9 \mathrm{H}_{2} \mathrm{O}$ & $0.26 \mathrm{~kg}$ \\
\hline $\mathrm{Na}_{2} \mathrm{HPO}_{4} .7 \mathrm{H}_{2} \mathrm{O}$ & $56.3 \mathrm{~g}$ \\
\hline $\mathrm{KNO}_{3}$ & $45.6 \mathrm{~g}$ \\
\hline $\mathrm{NaCl}$ & $42.14 \mathrm{~g}$ \\
\hline $\mathrm{NaF}$ & $35.28 \mathrm{~g}$ \\
\hline $\mathrm{Na}_{2} \mathrm{C}_{2} \mathrm{O}_{4}$ & $32.16 \mathrm{~g}$ \\
\hline $\mathrm{NH}_{4} \mathrm{NO}_{3}$ & $2.42 \mathrm{~g}$ \\
\hline $\mathrm{Na}_{2}\left(\mathrm{MoO}_{4}\right) \cdot 2 \mathrm{H}_{2} \mathrm{O}$ & $0.57 \mathrm{~g}$ \\
\hline $\mathrm{Zn}$ & $85 \mathrm{mg}$ \\
\hline $\mathrm{Sn}$ & $72 \mathrm{mg}$ \\
\hline $\mathrm{Pb}$ & $63 \mathrm{mg}$ \\
\hline $\mathrm{Fe}$ & $43.2 \mathrm{mg}$ \\
\hline $\mathrm{Cr}$ & $30 \mathrm{mg}$ \\
\hline $\mathrm{Ru}$ & $24.6 \mathrm{mg}$ \\
\hline $\mathrm{Cu}$ & $15 \mathrm{mg}$ \\
\hline $\mathrm{Pd}$ & $12.3 \mathrm{mg}$ \\
\hline $\mathrm{Rh}$ & $6.3 \mathrm{mg}$ \\
\hline $\mathrm{Hg}$ & $1.5 \mathrm{mg}$ \\
\hline $\mathrm{Ag}$ & $0.3 \mathrm{mg}$ \\
\hline HCOONa & $68.05 \mathrm{~g}$ \\
\hline $\mathrm{N}\left(\mathrm{CH}_{3}\right)_{3}$ & $0.86 \mathrm{mg}$ \\
\hline DBP & $0.324 \mathrm{mg}$ \\
\hline MBP & $0.324 \mathrm{mg}$ \\
\hline $\mathrm{C}_{4} \mathrm{H}_{13} \mathrm{OH}$ & $0.06 \mathrm{mg}$ \\
\hline TBP & $0.015 \mathrm{mg}$ \\
\hline
\end{tabular}

Viscosity Measurement: The viscosity of the CSSX solvent, the four-component simulant, and the full SRS waste simulant were measured as a function of temperature. A Brookfield LVT 25 viscometer equipped with a UL spindle was used for all measurements. The spindle was immersed in the fluid and rotated at $60 \mathrm{rpm}$ for the measurements reported in this document. The procedure outlined in ASTM D2196-99 was followed for all room-temperature measurements. At other temperatures, the vessel containing the fluid was immersed in a controlled-temperature bath, but the procedures were otherwise those listed in ASTM D2196. The temperature of the fluid was an average of that measured at different locations along the 
spindle cylinder. The variation in temperature was typically small, $<0.2^{\circ} \mathrm{C}$, with the exception of the lowest temperatures, where variations as high as $5^{\circ} \mathrm{C}$ were observed. Typically, the coldest temperatures were at the bottom of the fluid where more of the fluid container was in contact with the cooling medium.

Surface and Interfacial Tension: The surface tension of the optimized solvent, the fourcomponent simulant, and the full-component simulant were measured with a Fisher Scientific Tensiomet 100 tensiometer. The instrument is equipped with a platinum-iridium ring having a circumference of $5.993 \mathrm{~cm}$ and an $\mathrm{R} / \mathrm{r}$ of 53.1666. The ring is immersed in the fluid of interest and slowly pulled up through the fluid. The force required to break through the fluid surface of the interface between two fluids is recorded and converted to an interfacial tension. All measurements were made with the instrument in manual mode. The procedure outlined in the instrument manual, based on ASTM 1331-89, was followed for all of the room-temperature measurements. At other temperatures, the vessel containing the fluid was immersed in a controlled-temperature bath prior to placement on the instrument stage; the same procedure was followed. The temperature of the vessel was measured before and after each measurement.

The ring was cleaned by rinsing with acetone, immersing in benzene, rinsing with acetone, and heating in a butane torch to drive off any residual organic. Surface and interfacial tension measurements were made as a function of temperature. For the room-temperature measurement, the clean glass vessel was filled with full-component simulant, the ring was immersed in the simulant, and the optimized solvent was carefully poured onto the surface of the simulant. In subsequent measurements at other temperatures, the solvent was added to the simulant and immersed in a controlled-temperature bath prior to placement on the instrument stage. The ring was cleaned and immersed through the two layers after the temperature was equilibrated and prior to measurement. As a result, these measurements must be regarded only as showing the trend in interfacial temperature with temperature, since immersing the ring through both fluids contributes to experimental error.

\subsection{SOLVENT ENTRAINMENT TESTS}

A four-stage, 4-cm centrifugal contactor was used to study entrainment of solvent in the aqueous waste raffinate. The 4-cm contactors were chosen because (1) they should demonstrate higher stage efficiencies than 2-cm contactors [ARAFAT 2002A] and (2) they approach the expected 5.0- to $7.0-\mathrm{cm}$ size of the contactor for a waste treatment facility that is at $15 \%$ of full scale. The experimental flowsheet is shown schematically in Figure 2. The solvent was recycled. The simulant was used once and collected; it was subsequently reused for the laboratory-scale coalescer tests described below.

The aqueous waste simulant was set at a flow rate of $100 \mathrm{~mL} / \mathrm{min}$. It was contacted with the CSSX solvent, which was set at a flow rate of $30 \mathrm{~mL} / \mathrm{min}$ to induce entrainment of the solvent in the aqueous phase. The $\mathrm{O} / \mathrm{A}$ ratio, 0.3 , is similar to that in the extraction section of the CSSX process flowsheet. As the aqueous effluent left stage 1 it was collected in a container and stored. The organic effluent was collected from stage 4 and continuously pumped into stage 1 . The test was run for 2.5 hours. The test was started with $1.0 \mathrm{~L}$ of solvent and $\sim 25 \mathrm{~L}$ of simulant. At a number of intervals and at the end of the test, samples of the aqueous raffinate were 
collected for analysis of droplet size distribution and for shipment to SRTC for analysis of the various solvent components.

The SRTC developed an analytical procedure to measure the concentration of BOBCalixC6 and Cs-7SB modifier [WHITE 2002]; the entrained organic was extracted from the simulant by contacting with chloroform. The organic solution was then run through a series of chromatographic columns to isolate the BOBCalix6 and the Cs-7SB. A gas chromatograph-mass spectrometer was used to measure the Isopar ${ }^{\circledR}$ L content of the samples [CRUMP 2002]. The complete data set for these analyses given in Appendices A and B.

Droplet size analysis was performed with a Coulter Counter unit. This technique uses light scattering to determine the distribution in diameter of particles and droplets suspended in a solution. A Fraunhofer algorithm for water-based solutions was used to convert the absorbance spectrum into a particle size distribution. Results of the particle size analysis for the test samples, the SRS waste simulant, and the four-component simulant are given in Appendix C.

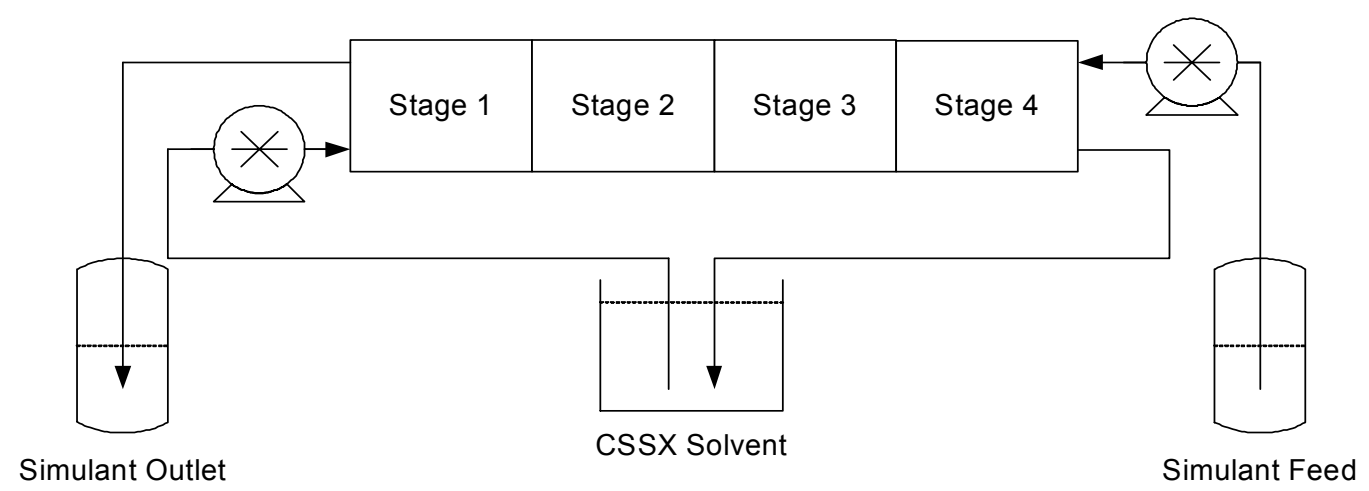

Fig. 2. Flowsheet for Solvent Entrainment Test

\subsection{COALESCER MEDIA INTEGRITY}

Samples of coalescer media were obtained from several vendors. The media consisted of polymeric, silica, or stainless steel mesh-like material. Samples of plastic and metal filter and structural components were also obtained from some vendors. The media were weighed and placed in a plastic bottle. The bottle was filled with $25-75 \mathrm{~mL}$ of simulant, to maintain a simulant-to-media mass ratio of 100, and capped solvent was subsequently added to the each of the sample bottles at a concentration of $1000 \mathrm{ppm}$. The media was initially completely immersed in the liquid in all cases; however, during the test, expansion of some media caused the samples to protrude from the surface of the solution. The samples were periodically examined visually to look for degradation. The presence of a film on the surface of the simulant indicated that some of the solvent had coalesced. After completion of the tests the samples were removed from the media, rinsed with deionized water, allowed to dry, and examined further with a light microscope. 


\subsection{LABORATORY-SCALE COALESCER TESTS}

A laboratory-scale coalescer was obtained from Franken Filtertechnik KG, Hurth, Germany. The unit dimensions are approximately 8 in. length and 2.5 in. diameter. A flanged section approximately $2 \mathrm{in}$. from the inlet port allows for access to the media housing and for internal cleaning. The unit contains eight $3 / 8$-in.-ID ports for the feed inlet, the organic and aqueous outlets, pressure measurement, level control, and draining of the vessel. The media are housed in a Teflon ${ }^{\circledR}$ "puck" that is inserted within the unit at the flange location. The unit is rated for flow rates between 25 and $117 \mathrm{~mL} / \mathrm{min}$. The unit is shown in Figure 3.

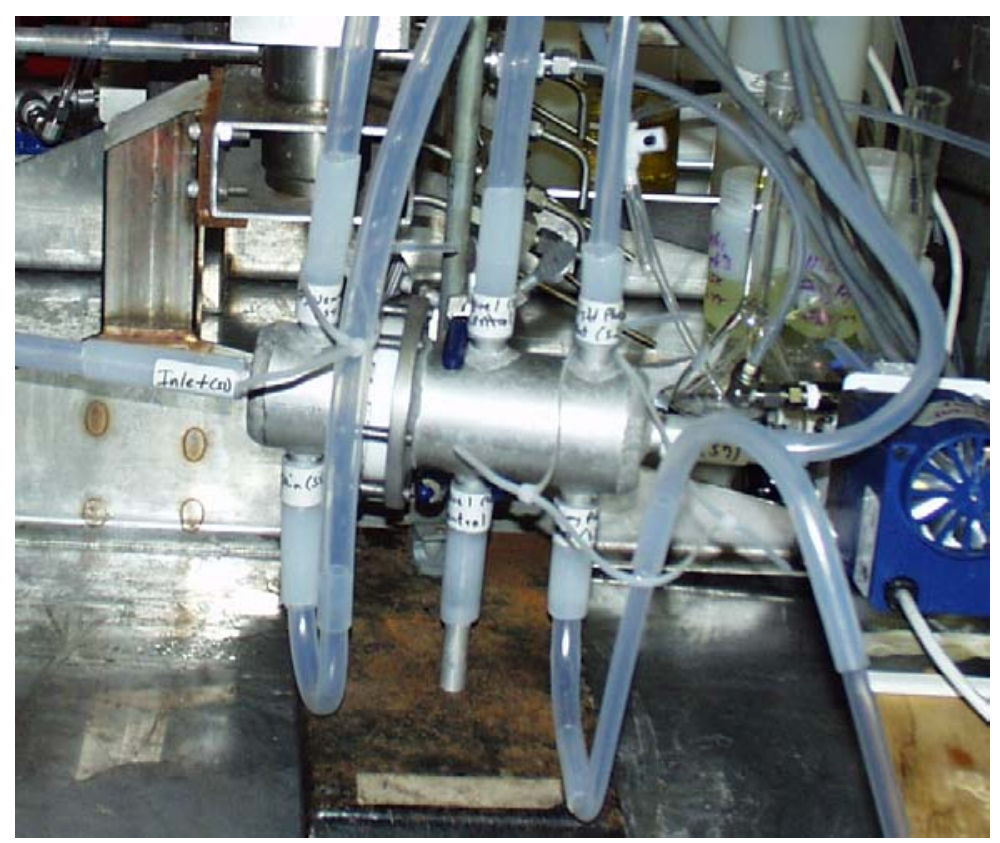

Fig. 3. Laboratory-Scale Coalescer

For the laboratory-scale tests, the unit was run in tandem with the four-stage, 4-cm contactor used in the entrainment tests described above. The aqueous effluent from the contactors was fed directly into the coalescer feed inlet. The level within the unit was controlled by adjusting the height of the aqueous outlet tube. The feed to the unit was kept at a level that prevented backflow into the last contactor stage. The pressure drop across the media was approximately 3 in. of water. The unit was run at steady state for up to 6 hours, after which the unit was drained of its contents. These contents were collected in a separatory funnel and placed into volumetric flasks to isolate the organic phase. The organic phase was removed from the flask with a pipette. The volume collected was measured with a graduated cylinder or a calibrated centrifuge tube. The experimental setup is shown in Figure 4. 


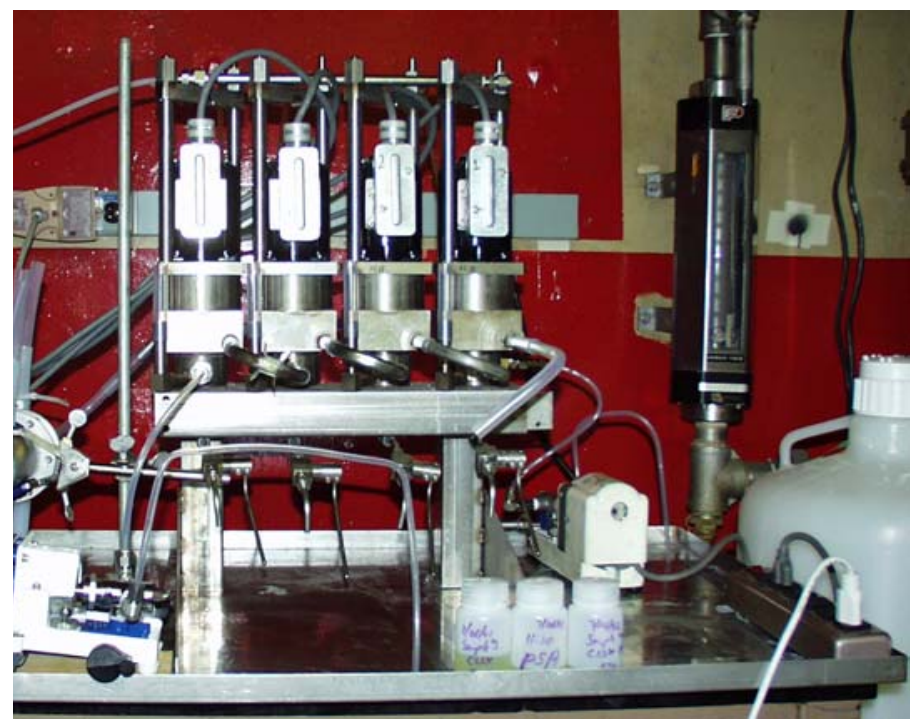

Fig. 4. Experimental Setup for Laboratory-Scale Coalescer Tests 


\section{COMMERCIAL COALESCERS}

Vendors of liquid-liquid coalescers and separators were sent a description of the separation process requirements and data on the measured droplet size distribution and available physical property data for the solvent and simulant [ARAFAT 2002B, MOYER 2001]. We have received proposals from several commercial vendors outlining dimensions, media type, and cost for a coalescer sized for a 3.2-gal/min-scale plant. The unit is sized to process $3 \mathrm{gpm}$ of waste. A summary of available commercial coalescers that may affect the separation is given in Table 2 . Appendix E provides quotations from two vendors and photographs of the vendor-supplied media and structural samples that were tested for stability in the SRS waste simulant containing 1000 ppm CSSX solvent.

Table 2. Commercial Coalescer Options

\begin{tabular}{|c|c|c|c|}
\hline Vendor & $\begin{array}{c}\text { Dimensions, } \mathrm{ft} \\
(\mathrm{LxWxH})\end{array}$ & Media & Cost, $\$$ \\
\hline Franken FilterTechnik & $6 \times 3 \times 6$ & Stainless steel & 15,000 \\
\hline Pall Equipment Corp. & $10 \times 1.25 \times 4$ & Fluoropolymer & 40,500 \\
\hline Koch-Otto York & $5 \times 1 \times 2.5$ & $\begin{array}{l}\text { Stainless steel/ } \\
\text { fluropolymer }\end{array}$ & 10,000 \\
\hline Mercer & NA & Stainless steel & NA \\
\hline McTighe & $5 \times 1 \times 2.5$ & Polypropylene & 6000 \\
\hline Filter Innovations & NA & $\begin{array}{l}\text { Polypropylene } \\
\text { stainless steel }\end{array}$ & 200,000 \\
\hline Amistco & $7 \times 1.5 \times 2$ & Polymer & 7,000 \\
\hline
\end{tabular}

Liquid-liquid coalescer systems generally consist of three components: pre-filter, coalescing medium, and separator. The pre-filter removes suspended particulates that may lodge in the coalescing medium, disrupting its function. The coalescing medium consists of a mesh or structure form to which the entrained droplets adhere and coalesce into larger droplets. The separator separates and collects the light phase from the heavy phase.

Several configurations and designs are available based on either a horizontal or vertical configuration [WINES 2002]. Vertical configurations generally separate an entrained aqueous phase from a continuous organic phase. Separation is accomplished by use of a hydrophobic barrier. The horizontal configuration is used to separate systems characterized by low interfacial tension $(<3$ dynes $/ \mathrm{cm})$ and for systems in which the entrained phase is the organic and the aqueous phase is continuous. In this configuration, phase separation is accomplished by density difference, allowing the lighter phase to accumulate above the heavy phase. The lighter phase can be collected in a sump above the primary vessel or removed by a surface skimmer into a 
separate segment of the vessel. Flat plate coalescers achieve simultaneous separation of solids and organics from an aqueous phase.

In the coalescer, $0.2-$ to $50-\mu \mathrm{m}$ droplets are transformed into $\sim 1000-\mu \mathrm{m}$ or larger droplets. This process is accomplished in following manner: droplets adhere to the media fiber or surface, bulk flow induces their translation to intersections where they combine or coalesce to form larger droplets that dislodge with the increase in drag due to bulk fluid flow. This process is repeated, with more open media if necessary, until droplets flow to the fluid interface. For interfacial tensions of $>20 \mathrm{dyne} / \mathrm{cm}$, large stable droplets are formed that are readily coalesced. Stable emulsions of small droplets are formed for interfacial tensions between 2 and 20 dyne/cm, which are more difficult to separate with a coalescer [WINES 2002, GARDNER $1997]$.

We have conducted tests with media from these vendors to determine the integrity of the media. The dimensions of the commercial units vary to a small extent. The largest unit is ten feet long; however, ancillary equipment such as particulate filter housings are not reflected in some of the dimensions given. There is a very wide variation in the price of the units. Selection will be based on several factors but stability of the media in the caustic simulant will be a major consideration. Radiation damage to the polymeric components will be a factor as well, but was not examined. 


\section{RESULTS AND DISCUSSION}

\subsection{PHYSICAL PROPERTIES MEASUREMENTS}

Density Measurement: The density of the full-component simulant is shown in Figure 5 as a function of temperature. For comparison, the change in density of water is also shown. There is only a moderate decrease in density with temperature. The density ranges from 1.26 $\mathrm{g} / \mathrm{mL}$ at $15^{\circ} \mathrm{C}$ to 1.24 at $43^{\circ} \mathrm{C}$. The trend observed for the simulant closely follows that shown by the deionized water. The density of the optimized solvent ranged from $0.86 \mathrm{~g} / \mathrm{mL}$ at $15^{\circ} \mathrm{C}$ to $0.84 \mathrm{~g} / \mathrm{mL}$ at $40^{\circ} \mathrm{C}$ [DELMAU 2002].

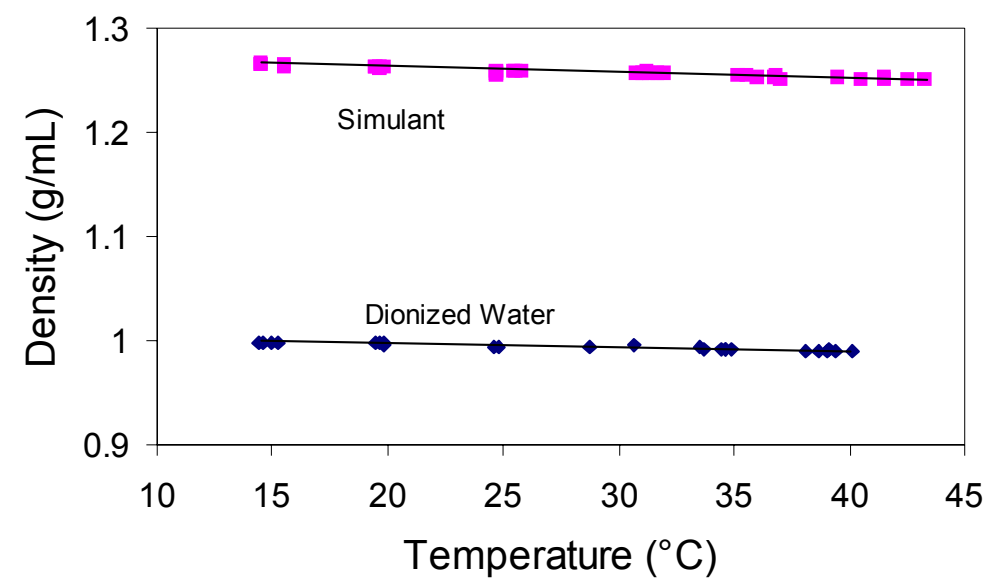

Fig. 5. Variation in Density as a Function of Temperature for the Full-Component Simulant and Deionized Water

Viscosity Measurement: The viscosity of the optimized solvent is shown in Figure 6. The viscosity of the four-component simulant and the full-component simulant as a function of temperature are shown in Figure 7. The viscosity of the solvent shows a steady decrease from $5.3 \mathrm{cP}$ at $12^{\circ} \mathrm{C}$ to $2.2 \mathrm{cP}$ at $46^{\circ} \mathrm{C}$. It should be noted that at the lower temperatures the variation in temperature along the length of the spindle of the viscometer was $\sim 5^{\circ} \mathrm{C}$ and contributes some uncertainty to the values measured at the lowest temperatures. The simulants show a similar downward trend in viscosity with temperature. The viscosity of the full-component simulant ranges from $4.6 \mathrm{cP}$ at $11^{\circ} \mathrm{C}$ to $2.0 \mathrm{cP}$ at $45^{\circ} \mathrm{C}$. The difference between the viscosity of the solvent and that of the full-component simulant decreases with temperature. The viscosity of the four component simulant shows a similar downward trend with temperature. 


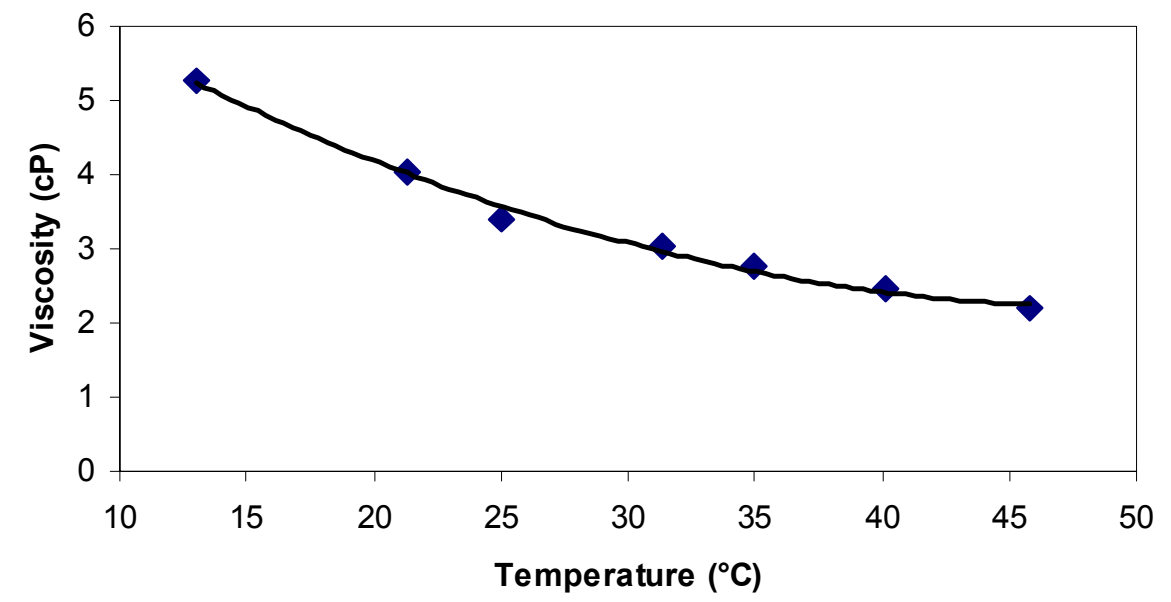

Fig. 6. Viscosity of Solvent vs. Temperature

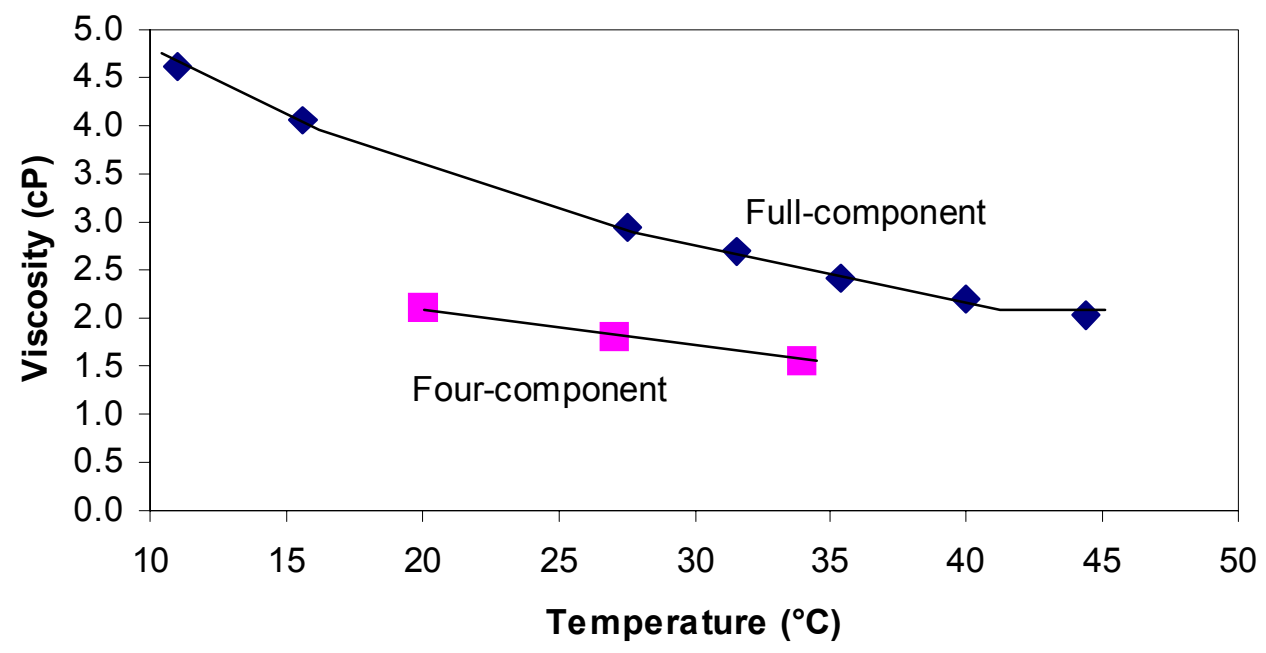

Fig. 7. Viscosity of Full- and Four-Component Simulants vs. Temperature

Surface and Interfacial Tension: The surface tension of the optimized solvent, the fourcomponent simulant, and the full-component simulant are given in Table 3. The measurement for each component was repeated five times; the average value for each is listed in Table 3 . The interfacial tension between the full simulant and the optimized solvent as a function of temperature is shown in Figure 8. Within experimental error there appears to be a slight increase in the interfacial tension with temperature, though one would expect a decrease with temperature. The values measured are slightly lower than the value of 18.8 dynes $/ \mathrm{cm}$ reported previously [MOYER 2001]. 
Table 3. Surface Tension Data

\begin{tabular}{cc}
\hline Component & Surface Tension, dynes/cm \\
\hline Solvent & $24.3 \pm 0.2$ \\
Four-component simulant & $59.7 \pm 0.2$ \\
Full-component simulant & $73.5 \pm 0.1$ \\
\hline
\end{tabular}

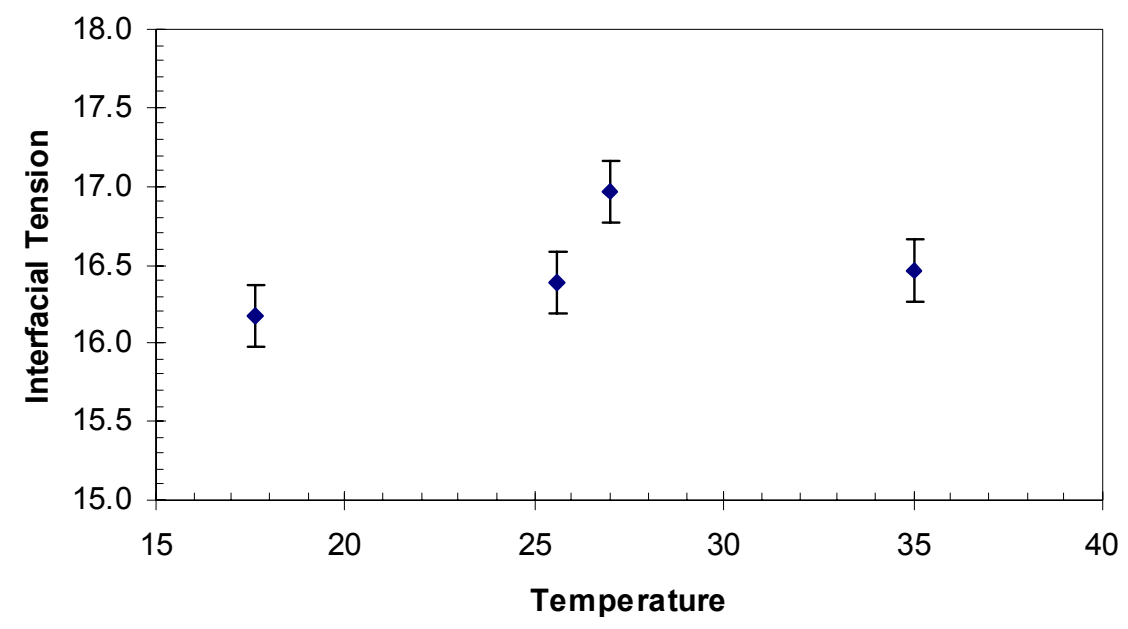

Fig. 8. Effect of Temperature on Interfacial Tension between Full SRS Simulant and CSSX Solvent

\subsection{SOLVENT ENTRAINMENT TESTS}

A four-stage, 4-cm centrifugal contactor unit was used to study entrainment of solvent in the aqueous waste raffinate. The experimental flowsheet is shown schematically in Figure 2 . The solvent was continually recycled with no additional treatment. The simulant was used once. The full simulant was contacted at a flow rate of $100 \mathrm{~mL} / \mathrm{min}$ with the CSSX solvent to create typical entrainment of the solvent in the aqueous phase. The $\mathrm{O} / \mathrm{A}$ ratio was maintained at 0.3 . The test was run for 2.5 hours. At a number of intervals and at the end of the test, samples of the aqueous raffinate were collected for droplet size distribution analysis and for shipment to SRTC for component analysis.

Six samples were submitted for chemical analysis. Four samples were taken during the test at 45-minute intervals. The last two were control samples consisting of simulant spiked with 100 and 300 ppm of the CSSX solvent. Results of the chemical analysis are shown in Table 4. The results of the chemical analysis for BOBcalixC6 and Cs-7SB content were in line with the concentration of these components in sample 5, the sample spiked with $300 \mathrm{ppm}$ solvent, while the concentrations for sample 6, containing $100 \mathrm{ppm}$ solvent, were at approximately one third of the concentrations in sample 5. Therefore, the control samples were internally consistent. However, the BOBcalixC6 concentrations measured for the control samples were higher than the 
calculated values. The measured Cs-7SB concentrations for the control samples were similar to the expected values. Analysis of the Isopar ${ }^{\circledR}$ L content was not consistent with this analysis.

Values tended to vary from sample to sample in an inconsistent fashion. The measured values for samples 5 and 6 were much lower than the expected values.

Table 4. Chemical Analysis of Solvent Entrainment Samples

\begin{tabular}{c|c|c|c|c|c|c}
\hline \multirow{2}{*}{ Sample } & \multicolumn{2}{|c|}{ BOBCalixC6 } & \multicolumn{2}{c|}{ Cs-7SB } & \multicolumn{2}{c}{ Isopar ${ }^{\circledR} \mathrm{L}$} \\
\cline { 2 - 7 } & $\begin{array}{c}\text { Conc., } \\
\mathrm{mg} / \mathrm{L}\end{array}$ & $\begin{array}{c}\text { Entrainment, } \\
\mathrm{ppm}\end{array}$ & $\begin{array}{c}\text { Conc., } \\
\mathrm{mg} / \mathrm{L}\end{array}$ & $\begin{array}{c}\text { Entrainment, } \\
\mathrm{ppm}\end{array}$ & $\begin{array}{c}\text { Conc., } \\
\mathrm{mg} / \mathrm{L}\end{array}$ & $\begin{array}{c}\text { Entrainment, } \\
\mathrm{ppm}\end{array}$ \\
\hline 1 & 4.2 & 522 & 101 & 398 & 7 & 10 \\
2 & 4.25 & 528 & 105 & 414 & 6.3 & 9 \\
3 & 3.71 & 461 & 88.1 & 347 & 3.2 & 5 \\
4 & 4.89 & 608 & 126 & 496 & 16 & 23 \\
AVG & 4.26 & 530 & 105 & 414 & 8.1 & 12 \\
5 & 4 & 497 & 90.8 & 358 & 24 & 34 \\
5 (expected) & 2.4 & 300 & 76.1 & 300 & 210 & 300 \\
6 & 1.33 & 165 & 25.3 & 100 & 2.4 & 3 \\
6 (expected) & 0.8 & 100 & 25.4 & 100 & 70 & 100 \\
\hline
\end{tabular}

The lack of consistency between the three analyses makes determination of a specific entrainment level difficult. However, it should be noted that the BOBCalixC6 and Cs-7SB concentrations match those of the control sample at $300 \mathrm{ppm}$ and are approximately three times higher than those of the sample at $100 \mathrm{ppm}$. Therefore, the best estimate for the level of solvent entrainment is $300 \mathrm{ppm}$. Because the concentrations measured for the diluent are much lower than those for the extractant and modifier, it appears that diluent was lost from the samples upon handling and storage.

Particle size analysis of the raffinate samples was inconclusive. The samples collected during the test were essentially identical, as can be seen in Figure 9. There is a major peak between 50 and $200 \mu \mathrm{m}$ centered at $120 \mu \mathrm{m}$. This large feature has a small shoulder centered at $\sim 80 \mu \mathrm{m}$. A shallower feature is evident between 1 and $20 \mu \mathrm{m}$. The particle size analysis was similar to results obtained previously for the previous solvent composition entrained in the fourcomponent simulant [ARAFAT 2002B]. Figure 10 shows particle size analysis of two samples left standing for 12 days. There is a shift in the large peak at $120 \mu \mathrm{m}$ to larger particle sizes, 180 $\mathrm{mm}$. The peak is also broader ranging from 50 to $300 \mu \mathrm{m}$. The shoulder at $80 \mathrm{~mm}$ has broadened as well. The features at smaller particle size have disappeared. The SRS simulant used in the entrainment test was also analyzed at this time and was found to be nearly identical to raffinate samples with entrained solvent that had been left standing, as can be seen in Figure 10; the four-component simulant had a particle size distribution similar to that of the SRS waste simulant. All of the particle size data are included in Appendix C. 
Although not conclusive, these results suggest that the particle size distributions obtained were primarily due to salt precipitates or other particulate suspended within the solution rather than organic droplets. It is possible that features observed in Figure 9 can be attributed to the organic phase; notably, the features at small particle sizes and the presence of similar features in the distribution for the blank simulant suggest that these are, at least in part, associated with the solid precipitates. Because the blank samples showed particle size distribution similar to the raffinate, other techniques must be developed to determine the droplet size of the entrained organic in the simulant. However, the presence of precipitates makes quantification of the organic phase by other techniques extremely difficult. For example, laser light scattering of the four-component simulant indicated that the turbidity of the unspiked simulant was too high for quantitative analysis.

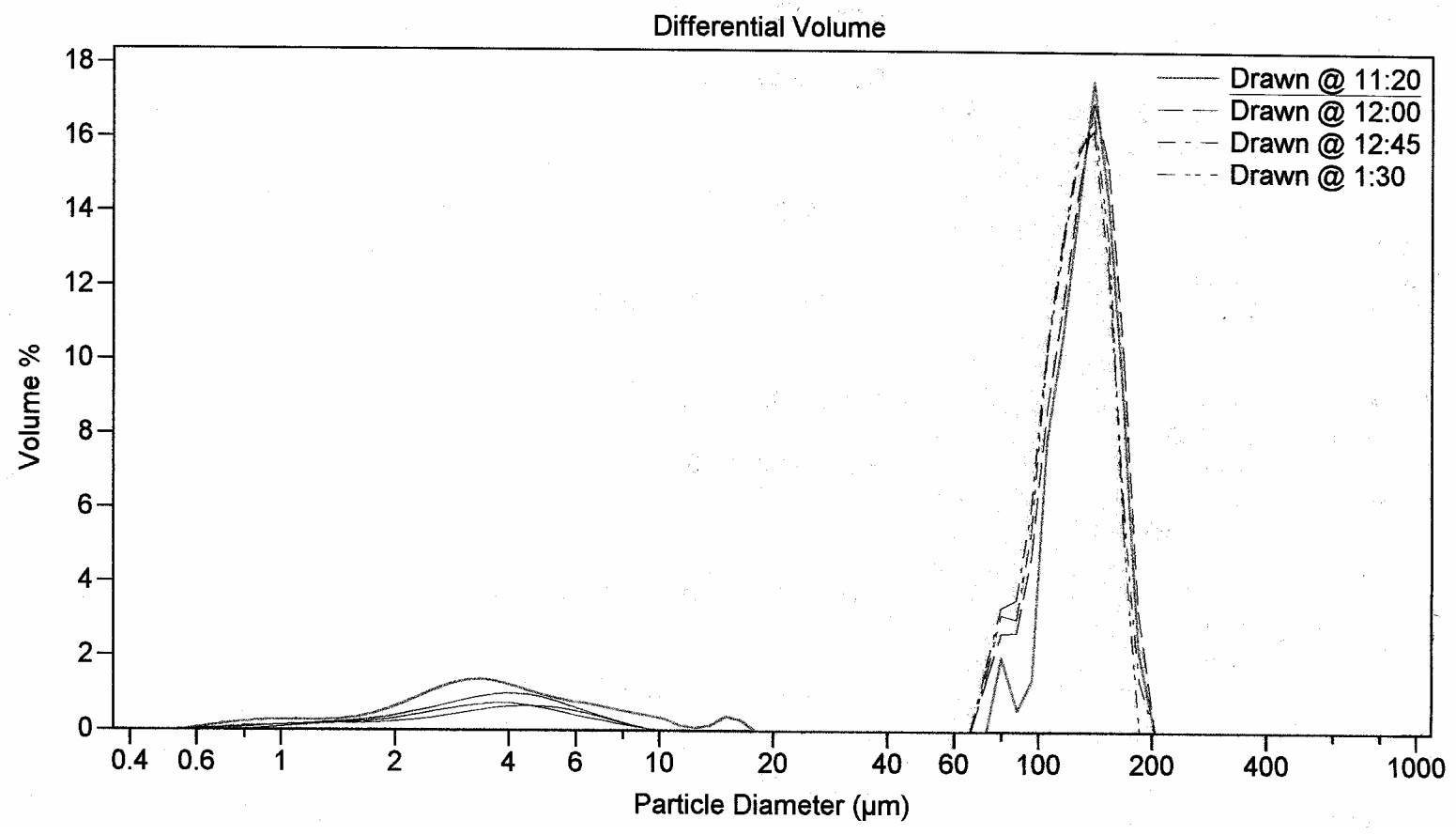

Fig. 9. Droplet Size Distributions for Entrainment Test Raffinate Samples 


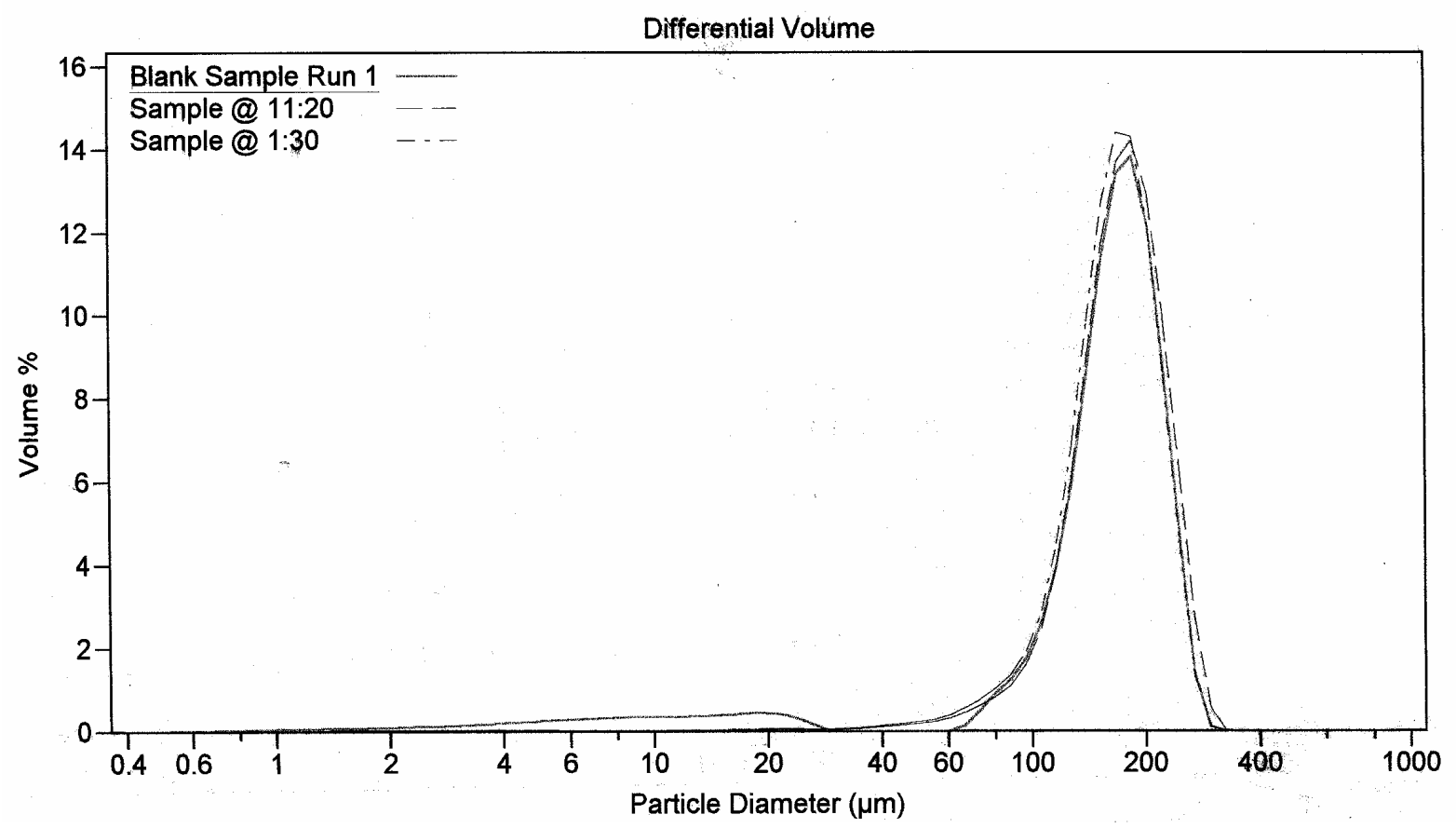

Fig. 10. Droplet Size Distributions for Two Entrainment Test Raffinate Samples and Blank SRS Waste Simulant after Standing for 12 Days

\subsection{WEBER NUMBER EVALUATION}

The effectiveness of a coalescer can be determined by evaluation of the Weber number, which is given by Equation (1), where $\mathrm{V}$ is the droplet velocity, $\rho$ is the liquid density, $\mathrm{D}$ is the droplet diameter, and $\sigma$ is the interfacial tension. The Weber number relates the shear forces of the flowing liquid on a droplet to the interfacial tension between phases. At a Weber number value above 1 , the droplets become unstable and break up. Also, in general, at interfacial tensions below 3 dynes/cm, separation of the phases becomes ineffective. [WINES 2002] The value of the velocity component can be derived from Stokes law as given in Equation (2), where $\mathrm{g}$ is the gravitational acceleration, $\rho$ and $\rho_{\mathrm{d}}$ are the densities of the continuous and entrained phases, and $\mu$ is the viscosity of the continuous phase.

$$
\begin{gathered}
\mathrm{We}=\rho \mathrm{DV}^{2} / \sigma \\
\mathrm{V}=\mathrm{gD}^{2}\left|\rho-\rho_{\mathrm{d}}\right| /(18 \mu)
\end{gathered}
$$

These equations were used to develop Figure 11, incorporating the solvent and simulant data discussed in Section 5.1 at $25^{\circ} \mathrm{C}$. Because of the turbidity of the full-component simulant, there is a lack of data on the particle size distribution. However, from the figure, it seems clear that for 
particle sizes less than $1000 \mu \mathrm{m}(1 \mathrm{~mm})$, a coalescer will be effective for solvent recovery at $25^{\circ} \mathrm{C}$. The same trend is observed at other temperatures with the Weber number increasing with increasing temperature as is shown in Figure 12.

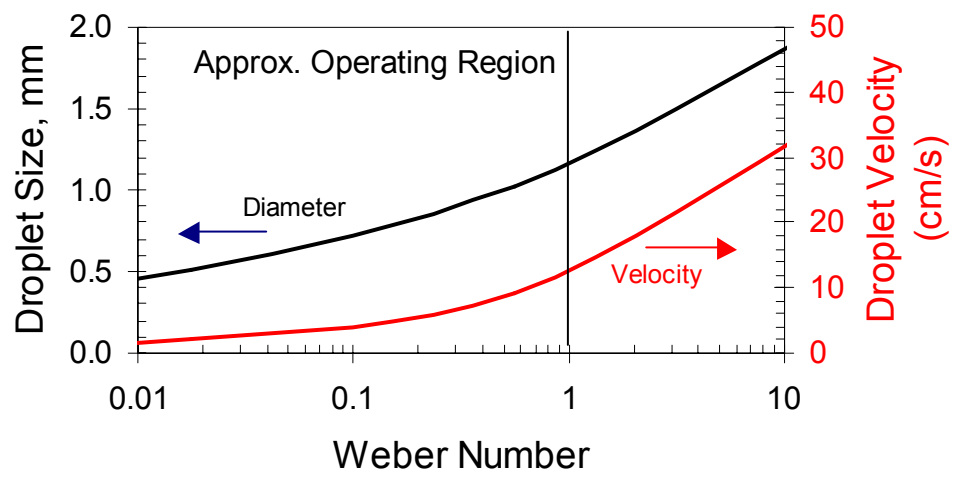

Fig. 11. Weber Number as a Function of Droplet Size and Velocity at $25^{\circ} \mathrm{C}$. Desired range for coalescer suitability is shaded region.

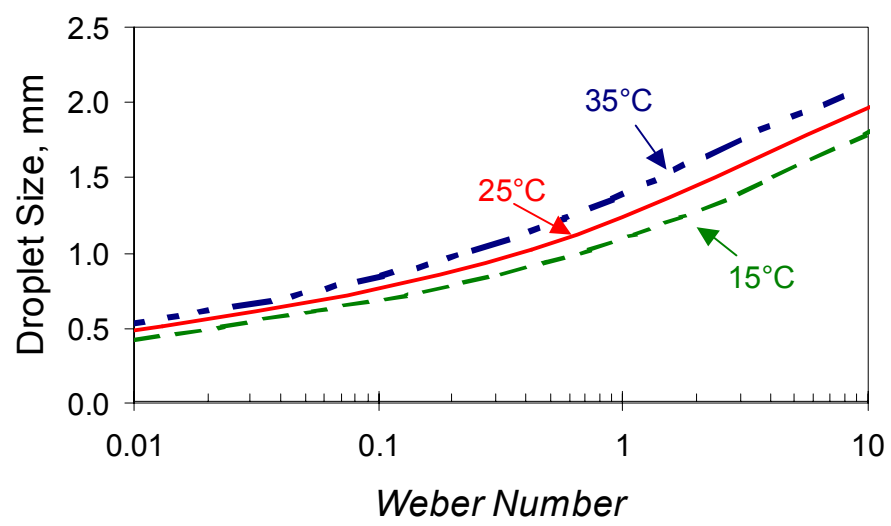

Fig. 12. Effect of Temperature on Weber Number

\subsection{COALESCER MEDIA INTEGRITY}

Samples of coalescer media were obtained from several vendors. The media consisted of plastic, silica, or stainless steel mesh-like material. Samples of plastic and metal filter and structural components were also obtained in some cases. The media were weighed and placed in plastic bottles. Each bottle was filled with 25 to $75 \mathrm{~mL}$ of simulant to maintain a simulant-tomedia mass ratio of 100 . The media was completely immersed in the liquid in most cases, although some expansion over time was observed. The samples were periodically examined visually to look for degradation. After completion of the tests the samples were removed from the media, allowed to dry and examined further with a light microscope. 
Several general observations of the media tests can be made:

- The silica medium was the only sample that showed clear embrittlement and degradation.

- The organic film on the fluid surface was generally more prevalent for the metal media.

- The organic phase tended to coat the plastic media.

- Degradation of the plastic meshes was observed, but only at the strand-to-strand junction points.

- Salt precipitation seemed more prevalent for the metal meshes.

- The finest metal meshes tended to retain the organic.

A summary of the media compatibility tests is given in Table 5 .

Solid particulates were observed suspended in the simulant solution upon completion of the media stability tests. There was also a small amount of precipitate in the bottom of some sample containers from these tests. Similar precipitates were observed at the base of the container housing the source simulant from which these samples were taken, and within the fourstage contactor used in the entrainment and coalescer tests. The precipitates are likely salt coming out of the meta-stable simulant. Small crystallites were evident adhering to all of the media samples once they had dried after the test were completed. It is possible that the media served as a nucleation center for salts that precipitated out of solution. The media from the labscale coalescer test did not show evidence of such crystallites. These results do suggest that a pre-filter should be used in tandem with the coalescer. 
Table 5. Media Compatibility Tests

\begin{tabular}{|c|c|c|}
\hline Media & Composition & Observations \\
\hline Franken GN & Silica Mesh & $\begin{array}{l}\text { Extensive swelling. Media became brittle with immersion. } \\
\text { Very cloudy simulant. }\end{array}$ \\
\hline Franken MF & $\begin{array}{l}\text { Stainless } \\
\text { Steel Mesh }\end{array}$ & $\begin{array}{l}\text { Some swelling. Most of organic was trapped within media. } \\
\text { Removed by compressing media. Clear simulant. }\end{array}$ \\
\hline Franken MN & $\begin{array}{l}\text { Stainless } \\
\text { Steel Mesh }\end{array}$ & $\begin{array}{l}\text { Slight swelling. Most of organic was trapped within media. } \\
\text { Removed by compressing media. Clear simulant. }\end{array}$ \\
\hline Mercer 1 & $\begin{array}{l}\text { Stainless } \\
\text { Steel Mesh }\end{array}$ & $\begin{array}{l}\text { Media was unchanged. Some organic formed film in web. } \\
\text { Organic at simulant surface. Extensive salt precipitation. }\end{array}$ \\
\hline Mercer 2 & $\begin{array}{l}\text { Stainless } \\
\text { Steel Coupon }\end{array}$ & Brown spots on coupon. Solution is clear. \\
\hline $\begin{array}{l}\text { Koch-Otto } \\
\text { York } 316\end{array}$ & $\begin{array}{l}\text { Stainless } \\
\text { Steel Mesh }\end{array}$ & $\begin{array}{l}\text { Media was unchanged. Some organic formed film in web. } \\
\text { Organic at simulant surface. Some salt precipitation. }\end{array}$ \\
\hline $\begin{array}{l}\text { Koch-Otto } \\
\text { York 316-TEF }\end{array}$ & $\begin{array}{l}\text { Stainless } \\
\text { Steel-Teflon } \\
\text { Mesh }\end{array}$ & $\begin{array}{l}\text { Media was unchanged. Some organic formed film in web. } \\
\text { Organic at simulant surface. Clear simulant. Few tiny droplets } \\
\text { on mesh. Some salt precipitation. }\end{array}$ \\
\hline $\begin{array}{l}\text { Koch-Otto } \\
\text { York 316/316- } \\
\text { TEF }\end{array}$ & $\begin{array}{l}\text { Stainless } \\
\text { Steel-Teflon } \\
\text { Mesh }\end{array}$ & $\begin{array}{l}\text { Media was unchanged. Some organic formed film in web. } \\
\text { Organic at simulant surface. Clear simulant. Few tiny droplets } \\
\text { on mesh; larger at steel-Teflon junctions. Some salt } \\
\text { precipitation. }\end{array}$ \\
\hline McTighe A & er & $\begin{array}{l}\text { Media was unchanged. Organic coats surface of thicker mesh } \\
\text { filaments. Solution is very clear with organic film on surface. }\end{array}$ \\
\hline McTighe B & $\begin{array}{l}\text { Polymer } \\
\text { Mesh }\end{array}$ & $\begin{array}{l}\text { Solvent coats sample but no clear evidence of degradation. } \\
\text { Less salt precipitation than on metal samples. }\end{array}$ \\
\hline McTighe $\mathrm{C}$ & $\begin{array}{l}\text { Polymer } \\
\text { Mesh }\end{array}$ & $\begin{array}{l}\text { Mesh beginning to unwind at junctions. Solution adheres to } \\
\text { triangular crevices in mesh. Organic is present on surface but } \\
\text { not as extensive as other media. }\end{array}$ \\
\hline McTighe D & $\begin{array}{l}\text { Polymer } \\
\text { Mesh }\end{array}$ & $\begin{array}{l}\text { Mesh broke apart. Small droplets adhered to straight sections. } \\
\text { Solution is similar to McTighe C. }\end{array}$ \\
\hline McTighe E & $\begin{array}{l}\text { Polymeric } \\
\text { Coupon }\end{array}$ & $\begin{array}{l}\text { Simulant, primarily organic, adheres to media. Solution is } \\
\text { clear. Organic surface layer is less substantial than in other } \\
\text { samples. }\end{array}$ \\
\hline McTighe $\mathrm{F}$ & $\begin{array}{l}\text { Polymeric } \\
\text { Coupon }\end{array}$ & $\begin{array}{l}\text { Simulant, primarily organic, adheres to media. Small } \\
\text { particulates are evident in solution. As for McTighe E, organic } \\
\text { surface layer is less substantial than in other samples less } \\
\text { substantial than in other samples. }\end{array}$ \\
\hline $\begin{array}{l}\text { Filter } \\
\text { Innovations }\end{array}$ & $\begin{array}{l}\text { Polymeric } \\
\text { Unit }\end{array}$ & $\begin{array}{l}\text { No indication of degradation. Simulant or organic coated the } \\
\text { surface; could be removed by wiping or washing. Simulant } \\
\text { solution was clear with small droplets of organic evident on } \\
\text { surface and suspended particulates. }\end{array}$ \\
\hline
\end{tabular}




\subsection{LABORATORY-SCALE COALESCER TESTS}

A laboratory-scale coalescer was obtained from Franken FiltertechnikKG. The unit was run in tandem with the four-stage, 4-cm contactor set used in the entrainment tests described above. The aqueous effluent from the contactors was fed directly into the coalescer feed inlet. The level within the coalescer was controlled by adjusting the liquid height in the aqueous-phase outlet tube. The feed to the unit was kept at a level that prevented backflow into stage 1 . The pressure drop across the coalescer media varied from approximately 3 to 4 in. of water. The test was run at steady state for 2.5 to 6.75 hours after which the coalescer was drained of its contents. These contents were collected in a separatory funnel and placed into volumetric flasks to isolate the organic phase. The deionized water used to flush the coalescer was also added to the separatory funnel. The organic phase was removed from the flask with a pipette. The volume collected was measured with a graduated cylinder.

Results are given in Table 6 for the three tests that were run. Tests were run at two flow rates with two different media - a fine media, MN, and a coarse media, MC. The results indicate that a greater quantity of solvent is recovered at the lower flow rate and with the finer media, MN. These results follow the expected trends for the performance of the coalescer. The coarser media does not appear to be as effective as the finer media. The higher flow rate was at the maximum-rated capacity of the coalescer, which may have limited its performance. The fraction of organic that can be recovered depends on the amount that is entrained. The solvent recovered in the initial test was consistent with entrainment at the $350 \mathrm{ppm}$ level; this entrainment is also consistent with the chemical analysis results for the entrainment tests discussed above. The quantity of organic in the raffinate from the contactor was not quantified, but based on the data above, the coalescer test results suggest that a major fraction of the entrained organic was recovered in the first test, but that a lesser fraction was recovered in the other two tests.

These tests indicate that a substantial fraction of the solvent can be recovered with the coalescer at appropriate flow rates and with suitable media. The variation in the amount of solvent recovered suggests a strong media effect. The effectiveness of the coalescer and the effect of the media on its performance can be readily quantified by conducting a systematic study with several different media and varying the operating conditions. For entrainment at the $300 \mathrm{ppm}$ level in a 20.1-gal/min plant-scale operation [HODGES 2000] for $240 \mathrm{day} / \mathrm{yr}$, the total annual cost of solvent lost via entrainment to both extraction and strip solutions would be approximately $\$ 14,000,000 / \mathrm{yr}$. At the lower level of entrainment, $100 \mathrm{ppm}$, the cost remains significant at $\sim \$ 5 \mathrm{M} / \mathrm{yr}$ for the same flow rate.

Table 6. Results of Tests with Laboratory-Scale Coalescer

\begin{tabular}{c|c|c|c|c}
\hline Test (media) & $\begin{array}{c}\text { Aqueous Flow } \\
\text { Rate, } \mathrm{mL} / \mathrm{min}\end{array}$ & $\begin{array}{c}\text { Organic Flow } \\
\text { Rate, } \mathrm{mL} / \mathrm{min}\end{array}$ & Duration, $\mathrm{h}$ & $\begin{array}{c}\text { Solvent Recovered, } \\
\mathrm{mL}\end{array}$ \\
\hline $1(\mathrm{MN})^{\mathrm{a}}$ & 57.7 & 17.3 & 6.75 & 8.1 \\
\hline $2(\mathrm{MN})$ & 90 & 27.5 & 5.3 & 2.3 \\
\hline $3(\mathrm{MC})^{\mathrm{a}}$ & 60.0 & 17.3 & 6.25 & 1.2 \\
\hline
\end{tabular}

${ }^{\mathrm{a}} \mathrm{MN}$ and $\mathrm{MC}$ are the designations used by Franken Filtertechnik for the media. 


\section{ACKNOWLEDGMENTS}

This work was supported by the U.S. Department of Energy, Office of Environmental Management, through the Office of Project Completion and the Tank Focus Area of the Office of Science and Technology under Contract W-31-109-Eng-38 with Argonne National Laboratory, managed by the University of Chicago. Thomas White and Steve Crump of SRTC performed the chemical analysis of the simulant from the solvent entrainment tests. 


\section{REFERENCES}

ARAFAT 2002A

H. A. Arafat, J.R. Falkenberg, and R. A. Leonard, Solvent Recovery from Aqueous Effluent Using Process Diluent in the Caustic Side Solvent Extraction (CSSX) Process, Argonne National Laboratory Report ANL-02/31 (2002).

ARAFAT 2002B

H. A. Arafat, M. C. Hash, A. S. Hebden, and R. A. Leonard, Characterization and Recovery of Solvent Entrained During the Use of Centrifugal Contactors, Argonne National Laboratory Report ANL-02/08 (2002).

CRUMP 2002

S. Crump, Savannah River Technology Center, private communication (2002).

DELMAU 2002

L. Delmau, Oak Ridge National Laboratory, private communication (2002).

GARDNER 1997

A. Gardner, "Refining Details: Advances in Liquid/Liquid Coalescing Technology," Today's Refinery, March 1997.

HODGES 2000

M.E. Hodges, Design Input-Caustic Side Solvent Extraction Flowsheet-Proof of Concept Testing, Westinghouse Savannah River Company Report HLW-SDT-2000-000356 (2000).

KLATT 2001

L. N. Klatt, J.F. Birdwell, Jr, P. V. Bonneson, L. H. Delmau, L. J. Foote, D. D. Lee, R. A. Leonard, T. G. Levitskaia, M. P. Maskarinec, and B. A. Moyer, "Caustic-Side Solvent Extraction-Composition Recommendation," Oak Ridge National Laboratory Report ORNL/TM-2001/258 (2002).

LEONARD 2000

R. A. Leonard, S. B. Aase, H. A. Arafat, C. Conner, J. R. Falkenberg, and G. F. Vandegrift, Proof-of-Concept Flowsheet Tests for Caustic-Side Solvent Extraction of Cesium from Tank Waste, Argonne National Laboratory Report ANL-00/30 (2000).

LEONARD 2002

R. A. Leonard, S. B. Aase, H. A. Arafat, C. Conner, D.B. Chamberlain, M.C. Regalbuto, and G. F. Vandegrift, Multi-Day Test of the Caustic-Side Solvent Extraction Flowsheet for Cesium Removal from a Simulated SRS Tank Waste, Argonne National Laboratory Report ANL-02/11 (2002). 


\section{LEVENSON 2000}

M. Levenson et al., "Alternatives for High-Level Waste Salt Processing at the Savannah River Site," National Research Council, National Academy Press, Washington, DC (2000).

MOYER 2001

B. A. Moyer, S. D. Alexandratos, P. V. Bonnesen, G. M. Brown, J. E. Caton, L. H. Delmau, C. R. Duchemin, T. J. Haverlock, T. G. Levitskaia, M. P. Maskarinec, F. V. Sloop, and C. L. Stine, "Caustic-Side Solvent Extraction Chemical and Physical Properties: Progress in FY2000 and FY2001," Oak Ridge National Laboratory Report ORNL/TM-2001/285 (2001).

\section{PETERSON 2000}

R. A. Peterson, "Preparation of Simulated Waste Solutions for Solvent Extraction," Westinghouse Savannah River Company Report WSRC-RP-2000-00361, Rev. 0 (2000).

WHITE 2002

T. White, Savannah River Technology Center, private communication (2002).

WINES 2002

T. H. Wines and R. L. Brown, "Minimizing Liquid Contaminants in Natural Gas Liquids," Pall Corporation Report (2002). 


\section{APPENDIX A. CHEMICAL ANALYSIS OF SIMULANT FROMENTRAINMENT TESTS FOR BOBCALIXC6 AND CS-7SB CONTENT}

The following report on the BOBCalixC6 and Cs-7SB entrainment levels was prepared by Thomas White of SRTC:

Concentrations in $\mathrm{mg} / \mathrm{L}$ were determined on an Agilent $\mathrm{LC}$ instrument with chloroform mobile phase and a Shodex K-801GPC column. The data is recorded in notebook \#2001-0141.

Salt Solution Results and Preparation

$\underline{\text { Sample ID }}$ CabtBC6 $\quad \underline{\text { Cs-7SB }}$

$1 \quad 4.20 \quad 101$

$2 \quad 4.25 \quad 105$

$3 \quad 3.71 \quad 88.1$

$4 \quad 4.89 \quad 126$

$\begin{array}{lll}5 & 4.00 & 90.8\end{array}$

$6 \quad 1.33 \quad 25.3$

Sample amounts were determined by weight and converted to volume using a density of 1.285. The samples were emptied into a separatory funnel and the containers were rinsed three times with chloroform. Each sample was extracted with chloroform three times $(3 \times 20 \mathrm{~mL})$, dried with anhydrous sodium sulfate, and the extracts were combined and concentrated to $2.00 \mathrm{~mL}$.

\section{Receipt of Samples}

Six yellow aqueous samples $(\sim 100 \mathrm{~mL})$ in Nalgene HDPE $125 \mathrm{~mL}$ were received from Argonne on $8 / 12 / 02$. The samples were double boxed with packing material. According to Pereira, these containers were the ones used to collect the sample from the solvent extraction process.

\section{Standards}

Standards of calix[4]arene-bis(tert-octylbenzo-crown-6) (extractant, IBC Advanced Technologies) and 1-(2,2,3,3-tetrafluoropropoxy)-3-(4-tert-octylphenoxy)-2-propanol (modifier) were prepared in chloroform and analyzed.

\begin{tabular}{|l|l|l|}
\hline & Extractant & Modifier \\
\hline Theoretical & $24.2 \mathrm{mg} / \mathrm{L}$ & $116 \mathrm{mg} / \mathrm{L}$ \\
\hline Actual & $25.8 \mathrm{mg} / \mathrm{L}$ & $116 \mathrm{mg} / \mathrm{L}$ \\
\hline
\end{tabular}

Cesium extraction solvent (PVB B000894-31W; 12,000 mg/L extractant and 170,000 mg/L modifier) was diluted 1:200 in chloroform and injected 5 times $(\mathrm{n}=5)$. 


\begin{tabular}{|l|l|l|}
\hline $\mathrm{n}=5$ & $\begin{array}{c}\text { Extractant, } \\
\mathrm{mg} / \mathrm{L}\end{array}$ & Modifier, mg/L \\
\hline$v=4$ & 11,700 & 174,000 \\
\hline $\mathrm{t}=2.776$ & 11,700 & 174,000 \\
\hline & 11,900 & 170,000 \\
\hline & 12,000 & 170,000 \\
\hline & 12,000 & 170,000 \\
\hline Average & 11,800 & 172,000 \\
\hline St. dev. & 160 & 2240 \\
\hline \%rsd & 1.35 & 1.31 \\
\hline 95\% con. & \pm 199 & \pm 2780 \\
\hline & & \\
\hline
\end{tabular}

Standards of cesium extraction solvent were analyzed before and after the sample analyses at 1 to 666 dilutions.

\begin{tabular}{|l|c|c|}
\hline & $\begin{array}{c}\text { Extractant, } \\
\mathrm{mg} / \mathrm{L}\end{array}$ & Modifier, mg/L \\
\hline Before & 12,100 & 171,000 \\
\hline After & 11,000 & 171,000 \\
\hline
\end{tabular}

Spike

After the initial three extractions and work-up of sample \#1, sample \#1 was extracted three more times and worked up. This indicates about three percent of the solvent remains in the salt solution after three extractions.

\begin{tabular}{|l|c|c|}
\hline & $\begin{array}{c}\text { Extractant, } \\
\mathrm{mg} / \mathrm{L}\end{array}$ & Modifier, mg/L \\
\hline Initial extraction round & 250 & 6020 \\
\hline Second extraction round & 6.33 & 119 \\
\hline \% yield in second & 2.47 & 1.94 \\
\hline
\end{tabular}

Cesium extraction solvent was then spiked into sample \#1 and a greater than $86 \%$ recovery was obtained for both components.

\begin{tabular}{|l|c|c|}
\hline & $\begin{array}{c}\text { Extractant, } \\
\mathrm{mg} / \mathrm{L}\end{array}$ & Modifier, mg/L \\
\hline Theoretical & 60.0 & 850 \\
\hline Actual & 52.0 & 940 \\
\hline \% Recovery & 87 & 110 \\
\hline
\end{tabular}




\section{APPENDIX B. CHEMICAL ANALYSIS OF SIMULANT FROM ENTRAINMENT TESTS FOR ISOPAR ${ }^{\circledR}$ L CONTENT}

The following report on the Isopar ${ }^{\circledR} \mathrm{L}$ content of the simulant from the entrainment tests was prepared by Steven Crump of SRTC:

SRT-ADS-02-0452

\section{Discussion of Results}

Six aqueous samples were analyzed for Isopar ${ }^{\circledR} \mathrm{L}$ content, and results are tabulated below. Sample 1B was analyzed to check for residual analyte in the aqueous sample after extractions had been carried out, and showed that $3 \%$ of the Isopar ${ }^{\circledR} \mathrm{L}$ remained in the aqueous samples after the initial extraction. The detection limit for all samples in this study was $0.02 \mathrm{mg} / \mathrm{L}$.

$\begin{array}{lrr}\text { Sample ID } & \text { Isopar }^{\circledR} \text { L, mg/L1A } & 7.0 \\ \text { 1B } & & 0.25 \\ 2 & & 6.3 \\ 3 & & 3.2 \\ 4 & & 16 \\ 5 & & 24 \\ 6 & & 2.4\end{array}$

\section{Experimental}

The aqueous samples were extracted three times with chloroform and the combined extracts were dried and concentrated under nitrogen, then analyzed by Gas Chromatography/Mass Spectrometry (GC/MS). Sample 1 was re-extracted an additional three times to generate sample 1B. GC/MS analysis was carried out using isotopic dilution to quantitate Isopar ${ }^{\circledR} \mathrm{L}$. The isotopic diluent employed for this study was dodecane-d26 (Aldrich).

GC/MS analysis was employed to identify organic compounds in the samples. Analysis were carried out in building 773-A, laboratory B-123. It should be noted that ADS is not certified by DHEC for NPDES discharge compliance monitoring.

Analytical separations were carried out on a Hewlett Packard 6890 gas chromatograph, equipped with a $30 \mathrm{~m}$ DB-5 column, with $0.25 \mathrm{~mm}$ diameter and $0.25 \mu \mathrm{m}$ film thickness. Quantification was performed using a Hewlett Packard 5973 mass selective detector. The mass spectrometer tuning was confirmed within 24 hours prior to each measurement using perfluorotributylamine. 


\section{APPENDIX C. DROPLET SIZE DISTRIBUTIONS AND DATA FOR ENTRAINMENT TESTS}

The following data present the droplet size distributions for the four samples taken from the solvent entrainment test, a blank full SRS waste simulant, and a blank four-component simulant. As can be seen from Figs. C.1-C.8, the droplet size distributions for the test samples are similar to those of the blank simulants (Figs. C.9-C.12), indicating that the observed droplet size distributions in the test samples are not related to the entrained solvent.

$\begin{array}{ll}\text { File name: } & \text { essx, } \$ 03 \\ \text { Sample ID: } & 072602-1 \\ \text { Operator: } & \text { ASH } \\ \text { Comments: } & \text { Sample drawn at 11:20am } \\ \text { Optical model: } & \text { Fraunhofer } \\ \text { LS } 100 \mathrm{Q} & \text { Small Volume Module } \\ \text { Start time: } & 12: 27 \text { 26 Jul 2002 } \\ \text { Obscuration: } & 11 \% \\ \text { Fluid: } & \text { Water } \\ \text { Software: } & 2.09\end{array}$
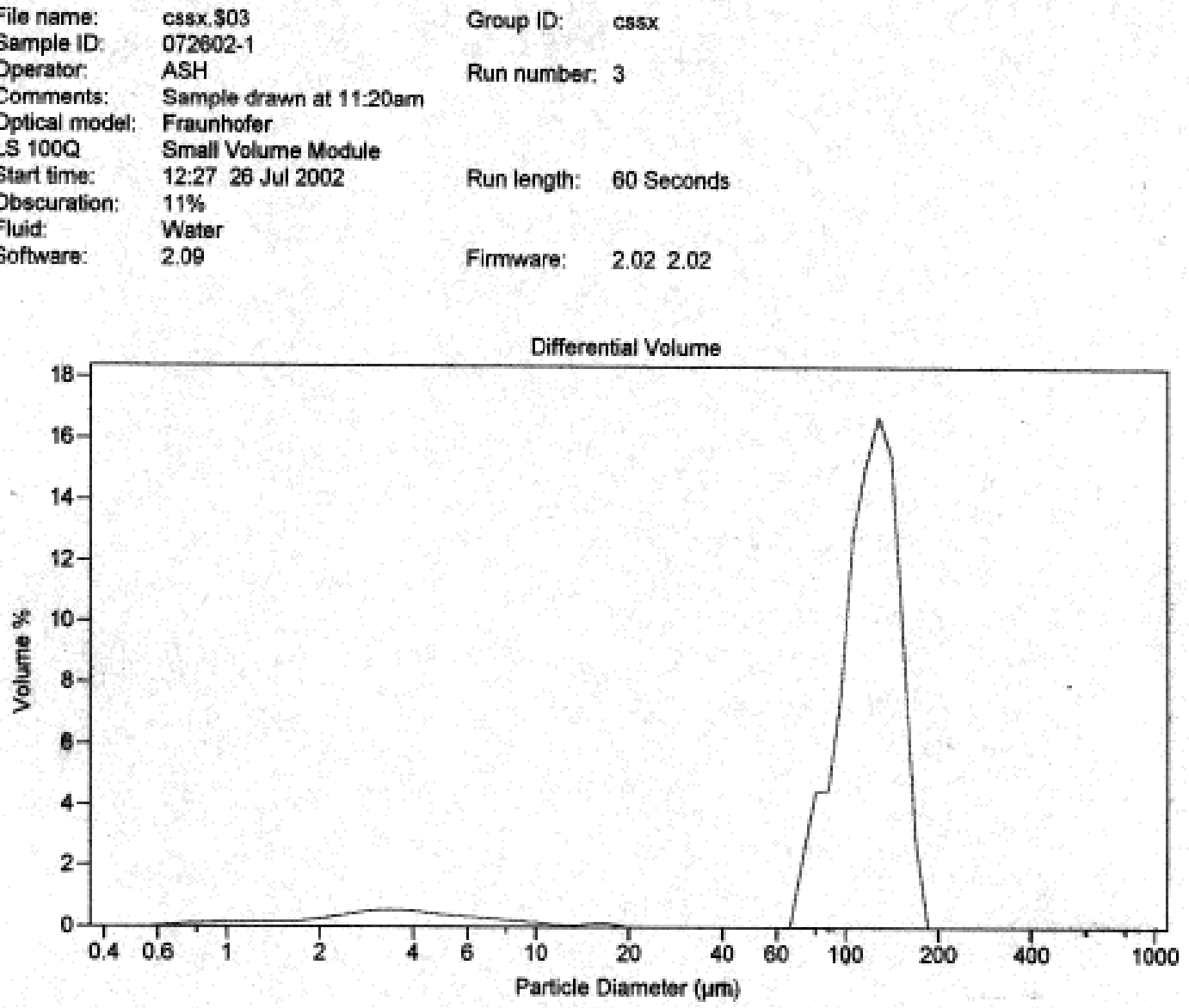

Volume Statistics (Anithmetic) $\quad$ cssx $\$ 03$

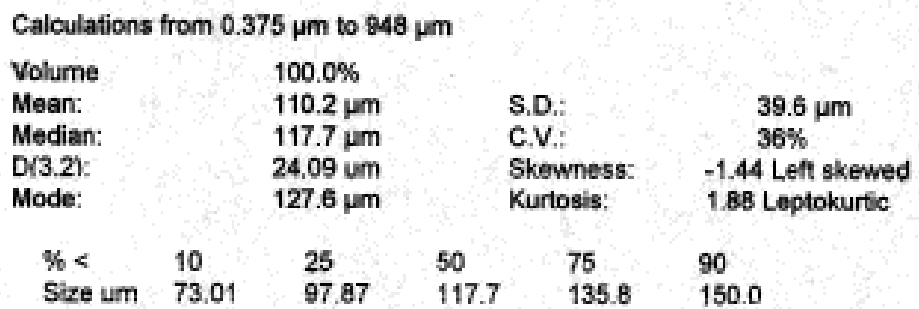

Fig. C.1. Droplet Size Distribution and Data for First Entrainment Test Sample 


\begin{tabular}{|c|c|c|c|c|c|}
\hline \multicolumn{6}{|l|}{ cssx.\$03 } \\
\hline Volume & Particle & & & & \\
\hline$\%$ & $\begin{array}{c}\text { Diameter } \\
\qquad \mu \mathrm{m}<\end{array}$ & & & & \\
\hline $\begin{array}{l}10.00 \\
25.00 \\
50.00 \\
75.00 \\
90.00\end{array}$ & $\begin{array}{l}73.01 \\
97.87 \\
117.7 \\
135.8 \\
150.0\end{array}$ & & & & \\
\hline \multicolumn{6}{|l|}{$\operatorname{css} x . \$ 03$} \\
\hline Channel & Diff. & Channel & Diff. & Channel & Diff. \\
\hline Diameter & Volume & Diameter & Volume & Diameter & Volume \\
\hline $\begin{array}{c}\text { (Lower) } \\
\mu \mathrm{m}\end{array}$ & $\%$ & $\begin{array}{c}\text { (Lower) } \\
\mu \mathrm{m}\end{array}$ & $\%$ & $\begin{array}{c}\text { (Lower) } \\
\mu \mathrm{m}\end{array}$ & $\%$ \\
\hline 0.375 & 0 & 9.819 & 0.127 & 256.8 & 0 \\
\hline 0.412 & 0 & 10.78 & 0.075 & 282.1 & 0 \\
\hline 0.452 & 0 & 11.83 & 0.040 & 309.6 & 0 \\
\hline 0.496 & 0 & 12.99 & 0.050 & 339.8 & 0 \\
\hline 0.545 & 0.015 & 14.26 & 0.109 & 373.1 & 0 \\
\hline 0.598 & 0.046 & 15.65 & 0.147 & 409.6 & 0 \\
\hline 0.657 & 0.078 & 17.18 & 0.074 & 449.7 & 0 \\
\hline 0.721 & 0.109 & 18.86 & 0 & 493.6 & 0 \\
\hline 0.791 & 0.133 & 20.70 & 0 & 541.9 & 0 \\
\hline 0.869 & 0.149 & 22.73 & 0 & 594.9 & 0 \\
\hline 0.953 & 0.155 & 24.95 & 0 & 653.0 & 0 \\
\hline 1.047 & 0.153 & 27.38 & 0 & 716.9 & 0 \\
\hline 1.149 & 0.146 & 30.07 & 0 & 786.9 & 0 \\
\hline 1.261 & 0.140 & 33.00 & 0 & 863.9 & 0 \\
\hline 1.385 & 0.141 & 36.24 & 0 & 948.2 & \\
\hline 1.520 & 0.152 & 39.77 & 0 & & \\
\hline 1.669 & 0.179 & 43.66 & 0 & & \\
\hline 1.832 & 0.222 & 47.93 & 0 & & \\
\hline 2.010 & 0.281 & 52.63 & 0 & & \\
\hline 2.207 & 0.351 & 57.77 & 0 & & \\
\hline 2.423 & 0.423 & 63.41 & 0 & & \\
\hline 2.660 & 0.488 & 69.62 & 2.30 & & \\
\hline 2.920 & 0.534 & 76.43 & 4.44 & & \\
\hline 3.206 & 0.553 & 83.90 & 4.51 & & \\
\hline 3.519 & 0.543 & 92.09 & 7.63 & & \\
\hline 3.862 & 0.508 & 101.1 & 12.87 & & \\
\hline 4.241 & 0.458 & 111.0 & 15.11 & & \\
\hline 4.656 & 0.406 & 121.8 & 16.77 & & \\
\hline 5.111 & 0.363 & 133.7 & 15.47 & & \\
\hline 5.611 & 0.331 & 146.8 & 9.19 & & \\
\hline 6.158 & 0.304 & 161.2 & 2.86 & & \\
\hline 6.761 & 0.273 & 176.8 & 0 & & \\
\hline 7.421 & 0.236 & 194.2 & 0 & & \\
\hline 8.147 & 0.200 & 213.2 & 0 & & \\
\hline 8944 & 0167 & 2341 & 0 & & \\
\hline
\end{tabular}

Fig. C.1. (Continued) 


$\begin{array}{llll}\text { File name: } & \text { cssx. } \$ 10 & \text { Group ID: } & \text { cssx } \\ \text { Sample ID: } & 072602-2 & \text { Run number: } & 3 \\ \text { Operator: } & \text { ASH } & \text { Sample drawn at 12:00 pm } & \\ \text { Comments: } & \text { Sutical model: } & \text { Fraunhofer } & \\ \text { Opticall } & & \\ \text { LS 100Q } & \text { Small Volume Module } & & \\ \text { Start time: } & 17: 1126 \text { Jul 2002 } & \text { Run length: } & 60 \text { Seconds } \\ \text { Obscuration: } & 13 \% & & \\ \text { Fluid: } & \text { Water } & \text { Firmware: } & 2.022 .02 \\ \text { Software: } & 2.09 & & \end{array}$

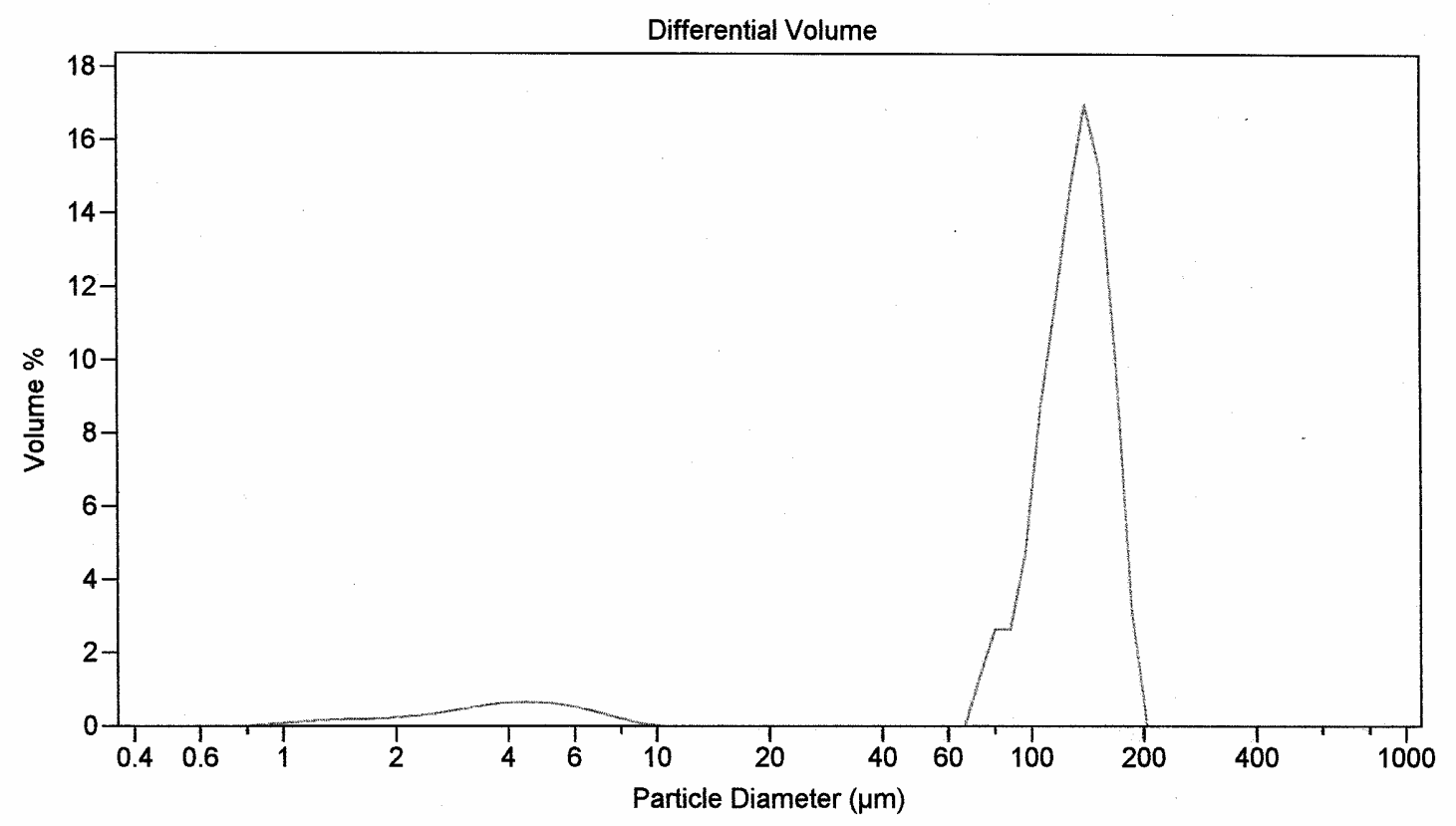

Volume Statistics (Arithmetic) cssx. $\$ 10$

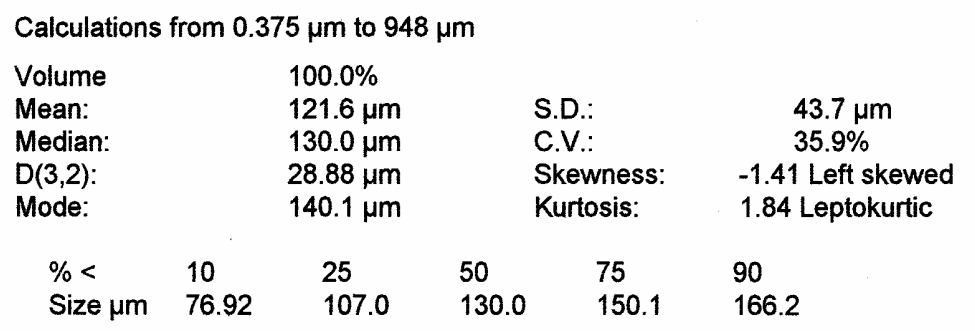

Fig. C.2. Droplet Size Distribution and Data for Second Entrainment Test Sample 


\begin{tabular}{|c|c|c|c|c|c|}
\hline \multicolumn{6}{|l|}{ cssx. $\$ 10$} \\
\hline Volume & Particle & & & & \\
\hline$\%$ & $\begin{array}{c}\text { Diameter } \\
\qquad \mu \mathrm{m}<\end{array}$ & & & & \\
\hline $\begin{array}{l}10.00 \\
25.00 \\
50.00 \\
75.00 \\
90.00\end{array}$ & $\begin{array}{l}76.92 \\
107.0 \\
130.0 \\
150.1 \\
166.2\end{array}$ & & & & \\
\hline \multicolumn{6}{|l|}{$\operatorname{css} x . \$ 10$} \\
\hline Channel & Diff. & Channel & Diff. & Channel & Diff. \\
\hline Diameter & Volume & Diameter & Volume & Diameter & Volume \\
\hline $\begin{array}{c}\text { (Lower) } \\
\mu \mathrm{m}\end{array}$ & $\%$ & $\begin{array}{c}\text { (Lower) } \\
\mu \mathrm{m}\end{array}$ & $\%$ & $\begin{array}{c}\text { (Lower) } \\
\mu \mathrm{m}\end{array}$ & $\%$ \\
\hline 0.375 & 0 & 9.819 & 0 & 256.8 & 0 \\
\hline 0.412 & 0 & 10.78 & 0 & 282.1 & 0 \\
\hline 0.452 & 0 & 11.83 & 0 & 309.6 & 0 \\
\hline 0.496 & 0 & 12.99 & 0 & 339.8 & 0 \\
\hline 0.545 & 0 & 14.26 & 0 & 373.1 & 0 \\
\hline 0.598 & 0 & 15.65 & 0 & 409.6 & 0 \\
\hline 0.657 & 0 & 17.18 & 0 & 449.7 & 0 \\
\hline 0.721 & 0 & 18.86 & 0 & 493.6 & 0 \\
\hline 0.791 & 0.016 & 20.70 & 0 & 541.9 & 0 \\
\hline 0.869 & 0.048 & 22.73 & 0 & 594.9 & 0 \\
\hline 0.953 & 0.081 & 24.95 & 0 & 653.0 & 0 \\
\hline 1.047 & 0.112 & 27.38 & 0 & 716.9 & 0 \\
\hline 1.149 & 0.138 & 30.07 & 0 & 786.9 & 0 \\
\hline 1.261 & 0.157 & 33.00 & 0 & 863.9 & 0 \\
\hline 1.385 & 0.171 & 36.24 & 0 & 948.2 & \\
\hline 1.520 & 0.182 & 39.77 & 0 & & \\
\hline 1.669 & 0.195 & 43.66 & 0 & & \\
\hline 1.832 & 0.213 & 47.93 & 0 & & \\
\hline 2.010 & 0.241 & 52.63 & 0 & & \\
\hline 2.207 & 0.281 & 57.77 & 0 & & \\
\hline 2.423 & 0.335 & 63.41 & 0 & & \\
\hline 2.660 & 0.400 & 69.62 & 1.38 & & \\
\hline 2.920 & 0.472 & 76.43 & 2.64 & & \\
\hline 3.206 & 0.542 & 83.90 & 2.65 & & \\
\hline 3.519 & 0.603 & 92.09 & 4.70 & & \\
\hline 3.862 & 0.644 & 101.1 & 8.67 & & \\
\hline 4.241 & 0.659 & 111.0 & 11.45 & & \\
\hline 4.656 & 0.643 & 121.8 & 14.60 & & \\
\hline 5.111 & 0.599 & 133.7 & 17.01 & & \\
\hline 5.611 & 0.531 & 146.8 & 15.25 & & \\
\hline 6.158 & 0.444 & 161.2 & 9.94 & & \\
\hline 6.761 & 0.344 & 176.8 & 3.26 & & \\
\hline 7.421 & 0.234 & 194.2 & 0 & & \\
\hline 8.147 & 0.123 & 213.2 & 0 & & \\
\hline 8.944 & 0.035 & 234.1 & 0 & & \\
\hline
\end{tabular}

Fig. C.2. (Continued) 


$\begin{array}{llll}\text { File name: } & \text { cssx.\$05 } & \text { Group ID: } & \text { cssx } \\ \text { Sample ID: } & 072602-3 & & \\ \text { Operator: } & \text { ASH } & \text { Run number: } 2 \\ \text { Comments: } & \text { Sample drawn at 12:45 pm } & & \\ \text { Optical model: } & \text { Fraunhofer } & & \\ \text { LS 100Q } & \text { Small Volume Module } & & \\ \text { Start time: } & 16: 0926 \text { Jul 2002 } & \text { Run length: } & 60 \text { Seconds } \\ \text { Obscuration: } & 11 \% & & \\ \text { Fluid: } & \text { Water } & \text { Firmware: } & 2.022 .02 \\ \text { Software: } & 2.09 & & \end{array}$

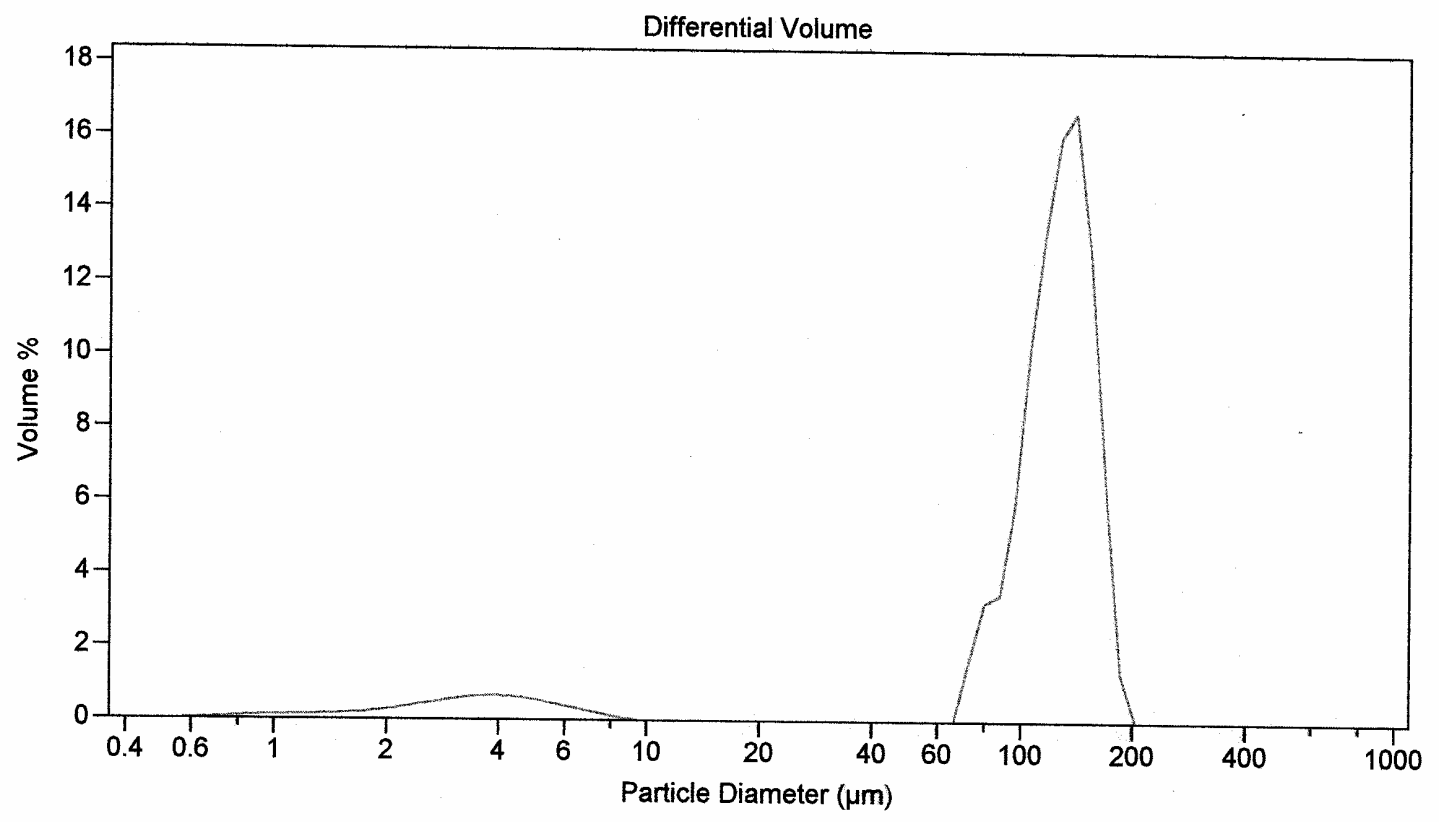

Volume Statistics (Arithmetic) cssx. $\$ 05$

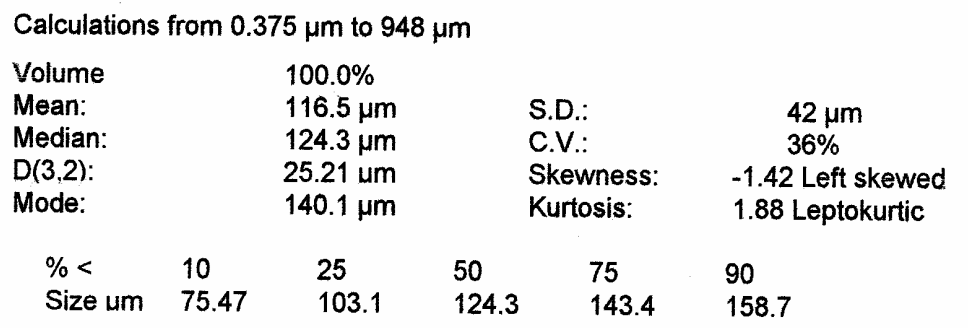

Fig. C.3. Droplet Size Distribution and Data for Third Entrainment Test Sample 


\begin{tabular}{|c|c|c|c|c|c|}
\hline \multicolumn{6}{|l|}{$\operatorname{css} x . \$ 05$} \\
\hline Volume & Particle & & & & \\
\hline$\%$ & $\begin{array}{c}\text { Diameter } \\
\qquad \mu \mathrm{m}<\end{array}$ & & & & \\
\hline $\begin{array}{l}10.00 \\
25.00 \\
50.00 \\
75.00 \\
90.00\end{array}$ & $\begin{array}{l}75.47 \\
103.1 \\
124.3 \\
143.4 \\
158.7\end{array}$ & & & & \\
\hline \multicolumn{6}{|l|}{$\operatorname{cssx} \$ 05$} \\
\hline Channel & Diff. & Channel & Diff. & Channel & Diff. \\
\hline Diameter & Volume & Diameter & Volume & Diameter & Volume \\
\hline (Lower) & $\%$ & (Lower) & $\%$ & (Lower) & $\%$ \\
\hline$\mu \mathrm{m}$ & & $\mu \mathrm{m}$ & & $\mu \mathrm{m}$ & \\
\hline 0.375 & 0 & 9.819 & 0 & 256.8 & 0 \\
\hline 0.412 & 0 & 10.78 & 0 & 282.1 & 0 \\
\hline 0.452 & 0 & 11.83 & 0 & 309.6 & 0 \\
\hline 0.496 & 0 & 12.99 & 0 & 339.8 & 0 \\
\hline 0.545 & 0.009 & 14.26 & 0 & 373.1 & 0 \\
\hline 0.598 & 0.027 & 15.65 & 0 & 409.6 & 0 \\
\hline 0.657 & 0.047 & 17.18 & 0 & 449.7 & 0 \\
\hline 0.721 & 0.068 & 18.86 & 0 & 493.6 & 0 \\
\hline 0.791 & 0.087 & 20.70 & 0 & 541.9 & 0 \\
\hline 0.869 & 0.103 & 22.73 & 0 & 594.9 & 0 \\
\hline 0.953 & 0.115 & 24.95 & 0 & 653.0 & 0 \\
\hline 1.047 & 0.124 & 27.38 & 0 & 716.9 & 0 \\
\hline 1.149 & 0.132 & 30.07 & 0 & 786.9 & 0 \\
\hline 1.261 & 0.140 & 33.00 & 0 & 863.9 & 0 \\
\hline 1.385 & 0.152 & 36.24 & 0 & 948.2 & \\
\hline 1.520 & 0.171 & 39.77 & 0 & & \\
\hline 1.669 & 0.200 & 43.66 & 0 & & \\
\hline 1.832 & 0.241 & 47.93 & 0 & & \\
\hline 2.010 & 0.295 & 52.63 & 0 & & \\
\hline 2.207 & 0.360 & 57.77 & 0 & & \\
\hline 2.423 & 0.433 & 63.41 & 0 & & \\
\hline 2.660 & 0.507 & 69.62 & 1.69 & & \\
\hline 2.920 & 0.575 & 76.43 & 3.23 & & \\
\hline 3.206 & 0.628 & 83.90 & 3.48 & & \\
\hline 3.519 & 0.657 & 92.09 & 5.93 & & \\
\hline 3.862 & 0.656 & 101.1 & 10.32 & & \\
\hline 4.241 & 0.624 & 111.0 & 13.39 & & \\
\hline 4.656 & 0.565 & 121.8 & 16.03 & & \\
\hline 5.111 & 0.486 & 133.7 & 16.70 & & \\
\hline 5.611 & 0.399 & 146.8 & 12.92 & & \\
\hline 6.158 & 0.311 & 161.2 & 6.40 & & \\
\hline 6.761 & 0.225 & 176.8 & 1.35 & & \\
\hline 7.421 & 0.141 & 194.2 & 0 & & \\
\hline 8.147 & 0.060 & 213.2 & 0 & & \\
\hline 8944 & 0.011 & 2341 & $n$ & & \\
\hline
\end{tabular}

Fig. C.3. (Continued) 


$\begin{array}{llll}\text { File name: } & \text { cssx. } \$ 07 & \text { Group ID: } & \text { cssx } \\ \text { Sample ID: } & 072602-4 & & \\ \text { Operator: } & \text { ASH } & \text { Run number: } 2 \\ \text { Comments: } & \text { Sample drawn at 1:30 pm } & & \\ \text { Optical model: } & \text { Fraunhofer } & & \\ \text { LS 100Q } & \text { Small Volume Module } & & \\ \text { Start time: } & 16: 49 \text { 26 Jul 2002 } & \text { Run length: } & 60 \text { Seconds } \\ \text { Obscuration: } & 9 \% & & \\ \text { Fluid: } & \text { Water } & \text { Firmware: } & 2.022 .02 \\ \text { Software: } & 2.09 & & \end{array}$

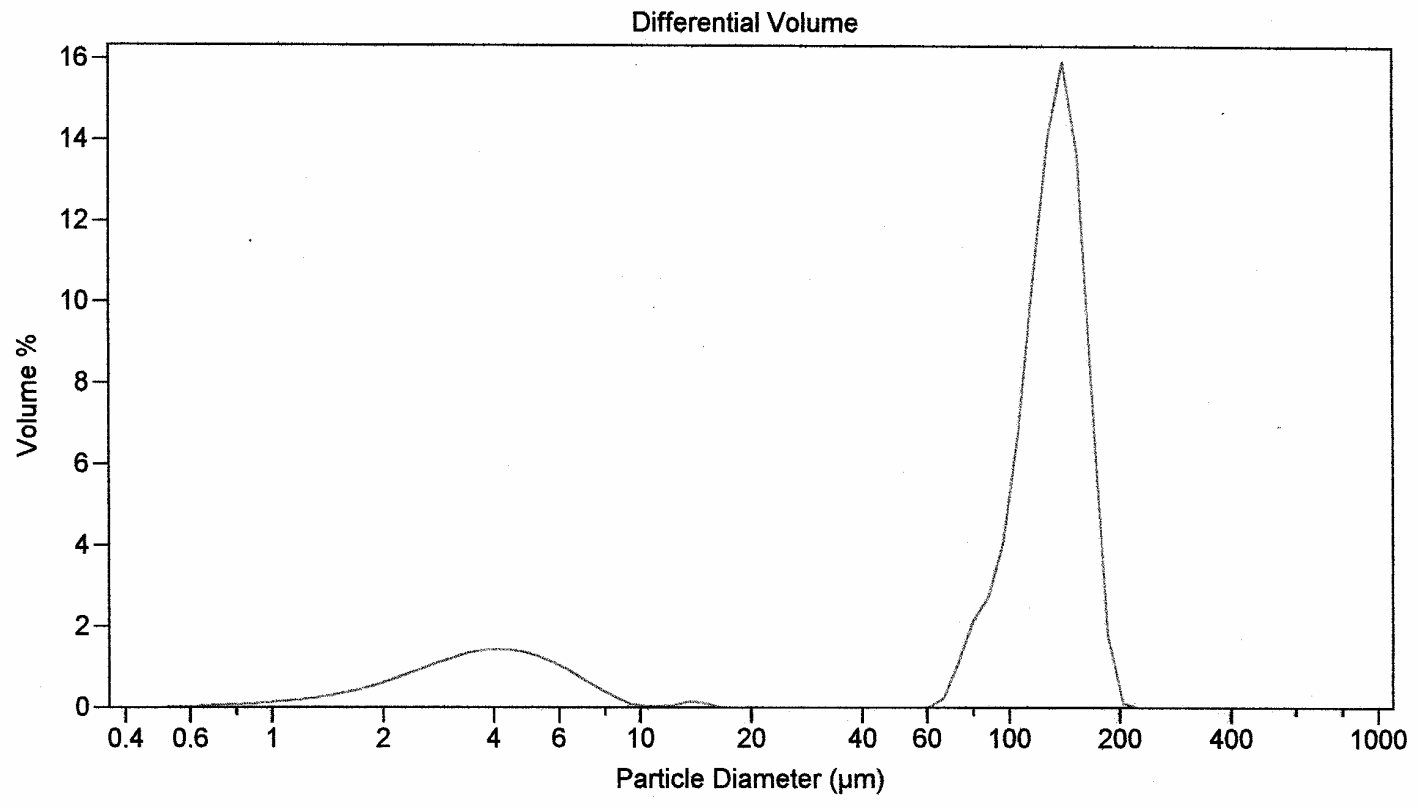

Volume Statistics (Arithmetic) css. $\$ 07$

Calculations from $0.375 \mu \mathrm{m}$ to $948 \mu \mathrm{m}$

\begin{tabular}{|c|c|c|c|c|c|}
\hline $\begin{array}{l}\text { Volume } \\
\text { Mean: } \\
\text { Median: } \\
D(3,2): \\
\text { Mode: }\end{array}$ & & $\begin{array}{l}100.0 \% \\
106.6 \mu \mathrm{m} \\
124.3 \mu \mathrm{m} \\
14.29 \mu \mathrm{m} \\
140.1 \mu \mathrm{m}\end{array}$ & & $\begin{array}{l}\text { S.D.: } \\
\text { C.V.: } \\
\text { Skewness: } \\
\text { Kurtosis: }\end{array}$ & $\begin{array}{c}55.2 \mu \mathrm{m} \\
51.8 \% \\
-0.958 \text { Left skewed } \\
-0.383 \text { Platykurtic }\end{array}$ \\
\hline $\begin{array}{l}\%< \\
\text { Size um }\end{array}$ & $\begin{array}{l}10 \\
3.817\end{array}$ & $\begin{array}{l}25 \\
90.19\end{array}$ & $\begin{array}{l}50 \\
124.3\end{array}$ & $\begin{array}{l}75 \\
145.1\end{array}$ & $\begin{array}{l}90 \\
160.4\end{array}$ \\
\hline
\end{tabular}

Fig. C.4. Droplet Size Distribution and Data for Fourth Entrainment Test Sample 


\begin{tabular}{|c|c|c|c|c|c|}
\hline \multicolumn{6}{|l|}{ cssX.\$07 } \\
\hline Volume & Particle & & \multicolumn{3}{|c|}{. } \\
\hline$\%$ & $\begin{array}{c}\text { Diameter } \\
\qquad \mu \mathrm{m}<\end{array}$ & & & & \\
\hline $\begin{array}{l}10.00 \\
25.00 \\
50.00 \\
75.00 \\
90.00\end{array}$ & $\begin{array}{l}3.817 \\
90.19 \\
124.3 \\
145.1 \\
160.4\end{array}$ & & & & \\
\hline \multicolumn{6}{|l|}{ cssx.\$07 } \\
\hline Channel & Diff. & Channel & Diff. & Channel & Diff. \\
\hline Diameter & Volume & Diameter & Volume & Diameter & Volume \\
\hline $\begin{array}{c}\text { (Lower) } \\
\mu \mathrm{m}\end{array}$ & $\%$ & $\begin{array}{c}\text { (Lower) } \\
\mu \mathrm{m}\end{array}$ & $\%$ & $\begin{array}{c}\text { (Lower) } \\
\mu \mathrm{m}\end{array}$ & $\%$ \\
\hline 0.375 & 0 & 9.819 & 0.021 & 256.8 & 0 \\
\hline 0.412 & 0 & 10.78 & 0.020 & 282.1 & 0 \\
\hline 0.452 & 0 & 11.83 & 0.057 & 309.6 & 0 \\
\hline 0.496 & 0.001 & 12.99 & 0.138 & 339.8 & 0 \\
\hline 0.545 & 0.010 & 14.26 & 0.106 & 373.1 & 0 \\
\hline 0.598 & 0.029 & 15.65 & 0.011 & 409.6 & 0 \\
\hline 0.657 & 0.049 & 17.18 & 0 & 449.7 & 0 \\
\hline 0.721 & 0.067 & 18.86 & 0 & 493.6 & 0 \\
\hline 0.791 & 0.085 & 20.70 & 0 & 541.9 & 0 \\
\hline 0.869 & 0.105 & 22.73 & 0 & 594.9 & 0 \\
\hline 0.953 & 0.127 & 24.95 & 0 & 653.0 & 0 \\
\hline 1.047 & 0.155 & 27.38 & 0 & 716.9 & 0 \\
\hline 1.149 & 0.190 & 30.07 & 0 & 786.9 & 0 \\
\hline 1.261 & 0.236 & 33.00 & 0 & 863.9 & 0 \\
\hline 1.385 & 0.294 & 36.24 & 0 & 948.2 & \\
\hline 1.520 & 0.366 & 39.77 & 0 & & \\
\hline 1.669 & 0.455 & 43.66 & 0 & & \\
\hline 1.832 & 0.559 & 47.93 & 0 & & \\
\hline 2.010 & 0.678 & 52.63 & 0 & & \\
\hline 2.207 & 0.810 & 57.77 & 0.007 & & \\
\hline 2.423 & 0.948 & 63.41 & 0.214 & & \\
\hline 2.660 & 1.09 & 69.62 & 1.13 & & \\
\hline 2.920 & 1.21 & 76.43 & 2.14 & & \\
\hline 3.206 & 1.32 & 83.90 & 2.74 & & \\
\hline 3.519 & 1.40 & 92.09 & 4.05 & & \\
\hline 3.862 & 1.44 & 101.1 & 6.81 & & \\
\hline 4.241 & 1.42 & 111.0 & 10.53 & & \\
\hline 4.656 & 1.36 & 121.8 & 14.09 & & \\
\hline 5.111 & 1.24 & 133.7 & 15.95 & & \\
\hline 5.611 & 1.08 & 146.8 & 13.67 & & \\
\hline 6.158 & 0.883 & 161.2 & 7.36 & & \\
\hline 6.761 & 0.664 & 176.8 & 1.80 & & \\
\hline 7.421 & 0.445 & 194.2 & 0.101 & & \\
\hline 8.147 & 0.247 & 213.2 & 0 & & \\
\hline 8.944 & 0.084 & 234.1 & 0 & & \\
\hline
\end{tabular}

Fig. C.4. (Continued) 


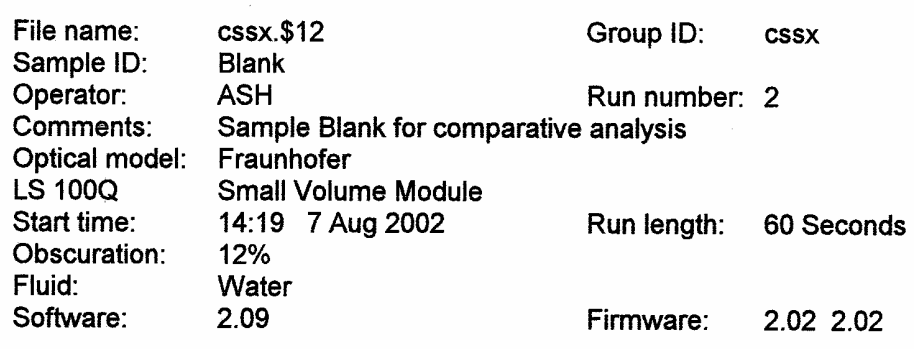

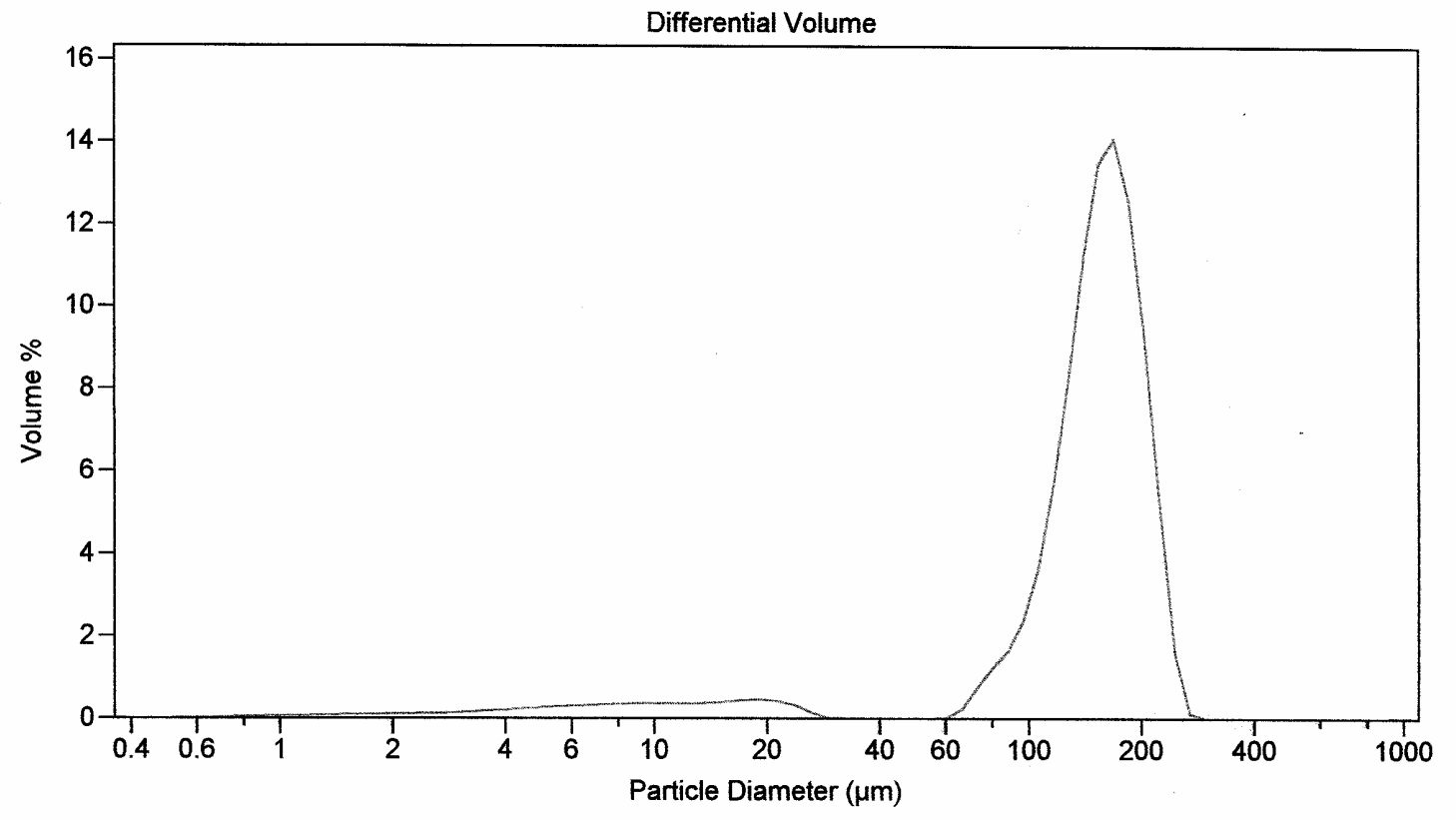

Volume Statistics (Arithmetic) $\quad$ cssx. $\$ 12$

\begin{tabular}{|c|c|c|c|c|c|}
\hline \multicolumn{6}{|c|}{ Calculations from $0.375 \mu \mathrm{m}$ to $948 \mu \mathrm{m}$} \\
\hline $\begin{array}{l}\text { Volume } \\
\text { Mean: } \\
\text { Median: } \\
D(3,2) \text { : } \\
\text { Mode: }\end{array}$ & & $\begin{array}{l}100.0 \% \\
145.5 \mu \mathrm{m} \\
153.5 \mu \mathrm{m} \\
43.22 \mu \mathrm{m} \\
168.8 \mu \mathrm{m}\end{array}$ & & $\begin{array}{l}\text { S.D.: } \\
\text { C.V.: } \\
\text { Skewness: } \\
\text { Kurtosis: }\end{array}$ & $\begin{array}{c}55 \mu \mathrm{m} \\
37.8 \% \\
-0.978 \text { Left skewed } \\
0.867 \text { Leptokurtic }\end{array}$ \\
\hline $\begin{array}{l}\%< \\
\text { Size } \mu \mathrm{m}\end{array}$ & $\begin{array}{l}10 \\
78.39\end{array}$ & $\begin{array}{l}25 \\
123.0\end{array}$ & $\begin{array}{l}50 \\
153.5\end{array}$ & $\begin{array}{l}75 \\
182.0\end{array}$ & $\begin{array}{l}90 \\
206.9\end{array}$ \\
\hline
\end{tabular}

Fig. C.5. Droplet Size Distribution and Data for Blank SRS Waste Simulant 


\begin{tabular}{|c|c|c|c|c|c|}
\hline \multicolumn{6}{|l|}{$\operatorname{css} x . \$ 12$} \\
\hline Volume & Particle & & & & \\
\hline$\%$ & $\begin{array}{c}\text { Diameter } \\
\qquad \mu \mathrm{m}<\end{array}$ & & & & \\
\hline $\begin{array}{l}10.00 \\
25.00 \\
50.00 \\
75.00 \\
90.00\end{array}$ & $\begin{array}{l}78.39 \\
123.0 \\
153.5 \\
182.0 \\
206.9\end{array}$ & & & & \\
\hline \multicolumn{6}{|l|}{ cssx.\$12 } \\
\hline Channel & Diff. & Channel & Diff. & Channel & Diff. \\
\hline Diameter & Volume & Diameter & Volume & Diameter & Volume \\
\hline $\begin{array}{c}\text { (Lower) } \\
\mu \mathrm{m}\end{array}$ & $\%$ & $\begin{array}{c}\text { (Lower) } \\
\text { um }\end{array}$ & $\%$ & $\begin{array}{c}\text { (Lower) } \\
\text { um }\end{array}$ & $\%$ \\
\hline 0.375 & 0 & 9.819 & 0.354 & 256.8 & 0.112 \\
\hline 0.412 & 0 & 10.78 & 0.355 & 282.1 & 0 \\
\hline 0.452 & 0 & 11.83 & 0.360 & 309.6 & 0 \\
\hline 0.496 & 0.0034 & 12.99 & 0.372 & 339.8 & 0 \\
\hline 0.545 & 0.005 & 14.26 & 0.394 & 373.1 & 0 \\
\hline 0.598 & 0.014 & 15.65 & 0.422 & 409.6 & 0 \\
\hline 0.657 & 0.023 & 17.18 & 0.448 & 449.7 & 0 \\
\hline 0.721 & 0.032 & 18.86 & 0.451 & 493.6 & 0 \\
\hline 0.791 & 0.040 & 20.70 & 0.408 & 541.9 & 0 \\
\hline 0.869 & 0.048 & 22.73 & 0.312 & 594.9 & 0 \\
\hline 0.953 & 0.054 & 24.95 & 0.138 & 653.0 & 0 \\
\hline 1.047 & 0.061 & 27.38 & 0.018 & 716.9 & 0 \\
\hline 1.149 & 0.066 & 30.07 & 0.0017 & 786.9 & 0 \\
\hline 1.261 & 0.071 & 33.00 & 0 & 863.9 & 0 \\
\hline 1.385 & 0.076 & 36.24 & 0 & 948.2 & \\
\hline 1.520 & 0.081 & 39.77 & 0 & & \\
\hline 1.669 & 0.087 & 43.66 & 0 & & \\
\hline 1.832 & 0.093 & 47.93 & 0 & & \\
\hline 2.010 & 0.101 & 52.63 & 0 & & \\
\hline 2.207 & 0.109 & 57.77 & 0.015 & & \\
\hline 2.423 & 0.120 & 63.41 & 0.227 & & \\
\hline 2.660 & 0.133 & 69.62 & 0.748 & & \\
\hline 2.920 & 0.148 & 76.43 & 1.23 & & \\
\hline 3.206 & 0.165 & 83.90 & 1.64 & & \\
\hline 3.519 & 0.185 & 92.09 & 2.35 & & \\
\hline 3.862 & 0.206 & 101.1 & 3.65 & & \\
\hline 4.241 & 0.228 & 111.0 & 5.64 & & \\
\hline 4.656 & 0.251 & 121.8 & 8.30 & & \\
\hline 5.111 & 0.274 & 133.7 & 11.21 & & \\
\hline 5.611 & 0.295 & 146.8 & 13.47 & & \\
\hline 6.158 & 0.314 & 161.2 & 14.10 & & \\
\hline 6.761 & 0.330 & 176.8 & 12.56 & & \\
\hline 7.421 & 0.342 & 194.2 & 9.27 & & \\
\hline 8.147 & 0.350 & 213.2 & 5.22 & & \\
\hline 8.944 & 0.353 & 234.1 & 1.58 & & \\
\hline
\end{tabular}

Fig. C.5. (Continued) 


$\begin{array}{llll}\text { File name: } & \text { cssx.\$22 } & \text { Group ID: } & \text { cssx } \\ \text { Sample ID: } & \text { 4-Component Simulant } & & \\ \text { Operator: } & \text { ASH } & \text { Run number: } 2 \\ \text { Comments: } & & & \\ \text { Optical model: } & \text { Fraunhofer } & & \\ \text { LS } 100 \mathrm{Q} & \text { Small Volume Module } & & \\ \text { Start time: } & 16: 24 \text { 13 Aug 2002 } & \text { Run length: } & 60 \text { Seconds } \\ \text { Obscuration: } & 8 \% & & \\ \text { Fluid: } & \text { Water } & \text { Firmware: } & 2.022 .02 \\ \text { Software: } & 2.09 & & \end{array}$

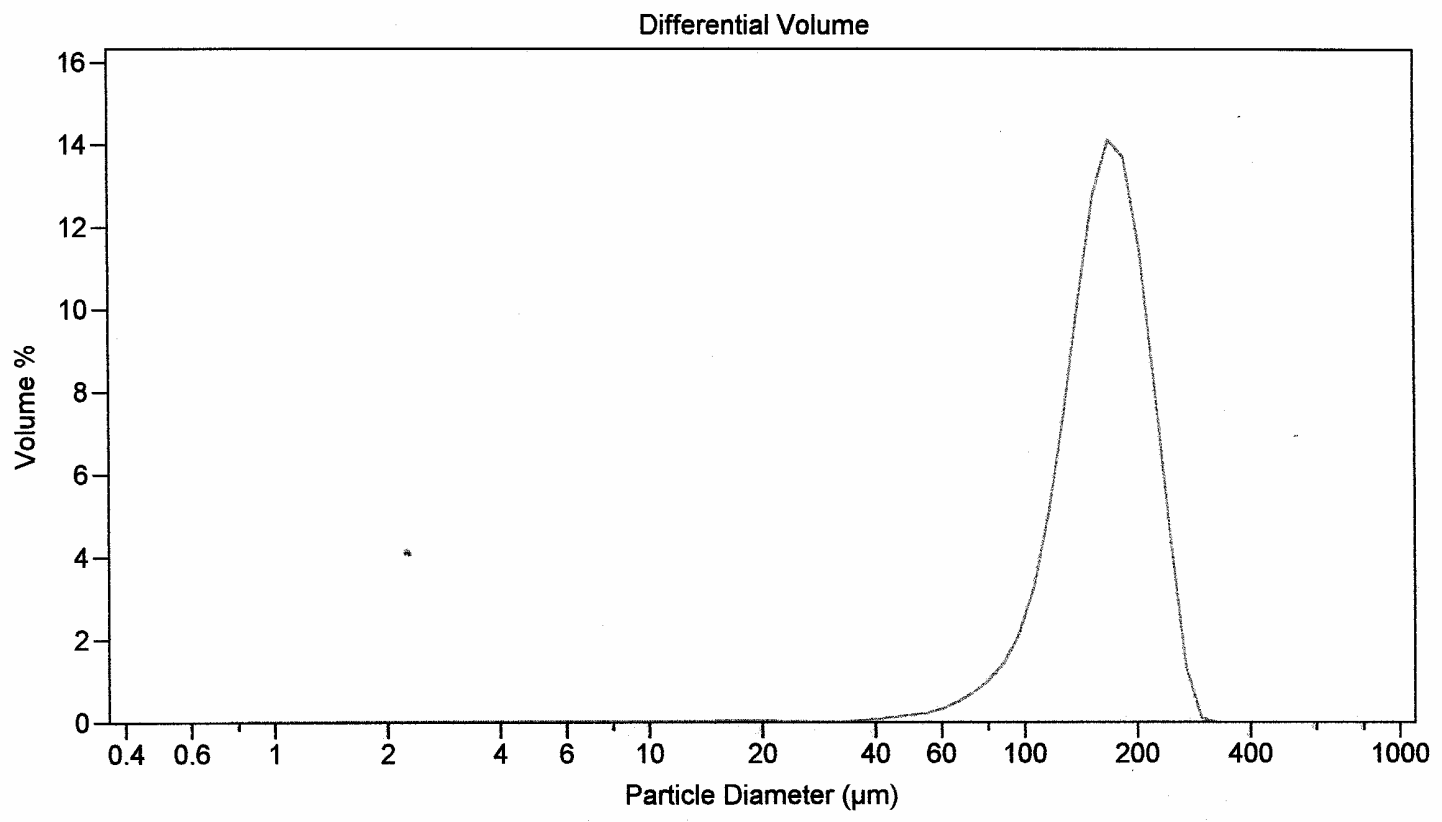

Volume Statistics (Arithmetic) css. $\$ 22$

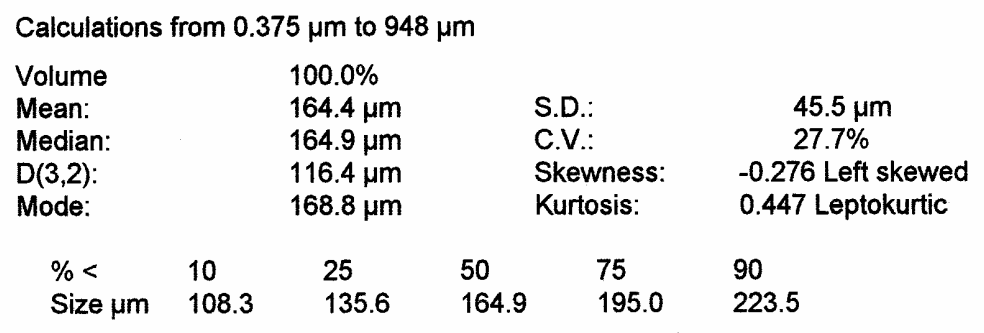

Fig. C.6. Droplet Size Distribution and Data for Blank Four-Component Simulant 


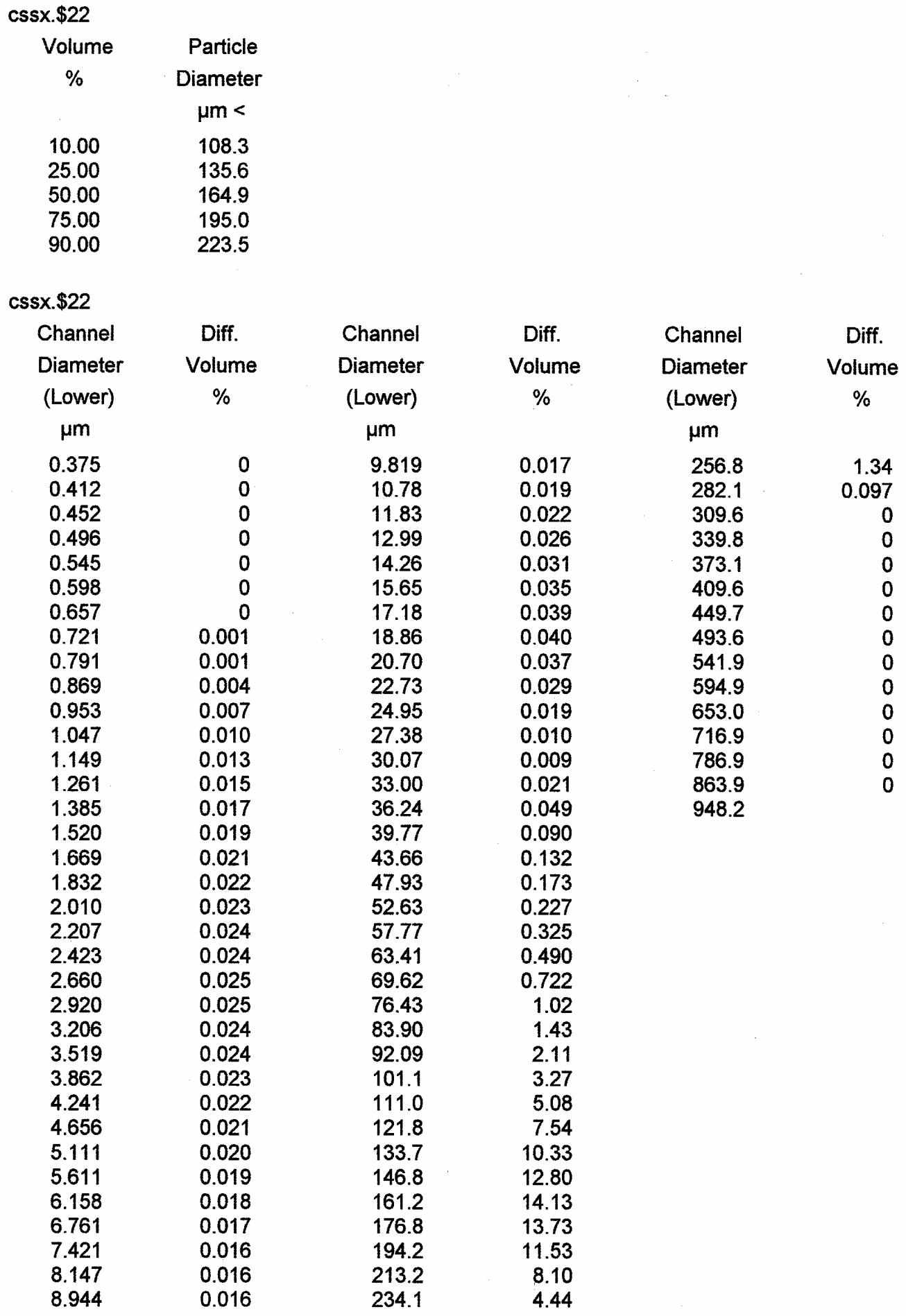

Fig. C.6. (Continued) 


\section{APPENDIX D. SUMMARY OF PHYSICAL PROPERTY DATA}

The tables in this appendix present the physical property data presented in Section 3 of the report. Table D. 1 presents the interfacial tension as a function of temperature. P represents the measured value and $\mathrm{S}$ represents the actual value given by the equations:

$$
\mathrm{S}=\mathrm{F}^{*} \mathrm{P}
$$

where $\mathrm{F}$ is a correction factor given by

$$
0.7250+\operatorname{sqrt}\left(0.01452 * \mathrm{P}\left(\mathrm{C}^{2 *}(\mathrm{D}-\mathrm{d})+0.04534-1.679 * \mathrm{r} / \mathrm{R}\right)\right.
$$

where $\mathrm{C}$ is the circumference of the ring $(\mathrm{C}=5.935 \mathrm{~cm}), \mathrm{r} / \mathrm{R}$ is the wire thickness:ring radius $(\mathrm{r} / \mathrm{R}$ $=53.1666), \mathrm{D}$ is the heavy phase density, and $\mathrm{d}$ is light phase density. Density values of 1.28 $\mathrm{g} / \mathrm{mL}$ and $0.82 \mathrm{~g} / \mathrm{mL}$ were used for the simulant and solvent, respectively.

Table D.1. Interfacial Tension vs. Temperature

\begin{tabular}{|c|c|c|c|c|}
\hline Temp & 27 & 17.6 & 25.6 & 35 \\
\hline & 18.7 & 17.9 & 18 & 18.2 \\
& 18.7 & 17.9 & 18.1 & 18.2 \\
& 18.9 & 17.9 & 18.3 & 18.1 \\
& 18.8 & & 18.1 & 18.3 \\
& & & 18.2 & 18.3 \\
\hline P & 18.78 & 17.9 & 18.1 & 18.2 \\
S & 17.0 & 16.2 & 16.4 & 16.5 \\
\hline
\end{tabular}

Tables D.2 and D.3 present the surface tension and viscosity data for the solvent, full simulant, and four-component simulant. Table D.4 presents the viscosity data for the simulant as a function of temperature. Table D.5 presents the values for the Weber number calculated for the CSSX solvent-full simulant system.

\begin{tabular}{|c|c|c|c|}
\hline & Solvent & Full Simulant & 4 Comp. Simulant \\
\hline \multirow[b]{7}{*}{$A Y G$} & 24.6 & 59.7 & 73.5 \\
\hline & 24 & 59.8 & 73.7 \\
\hline & 24.6 & 59.5 & 73.5 \\
\hline & 24.2 & 59.5 & 73.3 \\
\hline & 24.1 & 60 & \\
\hline & 24.2 & & \\
\hline & 24.28 & 59.7 & 73.5 \\
\hline
\end{tabular}

Table D. 2. Surface Tension at Ambient Temperature 
Table D.3. Viscosity vs. Temperature

\begin{tabular}{|c|c|c|c|}
\hline Temperature & Solvent & Full Simulant & 4-Comp. Simulant \\
\hline 11 & & 4.6 & \\
\hline 13 & 5.28 & & \\
\hline 15.6 & & 4.05 & \\
\hline 20 & & & 2.12 \\
\hline 21.3 & 4.038 & & \\
\hline 25 & 3.4 & & 1.8 \\
\hline 27 & & & \\
\hline 27.5 & & 2.958 & \\
\hline 31.4 & 3.025 & & 1.55 \\
\hline 31.6 & & 2.705 & \\
\hline 34 & & & \\
\hline 35 & 2.755 & & \\
\hline 35.4 & & 2.425 & \\
\hline 40 & & 2.2 & \\
\hline 40.1 & 2.473 & & \\
\hline 44.4 & & 2.04 & \\
\hline 45.8 & 2.188 & & \\
\hline
\end{tabular}

Table D.4. Simulant Density vs. Temperature

\begin{tabular}{|r|r||r|r|}
\hline \multicolumn{1}{|l|}{ Temp } & Density & Temp & Density \\
\hline 14.5 & 1.264948 & 30.8 & 1.257404 \\
\cline { 2 - 3 } & 1.265812 & 31 & 1.256796 \\
& 1.266956 & 31.2 & 1.258528 \\
& 1.266076 \\
\hline 15.5 & 1.265508 & 31.3 & 1.257164 \\
& 1.2641 \\
\cline { 2 - 3 } & 1.263012 & 31.7 & 1.256944 \\
\hline 19.5 & 32 & 1.257408 \\
\hline 19.6 & 1.262856 & 35.2 & 1.25412 \\
& 1.261316 & 35.5 & 1.254636 \\
& 1.26408 & 36 & 1.253868 \\
& 1.263264 & 36.7 & 1.254004 \\
\hline 19.8 & 1.26304 & 36.8 & 1.254384 \\
\cline { 3 - 4 } & 1.25766 & 37 & 1.252032 \\
\hline & 1.258612 & 39.5 & 1.252732 \\
& 1.25558 & 40.5 & 1.250388 \\
\hline 25.4 & 1.258268 & 41.5 & 1.252284 \\
& 1.258344 & 41.5 & 1.251356 \\
& 1.258664 & 42.5 & 1.250084 \\
& & 43.3 & 1.2508 \\
\hline
\end{tabular}


Table D.5. Weber Number Calculation

\begin{tabular}{|c|c|c|}
\hline $\begin{array}{l}\rho \\
\rho d \\
V \\
\sigma \\
\mu \\
\mu d\end{array}$ & $\begin{array}{r}1.25 \\
0.84 \\
8.1 \mathrm{E}-06 \\
16.5 \\
2.7 \\
3.5 \\
\end{array}$ & $\begin{array}{l}\mathrm{g} / \mathrm{cc} \\
\mathrm{g} / \mathrm{cc} \\
\mathrm{cm} / \mathrm{s} \\
\text { dyne/cm } \\
\mathrm{cP} \\
\mathrm{cP}\end{array}$ \\
\hline D microns & $\mathrm{V} \mathrm{cm} / \mathrm{s}$ & $\mathrm{We}$ \\
\hline 1 & 8.07E-06 & $4.89 \mathrm{E}-16$ \\
\hline 2 & 3.23E-05 & 1.56E-14 \\
\hline 4 & 1.29E-04 & 5.01E-13 \\
\hline 8 & $5.16 \mathrm{E}-04$ & 1.60E-11 \\
\hline 16 & 2.06E-03 & $5.13 E-10$ \\
\hline 32 & 8.26E-03 & 1.64E-08 \\
\hline 64 & 3.30E-02 & 5.25E-07 \\
\hline 64 & 3.30E-02 & 5.25E-07 \\
\hline 128 & 1.32E-01 & 1.68E-05 \\
\hline 256 & $5.29 \mathrm{E}-01$ & 5.38E-04 \\
\hline 512 & $2.11 \mathrm{E}+00$ & 1.72E-02 \\
\hline 1024 & $8.46 \mathrm{E}+00$ & 5.50E-01 \\
\hline 2048 & $3.38 \mathrm{E}+01$ & $1.76 \mathrm{E}+01$ \\
\hline
\end{tabular}




\section{APPENDIX E. COALESCER VENDOR CONTACTS AND MEDIA SAMPLES}

Table E. 1 contains contact information for several coalescer vendors. This appendix also includes two full quotations from two coalescer vendors, Franken Filtertechnik KG and Koch Otto-York. The quotations are listed based on results with the lab-scale coalescer, the media tests, and cost.

Figures E.1-E.13 are photographs of the vendor-supplied media and structural samples that were tested for stability in the SRS waste simulant containing 1000 ppm CSSX solvent. In each photograph, the item on the left is the pristine sample, on the right is the sample taken from the test vessel after 36 days and dried at ambient conditions. In some samples, crystallites adhere to the surface. These appear to be salt residue from the simulant. Designations used by the vendor are used when they have been provided.

Table E.1. Vendor Contact Information

\begin{tabular}{l|c|c}
\hline \multicolumn{1}{c|}{ Vendor } & Contact Name & Telephone \\
\hline $\begin{array}{l}\text { Franken FilterTechnik KG } \\
\text { Hurth, Germany }\end{array}$ & Michael Chatterjee & $+49 .(0) 2233 / 97440.0$ \\
$\begin{array}{l}\text { Pall Equipment Corp. } \\
\text { Cortland, NY }\end{array}$ & John Sica & $(516) 801-9852$ \\
$\begin{array}{l}\text { Koch-Otto York, Inc. } \\
\text { Wichita, KS }\end{array}$ & Hubert Zey & $(316) 828-8472$ \\
$\begin{array}{l}\text { Mercer International, Inc. } \\
\text { Mendham, NJ }\end{array}$ & David Goding & (973) 543-9000 \\
$\begin{array}{l}\text { McTighe Industries, Inc. } \\
\text { Sioux fall, SD }\end{array}$ & Patrick Moen & $(888) 776-0581$ \\
$\begin{array}{l}\text { Filter Innovations, Inc. } \\
\text { North York, ONT, Canada }\end{array}$ & John Dragasevich & $416-490-7848$ \\
Amistco Separations \\
$\begin{array}{l}\text { Products, Inc. } \\
\text { Alvin, TX }\end{array}$
\end{tabular}


Attn.: Mrs. Monica C. Regalbuto Ph. D.

Subject: Coalescer for Pilot Plant Scale

Dear Mrs. Regalbuto, Dear Mrs. Teitlus, Dear Mr. Pereira,

we refer to your above mentioned separations task and send you now our quotation for a testing unit in a pilot plant scale for separation Task 1 . Referring to the eMail of Mr. Pereira we quote on base of buying (not rental).

We stipulate the following discussion points:

1. The main components of the testing unit are two different types of prefilters and the phase separator itself. In general the pre-fitters are used as a protection for the phase separator. One pre-filter is a bag and the other an element filter. Here are different filtration grades available. We install different types of pre-filters because in general a bag filter has another filtration characteristic than an element filter. Controlling the pressure drop of each component a possible contamination through solids can be detected. In the following we also give you a suggestion for a first equipment of all components.

2. Regarding the phase separation element the lab scale test can help to choose an optimized micro fiber bed. The here offered element is equipped with a combined fiber bed. On the intake side a fine bed is used to coalesce even very fine droplets and at the outlet side layer of course fibers are used to form big droplets for an enhanced sedimentation.

3. As explained in the following several combinations of the filter devices and the phase separator are possible.

-2 - 
Page 2

FRANKEN

of Quotation P1 22411

to Argonne Nation Laboratory, Argonne IL 60439-4837

of June 17, 2002

4. Stainless steel is suitable for the separation task.

5. To protect the sight glasses sgainst chemical attack we might use a thin plastic film made of PP or PTFE. Please give us further information concerning this point.

We quote as follows:

I Prices

II Technical deta of the testing plant and the phase separation units

III Racommended process data for pilot plant scale for aqueous raffinate

I Prioes

Pos. Oty Description/type

Unit priee

011 Testing plant

type FP 200-S (pre-filter and phase separator)

e $14.965,00$

without phese separation element

according to drawing no. 0 - PA -207008

tachnical data and scope of delivery

as specified below

021

Phase separation element for Pos. 01

type FTC Hi/500-CM-N

material

body

stainless stoel 1,4571

medium of

coalescence

gasket

micro stainless steel type $\mathrm{F}+\mathrm{N}$

PTFE

031 Filter bag for pre-titer F1

type POXL-01-P01

grade of filtuation

material

$25 \mathrm{sm}$

Polvpropylene

C 828,00

E 21,30 
Page 2

of Quotation Pl 22411

FRANKEN

to Argonne Nation Laboratory, Argonne IL 60439-4837

of June 17, 2002

4. Stainless steel is sultable for the separation task.

5. To protect the sight glasses egainst chernical attack we might use a thin plastic film made of PP or PTFE. Ploase give us further information concerning this poirt.

We quote as follows:

I Prices

II Technical data of the testing plant and the phase soparation units

III Recommended process data for pilot plant scale for aqueous raffinate

1 Prices

Pos. Oty Description/type Unit price

type FP 200-S (pre-filter and phase separator)

$\epsilon 14.965,00$

without phase separation elemem

according to drawing no. O - PA -207008

technicel data and scope of dellvery

as specified below

021 Phase separation element for Pos. 01

€ 828,00 type FTC III/500-CM-N

material

body

stainless steol 1.4571

medium of

coalescence micro stainless sted type $F+N$

gasket PTFE

031 Filter bag for pre-filter F1

type POXL-01-P01

grade of filtration

$25 \mu \mathrm{m}$

material

Polypropylene

$\epsilon \quad 21.30$

$$
-3-
$$




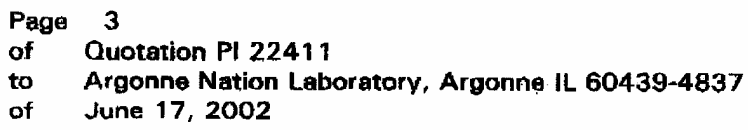

of Quotation PI 22411

to Argonne Nation Laboratory, Argonne IL 60439-4837

of June 17, 2002

\section{Pos. Oty Description/type}

041 set Filter elements for pre-filter F2 type POXL-01-P01 grade of filtration material (1 set $=4$ pieces $)$

051
Unit price

e 38,00

\section{$5 \mu \mathrm{m}$}

Polypropylene

645.00/day

II Technical data of the testing plant and the phase separation units

\author{
All components are ready for use and mounted into a mobile frame for \\ connection. \\ design \\ material \\ vessel \\ gaskets \\ connection flange \\ sight glasses \\ design \\ sight diameter \\ material \\ flange, counter flange \\ sight glass \\ gaskets \\ $-1 /+6$ bar $\max .150^{\circ} \mathrm{C}$ \\ stainless steel 1.4571 \\ PTFE \\ ANSI B $16.5 / 1^{n} 150 \mathrm{lbs} /$ Facing RF \\ DIN 28121 \\ $100 \mathrm{~mm}$ \\ stainless steel $1.4571 / 1.4541$ \\ borosilicate glass, at product side \\ equipped with a sealing film (PP or PTFE) \\ PTFE/C4400 \\ possible operation modes according to process scheme \\ drawing no. 2 - PA - 207009 \\ - only phase separator \\ - pre-filter 1 (bag filter) + phase separator \\ - pre-filter 2 (filter elements) + phase separator \\ - pre-filter 1 (bag filter) + pre-filter 2 (filter elements) + phasa separator
}


Page 4

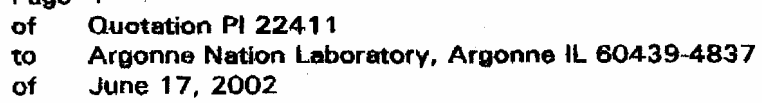

Phase separation unit

This phase separation unit can be equipped with a phase separation element of type FTC III/500. Hereby it is possible to adapt the micro fiber bed of this element individually to the separation task, for example concerning the micro fiber material, thickness of the micro fiber or the porosity of the micro fiber bed.

design

material

gasket

Efficiency of separation: adapred to vessel PT 200 and able to be equipped with (1) phase separation element of type FTC III/500

stainless steel 1.4571

PTFE

depending on the phase separation element droplets of the dispersed phase can be separated down to a diameter of $1 \mathrm{\mu m}$.

Pressure loss:

new

depending on the used phase separation element

max. allowed

$<500$ mbar (typical < 100 mbar)

1,5 bar

III Rocommended process data for pilot plant scale for aqueous raffinate

total flow rate

operating temperature

operating pressure maximum

solids

main phase (coherent phase)

$\mathrm{pH}$

viscosity

specific weight

dispersed phase

percent of total flow

viscosity

specific weight

interfacial tension between main and dispersed phase
$300 \mathrm{t} / \mathrm{h}$ to $\max .750 \mathrm{l} / \mathrm{h}$ (to be varied)

$22-32^{\circ} \mathrm{C}$

pressure drop of the phase separation stage

typical 0,1 bar to max. 1,5 bar

none (pre-filter if needed)

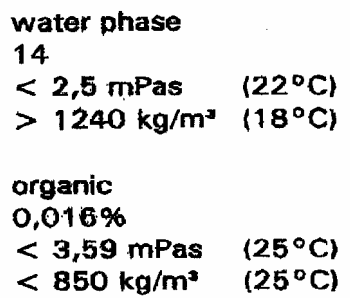

$18,8 \mathrm{dynes} / \mathrm{cm}$

$$
-5 \text { - }
$$


Page 5

Quotation PI 22411

Argonne Mation Laboratory, Argonne IL 60439-4837

June 17, 2002

Documentation:

Terms:

Validity:

Delivery time:

Payment:

Guarantee: 3-fold, english

EXW, excl. sea worthy packing, excl. taxes/duties

until October 31, 2002

3 weeks

according to mutual agreement

12 months

If you have any further questions, please do not hesitate to contact us.

Yours sincerely

FRANKEN FILTERTECHNIK KG
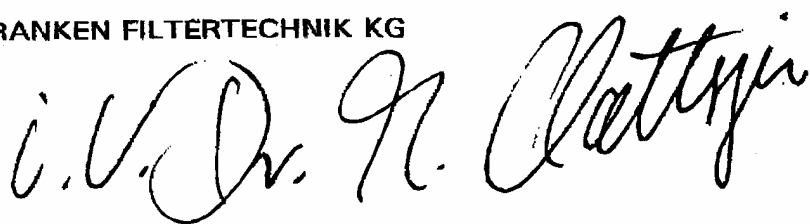

Encl. 


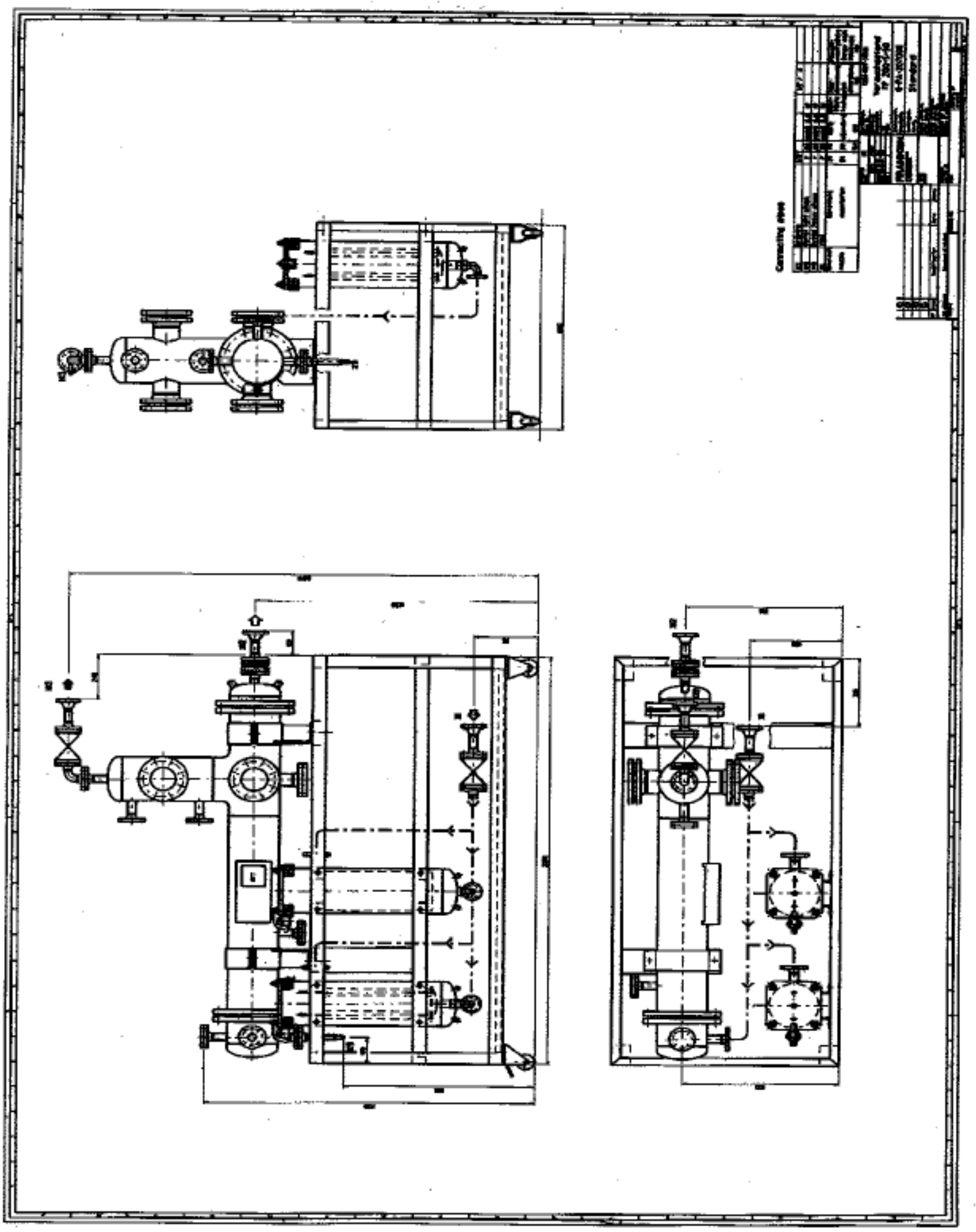




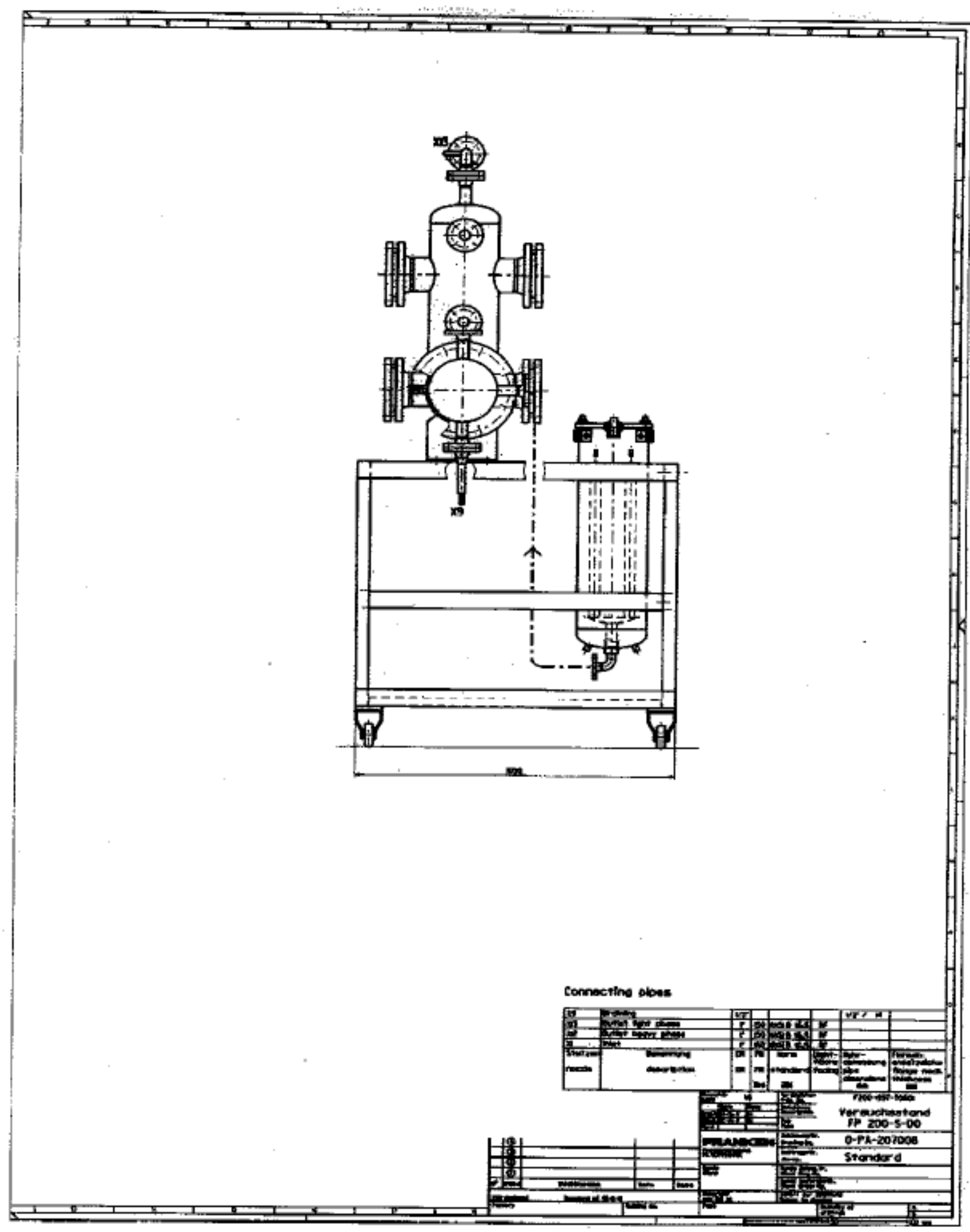




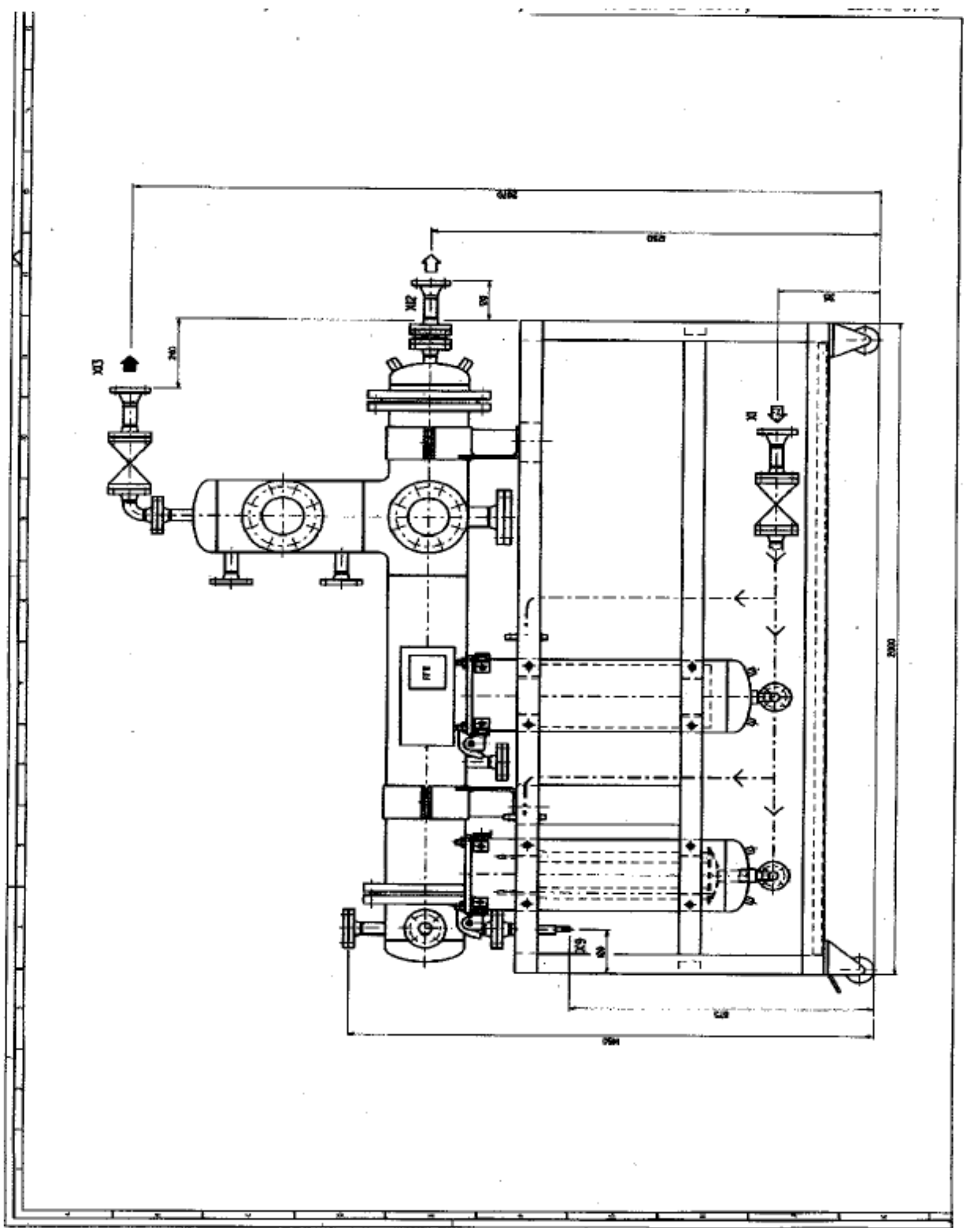




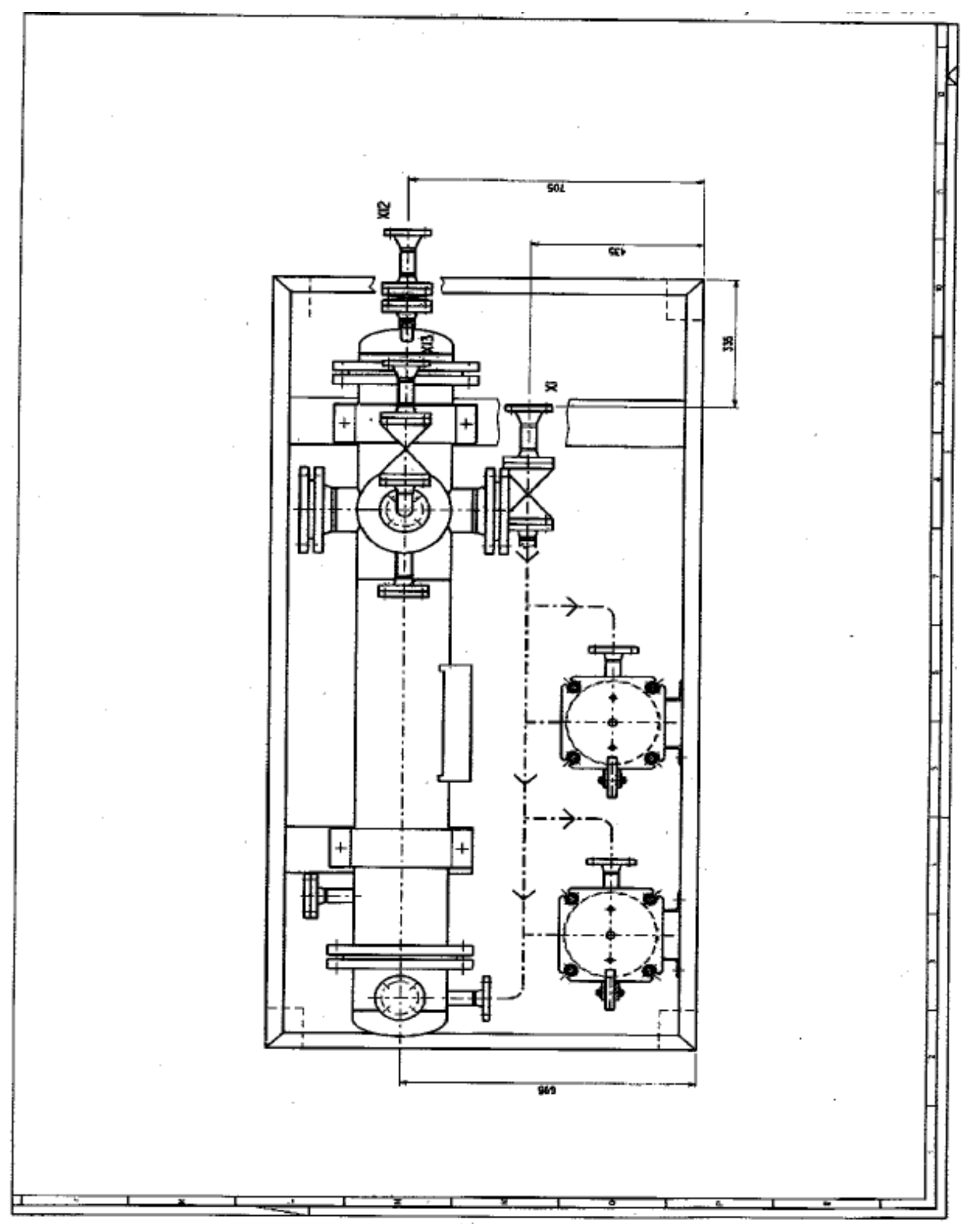




\section{TIKDCH-OTTO YORK}

SEPARATIONS TECHNOLOGY

A Koch-Gittach, Inc. Businass Group

Argonne National Laboratory

9700 South Cass Ave CMT/205

Argonne, IL 60439-4837

T) $630-252-1540$

F) $630-252-5246$

Attn: Ms. Monica Regalbuto, Ph.D.

RE: Coalescer

Date: $5 / 28 / 2002$

KOY \#: CHWZ0205029 R.1

We are pleased to submit the following quotation for our Koch-Otto York Coalescer equipment.

\section{DESIGN CONDITIONS:}

\begin{tabular}{|c|c|}
\hline Flow Rate (Total) & $3.21 \mathrm{gpm}$ \\
\hline Continuous Phase & $3.21 \mathrm{gpm}$ \\
\hline Dispersed Phase ....... & TRACE \\
\hline Density: & \\
\hline Continuous Phase & $1.24 \mathrm{~g} / \mathrm{mL}$ \\
\hline Dispersed Phase ......... & $0.85 \mathrm{~g} / \mathrm{mL}$ \\
\hline Viscosity: & \\
\hline Continuous Phase & $2.5 \mathrm{cP}$ \\
\hline Dispersed Phase . & $3.59 \mathrm{cP}$ \\
\hline Interfacial Tension ... & 18.8 dynes $/ \mathrm{cm}$ \\
\hline Design Temperature . & $200^{\circ} \mathrm{F}$ \\
\hline Design Pressure ...... & 15 psig \\
\hline
\end{tabular}

\section{EOUIPMENT DESCRIPTION:}

\begin{tabular}{|c|c|}
\hline Quantity .. & One (1) \\
\hline & $12 * \varnothing \times 24 *$ Thick KY-F4 \\
\hline M.o.C.-Coalescer .................... & FEP TEFLON $\circledast / 316 L$ \\
\hline $\begin{array}{l}\text { Vessel Size } \ldots \ldots \ldots \ldots \ldots \ldots \ldots \\
\text { M.o.C.-Vessel ................ }\end{array}$ & $\begin{array}{l}12 " \mathrm{OD} \times 60 " \mathrm{~S} / \mathrm{S} \text { per attached sketch } \\
316 \mathrm{~L}\end{array}$ \\
\hline Est. Shipping Weight & $650 \mathrm{lb}$. \\
\hline
\end{tabular}

\section{ESTIMATED PERFORMANCE:}

Coalescer efficiency will be essentially $100 \%$ of all particles greater than 40 microns in diameter. Pressure drop across the Coalescer only when saturated with liquid, but free of undissolved solids, will not exceed 3.0 inches W.G. Please see attached performance curve.

\footnotetext{
4111 East 37th Street North * Wichita, Kansas 67220 - 316/828-7181 - FAX 316/828-8018

42 Intervale Road - P.O. Box 3100 - Parsippany, New Jersey 07054-3100 * 973/299-9200 - 800/524-1543 * FAX 973/299-9401

6611 Killough Road - Houston, Texas 77086 - 281/445-7026 - 800/736-7036 - FAX 281/445-7032
} 
Page 2

As the vessel design incorporates a smaller boot length and diameter, a continuous interface level measurement device and a vortex breaker on the dispersed phase outlet at the bottom of the boot are recommended.

Note: The material of construction for all equipment as well as design pressure \& temperature are offered for your evaluation of applicability. Please let us know if you require additional information.

\section{EQUIPMENT PRICE:}

The price of the equipment as described will be $\$ 9,955.00$ F.O.B. point of manufacture, domestic crating, freight collect. Terms are net 30 days. This price is firm for 30 days from the date of this proposal and does not include any applicable taxes.

\section{SHIPMENT:}

Drawing (s): 2-3 weeks after receipt of purchase order, for approval.

Shipment: $\quad 4-6$ weeks after receipt of approved drawings.

Note: Drawing and shipping times are subject to review at time of order.

This quotation, and specifically the prices quoted, are offered contingent upon your express acceptance of Koch's Terms and Conditions, stated on the reverse side of Page 1.

If you have any questions or require additional information, please do not hesitate to contact us, or our representative in your area:

Somes-Nick \& Co.

407 S. Dearborn St.

Chicago, IL 60605

(312) 427-5892 Ph.

(312) 427-0631 Fax

Attn: Sandy

Thank you for your interest in our Koch-Otto York Coalescer equipment. We look forward to serving you.

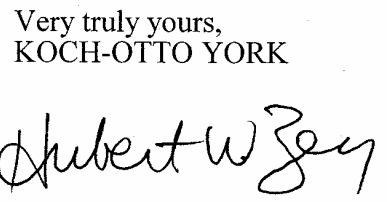

Hubert W. Zey

Sales Engineer 


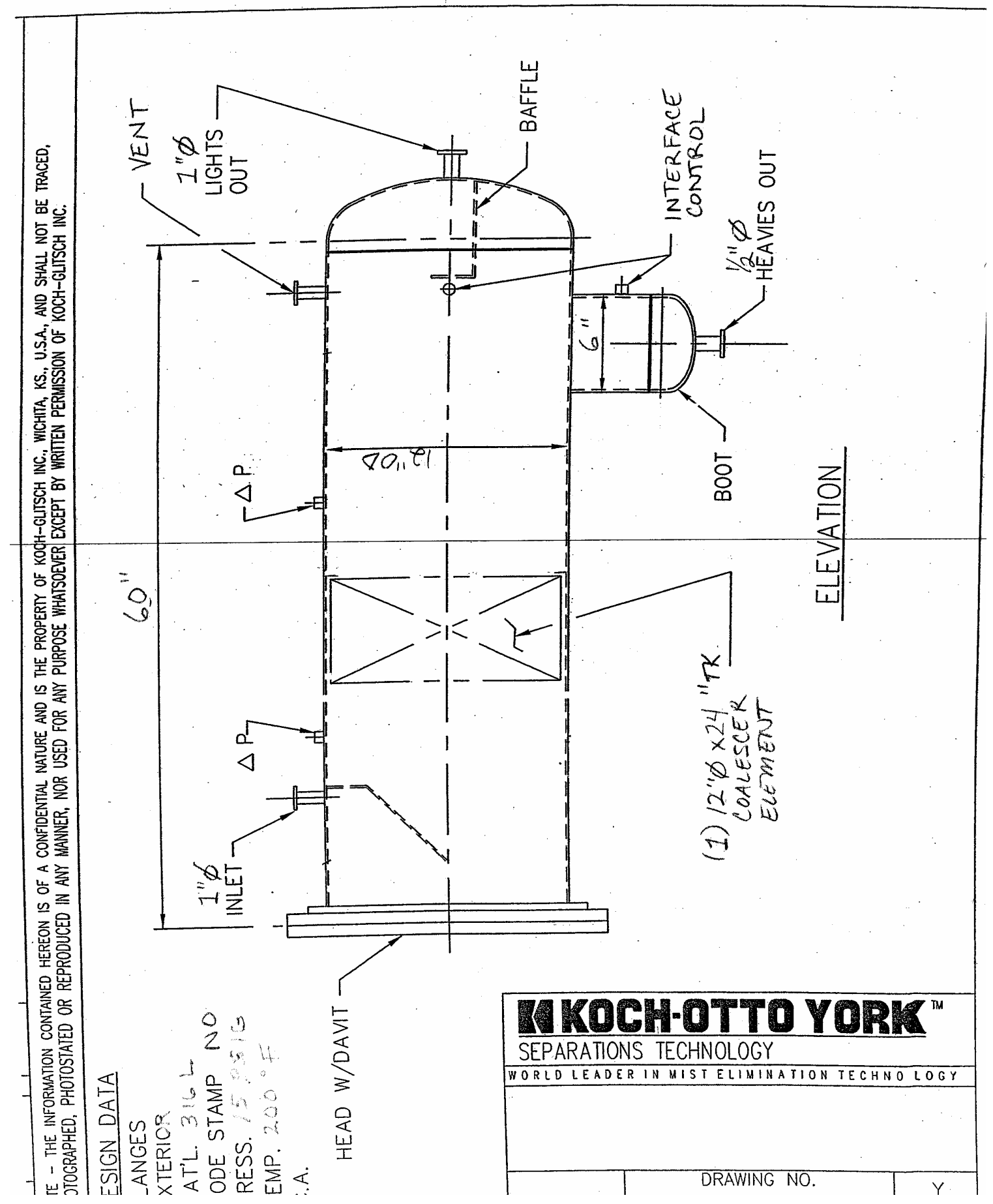




\section{Coalescer Inlet and Outlet Distributions}

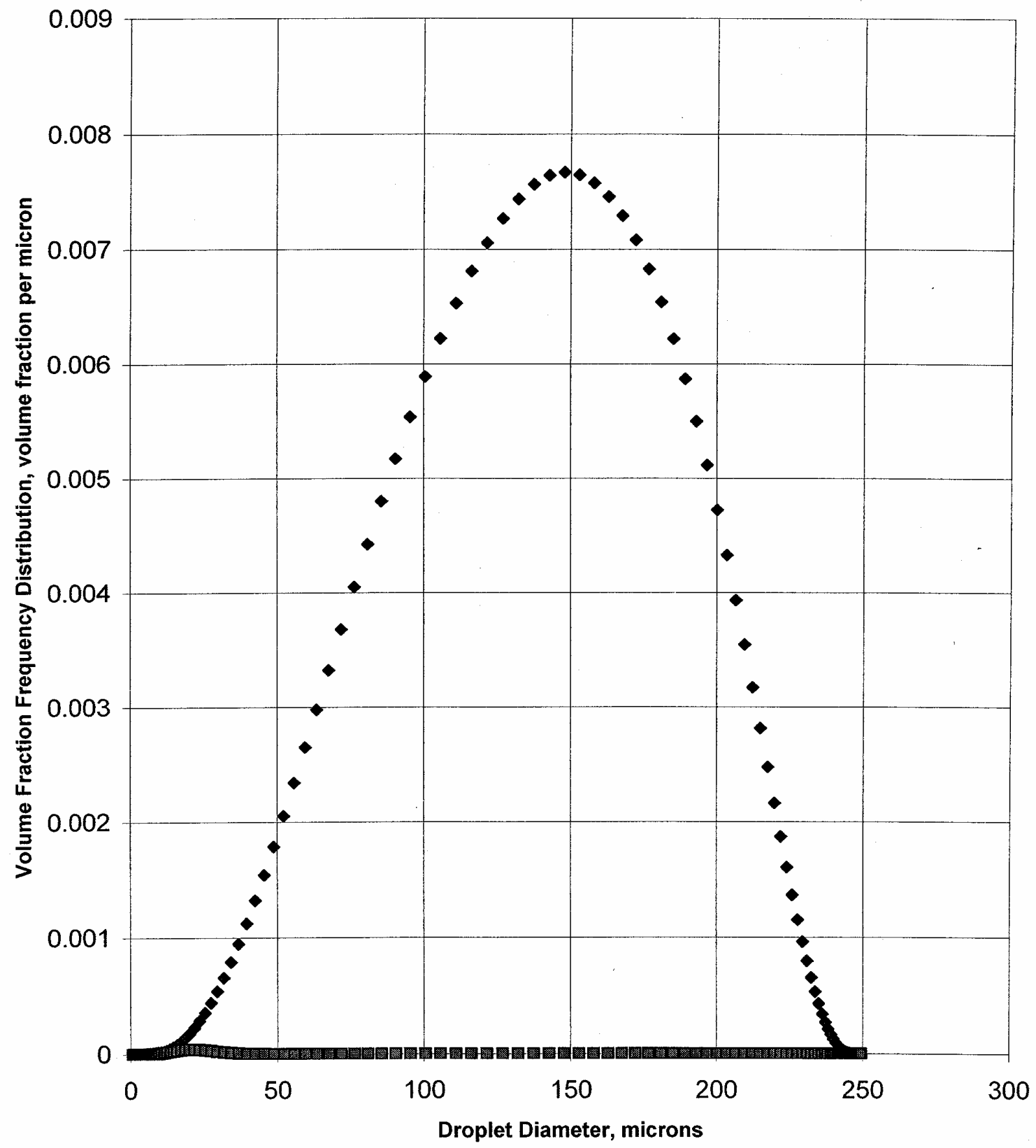

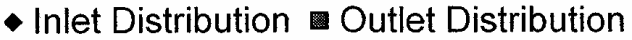




\section{Estimated Coalescer Efficiency}

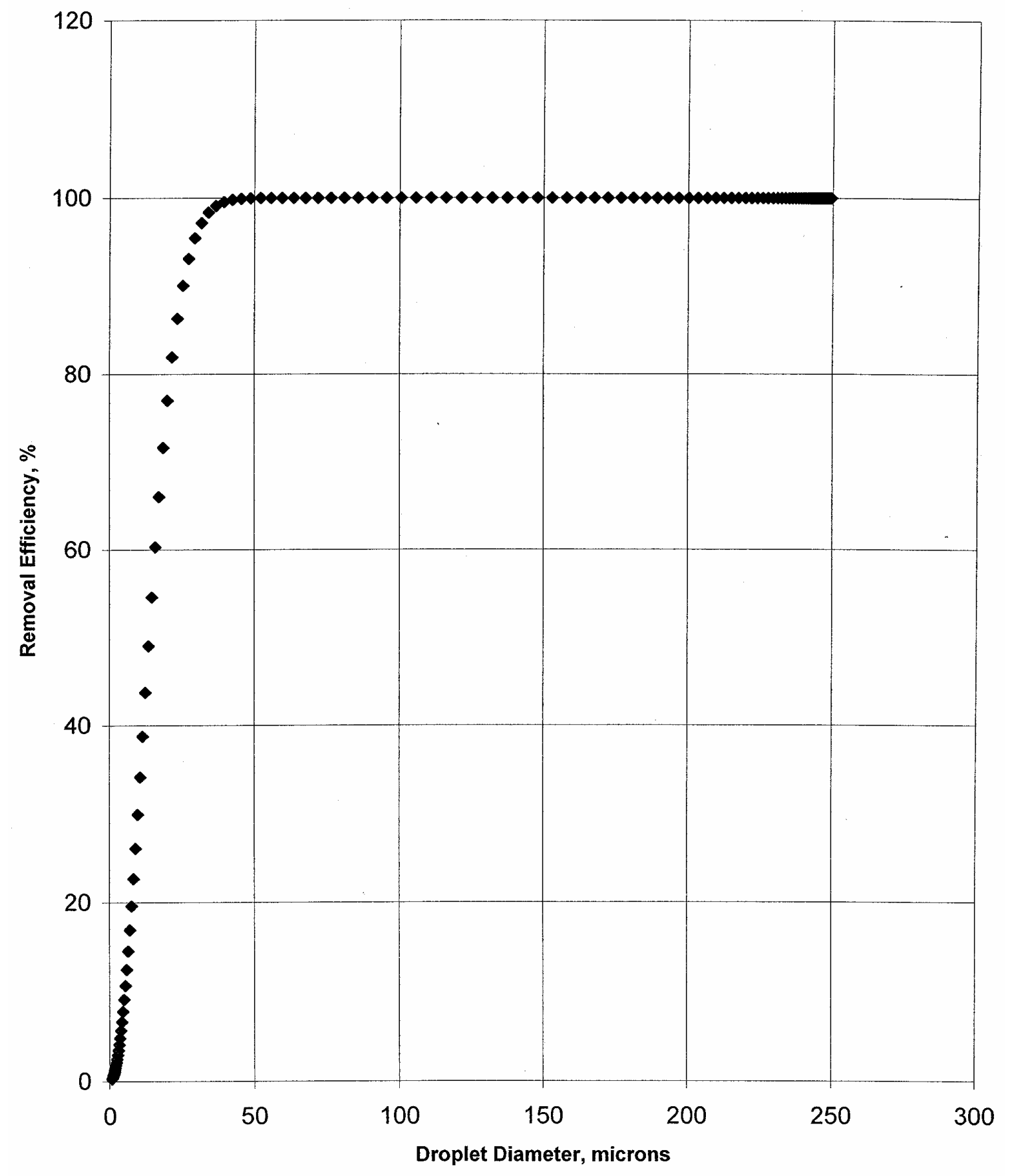




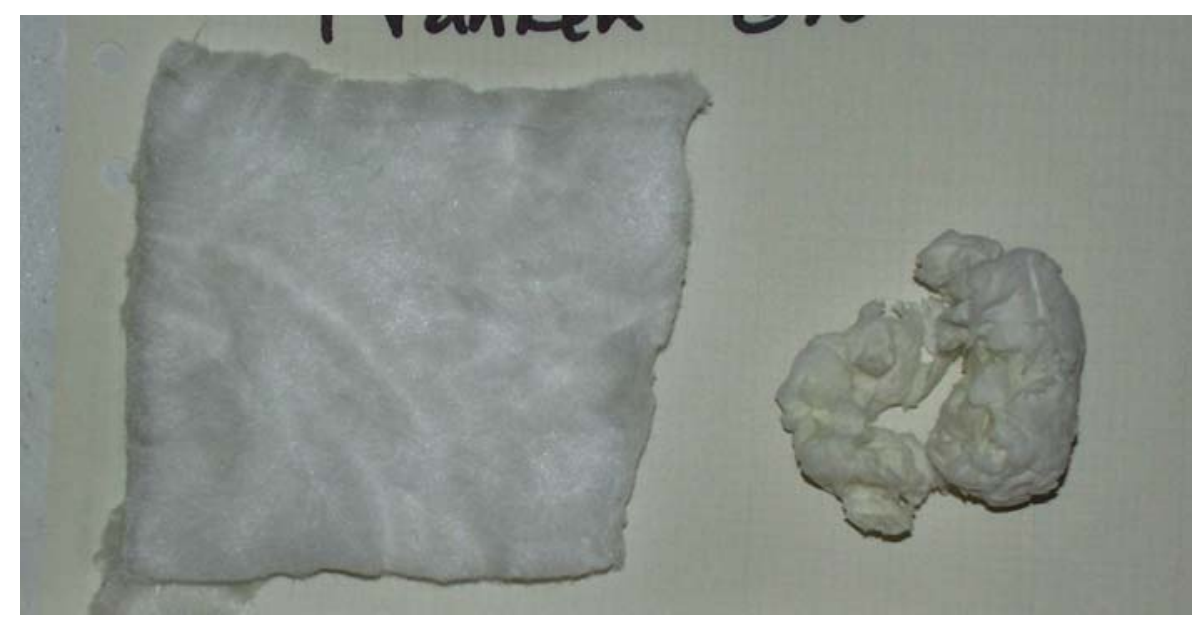

Figure E.1. Franken Filtertechnik GN Silica-Based Media. Sample was compressed to remove entrained liquid.

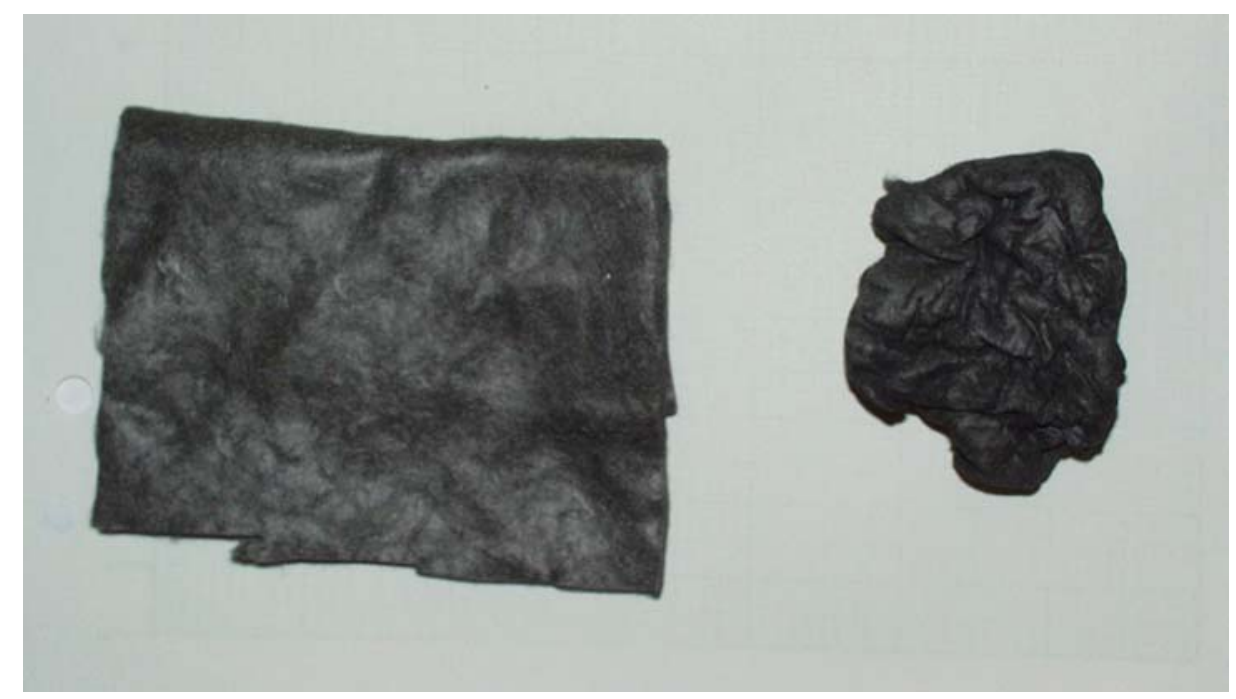

Figure E.2. Franken Filtertechnik MF Stainless Steel Media. Sample was compressed to remove entrained liquid. 


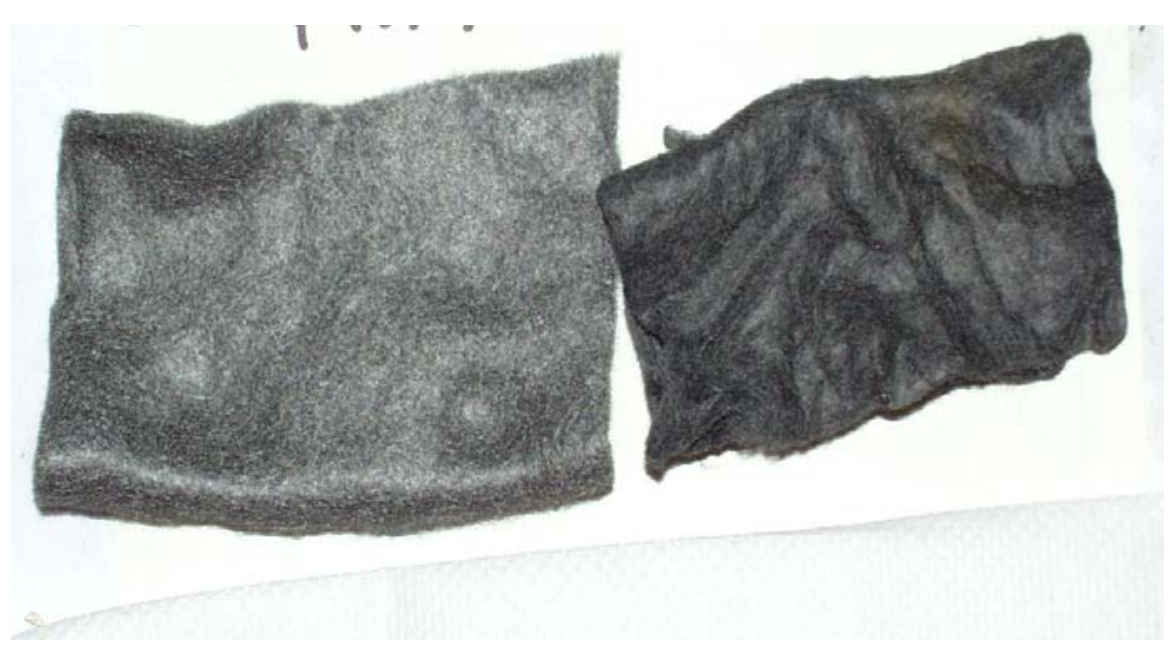

Figure E.3. Franken Filtertechnik MN Stainless Steel Media. Sample was compressed to remove entrained liquid.

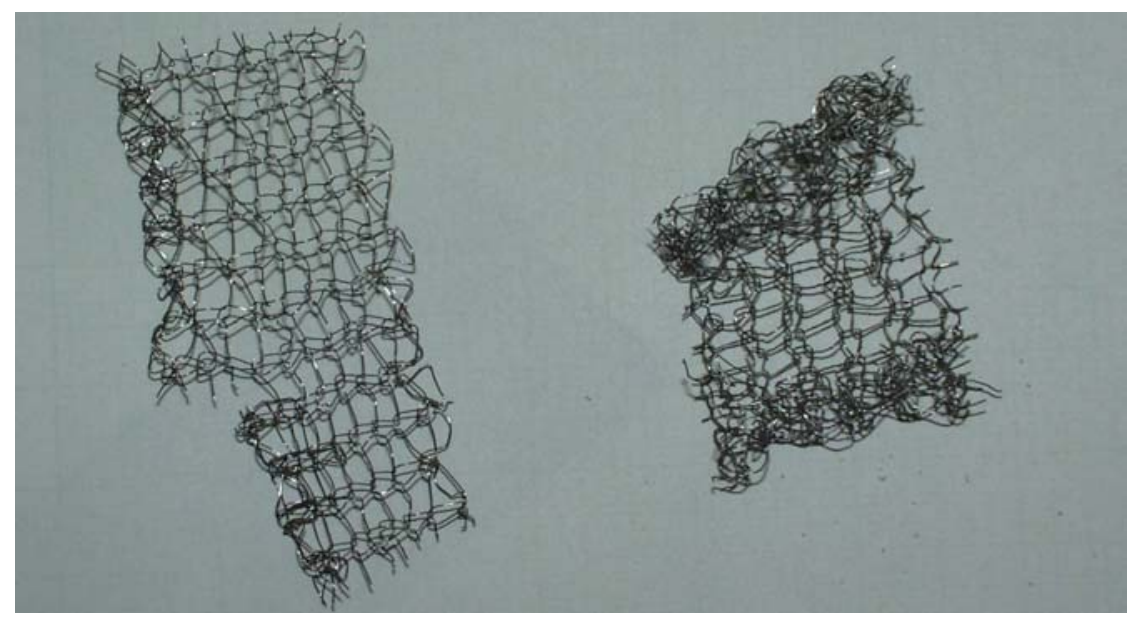

Figure E.4. Koch Otto-York 316SS Mesh Sample, Stainless Steel Mesh 


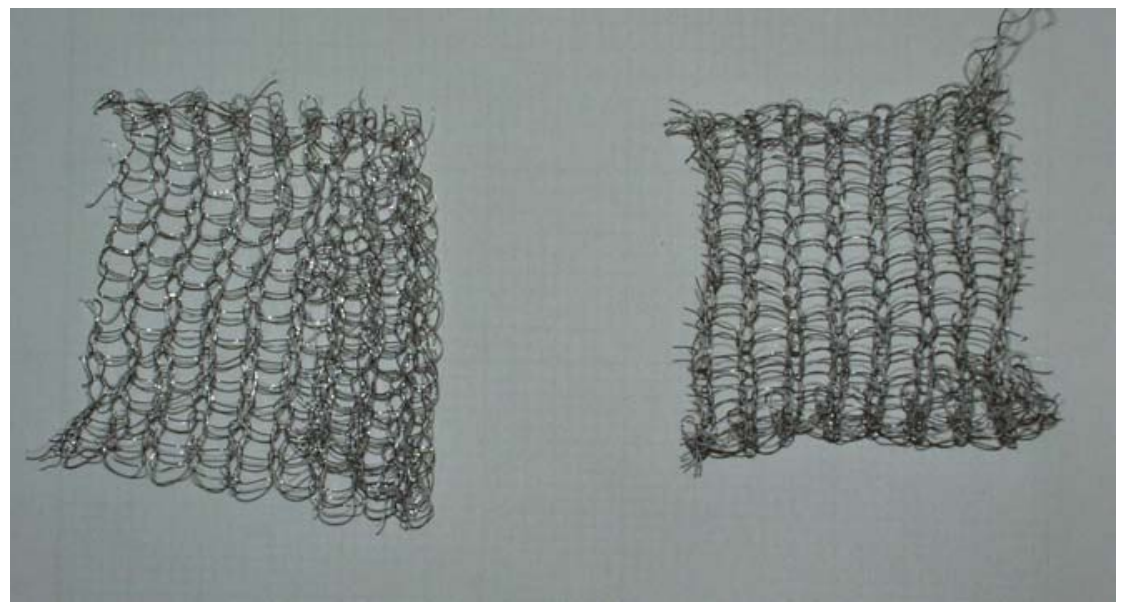

Figure E.5. Koch Otto-York 316SS/TEF Mesh Sample, Stainless Steel and Fluoropolymer Mesh

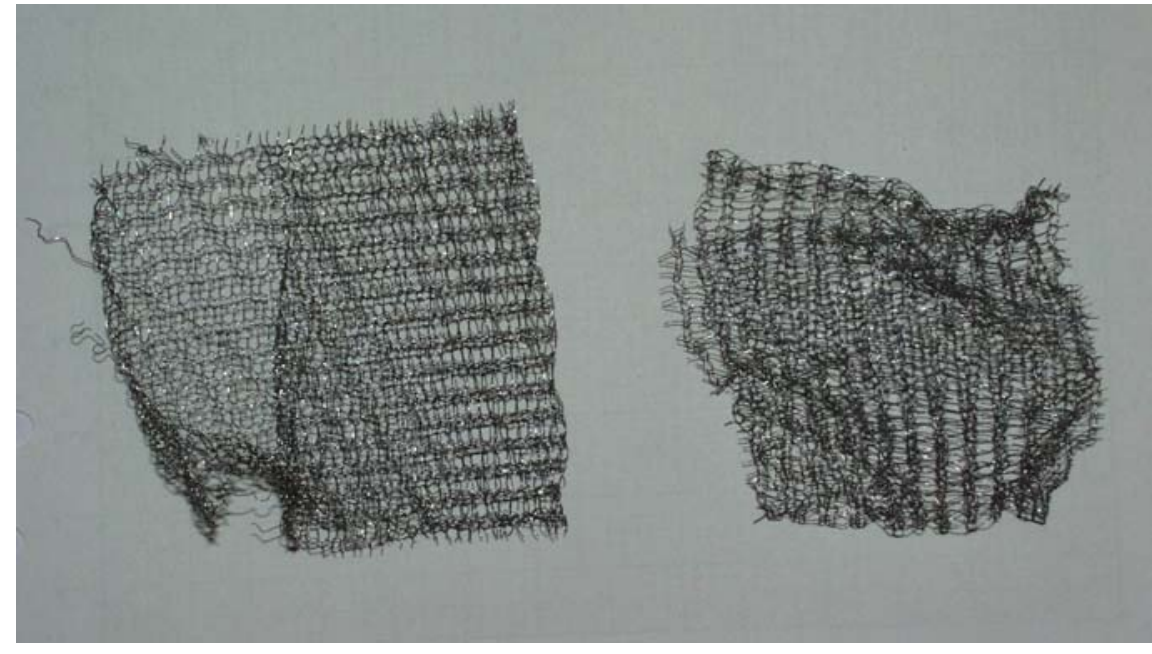

Figure E.6. Mercer International Sample 1, Stainless Steel Mesh

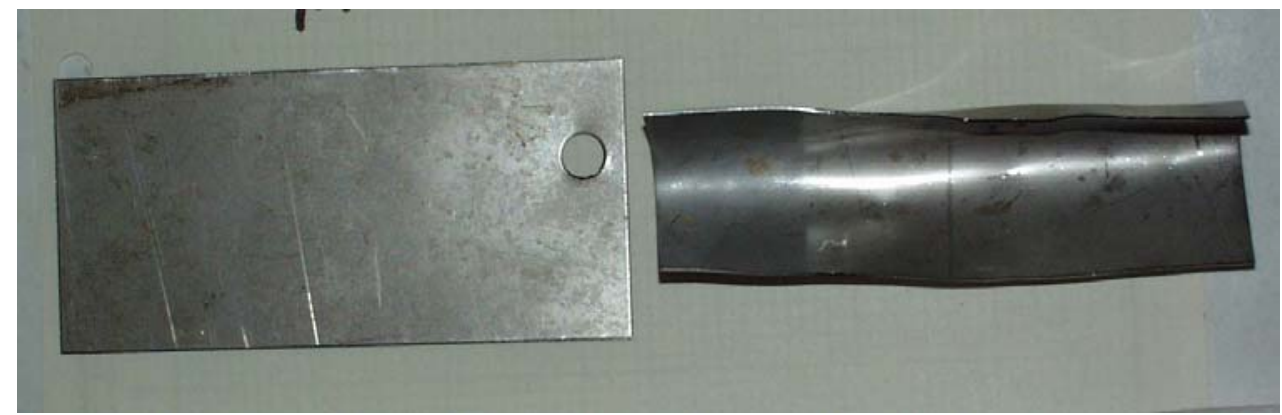

Figure E.7. Mercer International Sample 2, Stainless Steel Coupon 


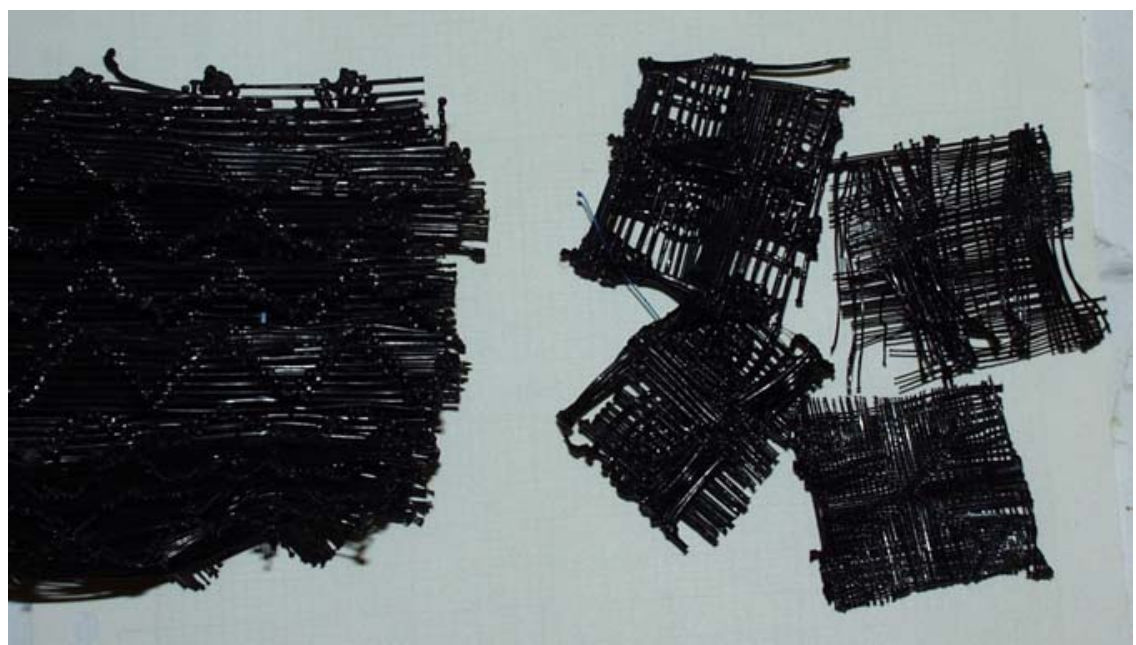

Figure E.8. McTighe Industries Sample A, Polymer Mesh Mixture

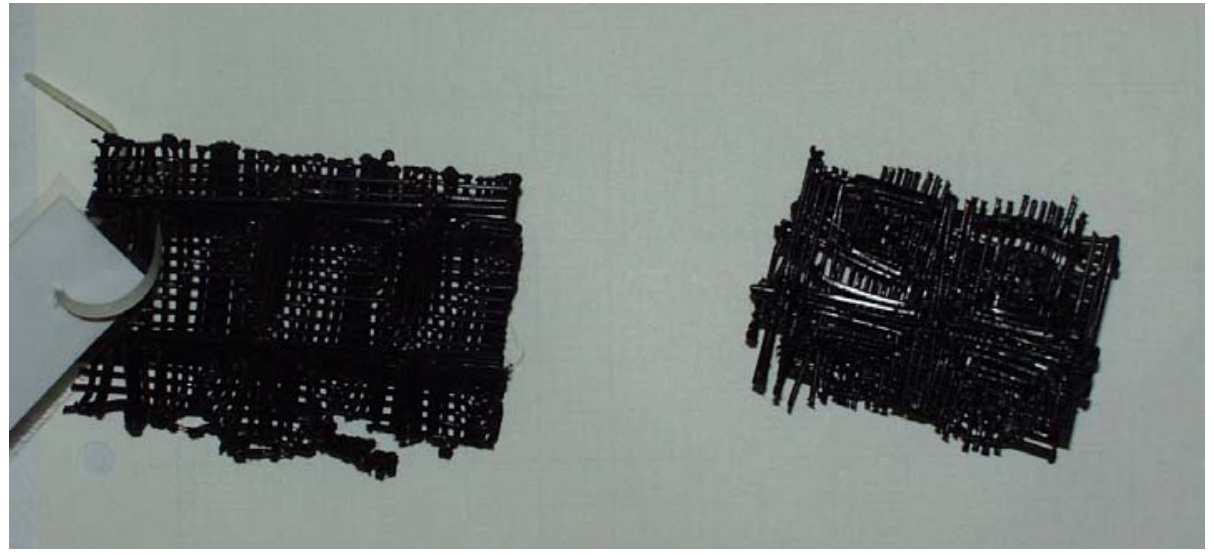

Figure E.9. McTighe Industries Sample B, Polymer Mesh

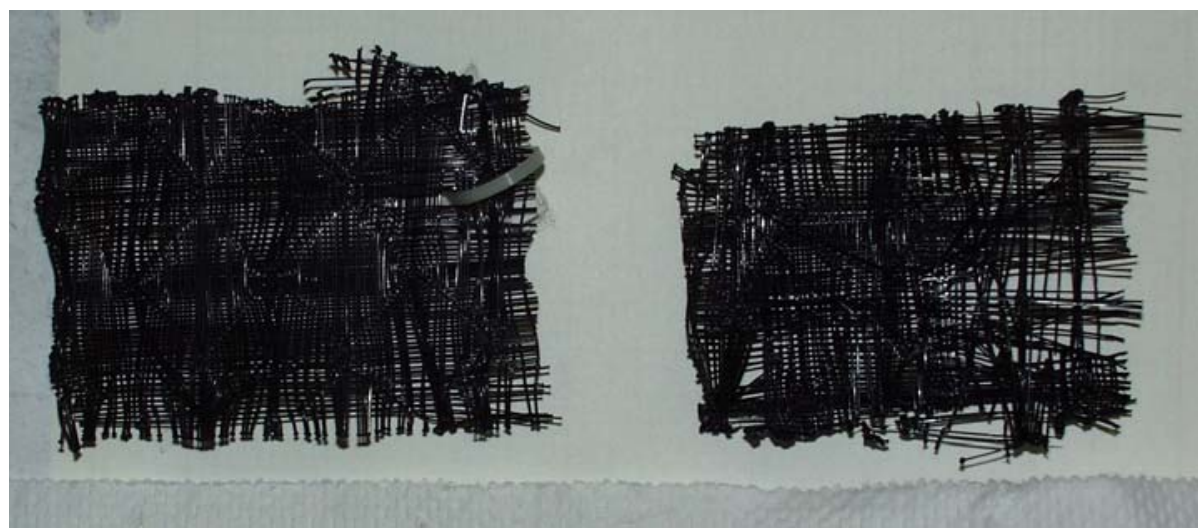

Figure E.10. McTighe Industries Sample C, Polymer Mesh 


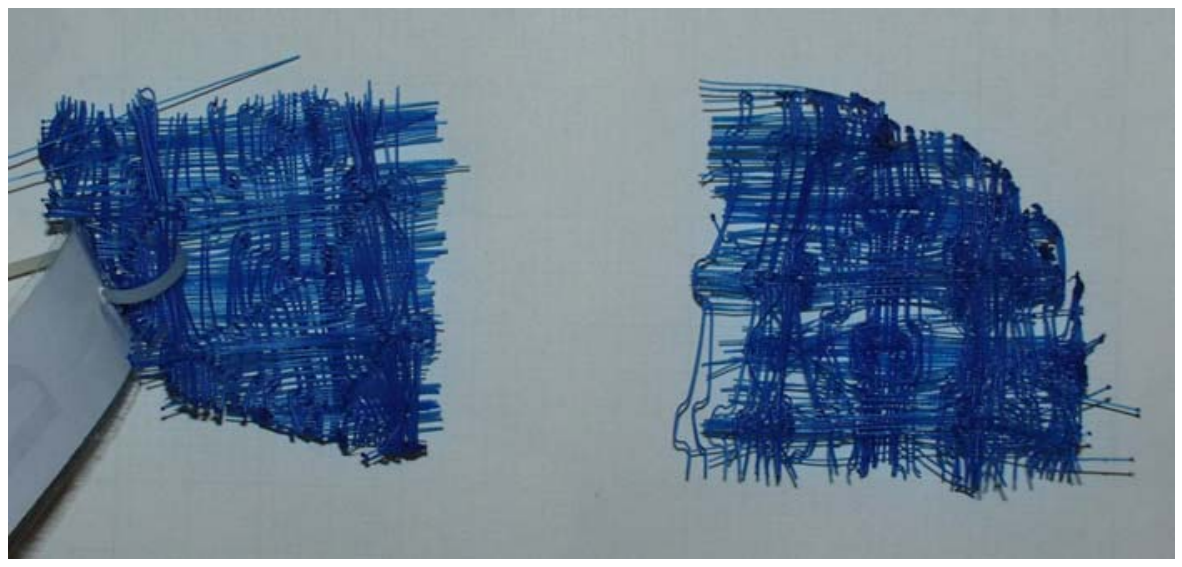

Figure E.11. McTighe Industries Sample D, Polymer Mesh

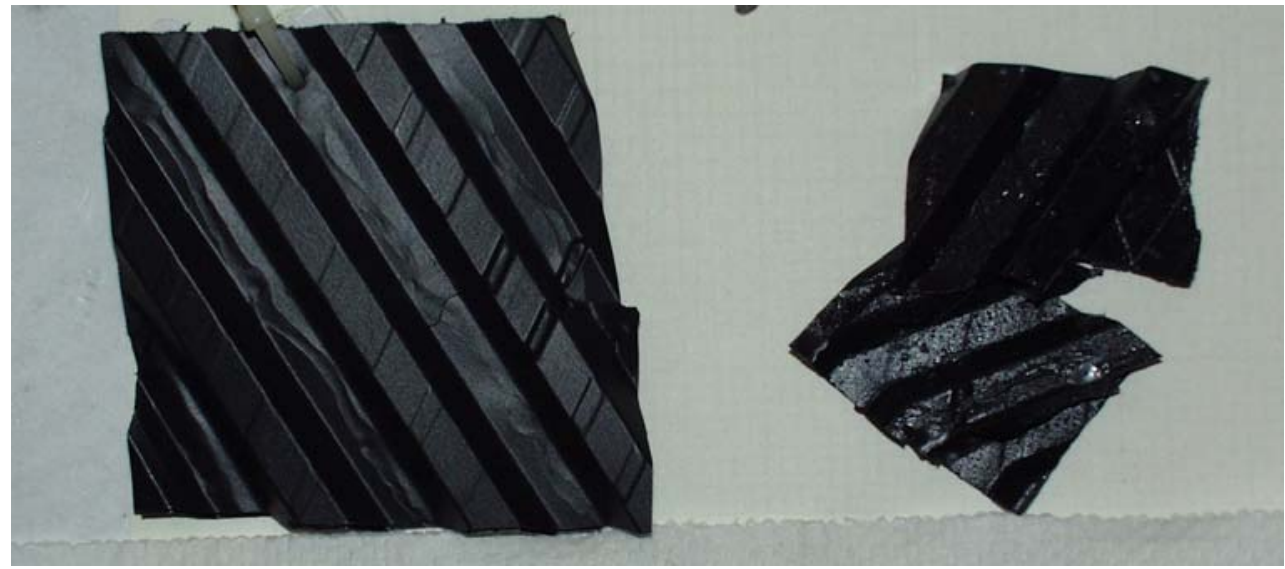

Figure E.12. McTighe Industries Sample E, Polymer Coupons 


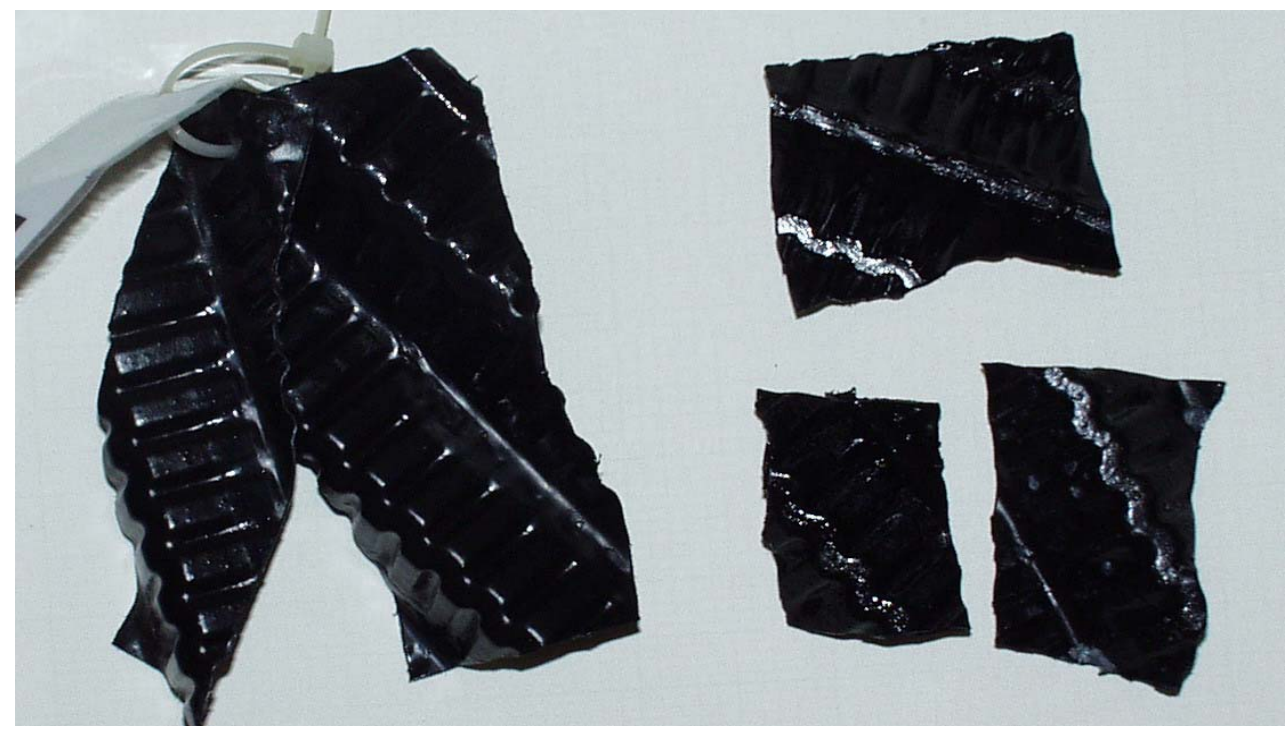

Figure E.13. McTighe Industries Sample F, Polymer Coupons

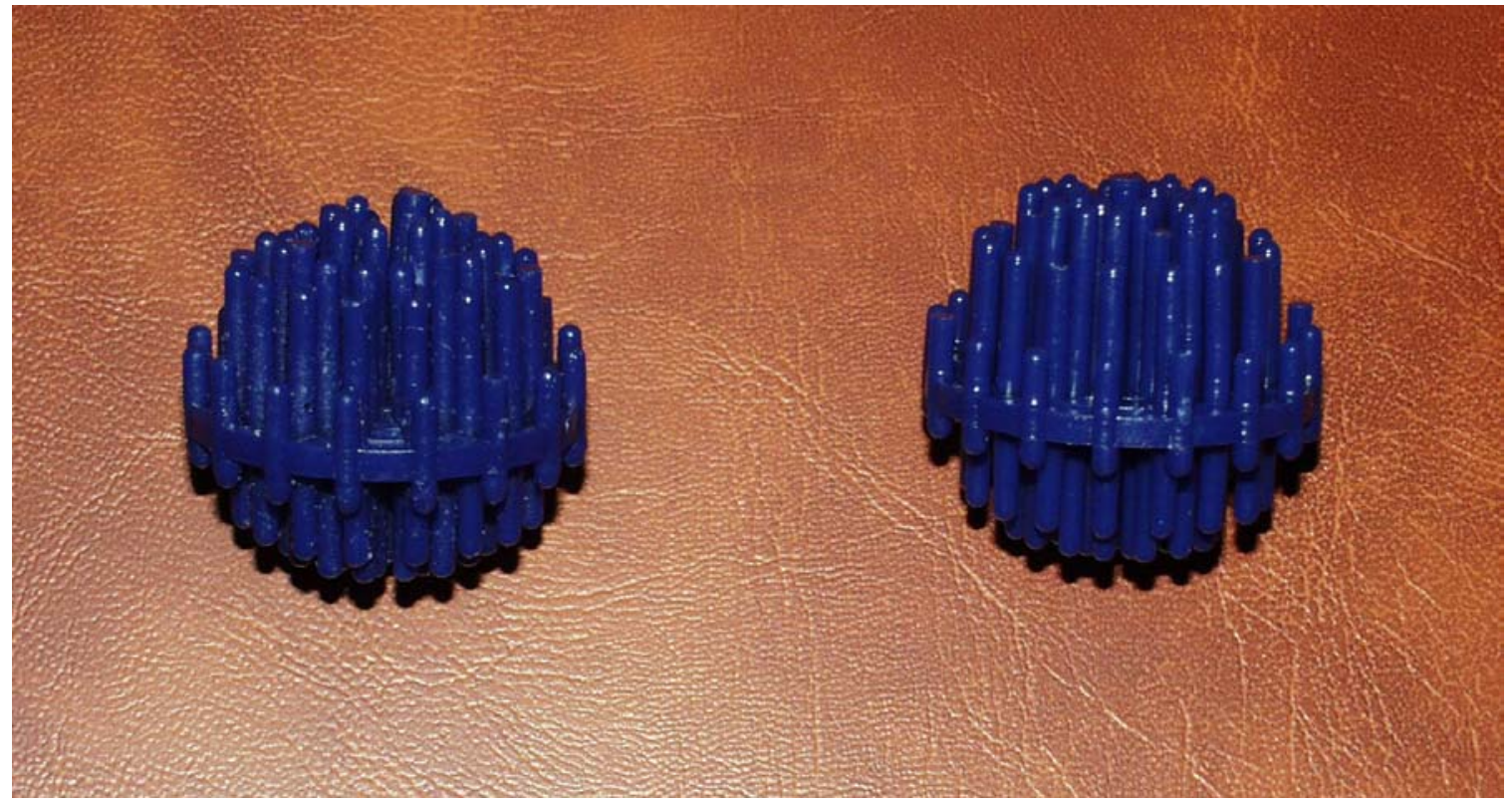

Figure E.14. Filter Innovations Polymer Spheres 


\section{Distribution for ANL-02/34}

Internal (Printed and Electronic Copies):
S. B. Aase
M. L. Dietz
K. L. Nash
H. A. Arafat
A. V. Guelis
C. Pereira (5)
A. J. Bakel
J. E. Helt
M. C. Regalbuto
D. B. Chamberlain
R. A. Leonard
G. F. Vandegrift

Internal (Printed Copy Only):

V A. Davis

M. J. Steindler

S. K. Zussman (2)

Internal (Electronic Copy Only):
D. L. Bowers
E. C. Gay
C. J. Mertz
Y. I. Chang
M. R. Hale, TIS
J. I. Sackett
R. J. Finch
D. Lewis
J. Sedlet

External (Printed and Electronic Copies):

J. F. Birdwell, Oak Ridge National Laboratory, Oak Ridge, TN

P. V. Bonnesen, Oak Ridge National Laboratory, Oak Ridge, TN

S. G. Campbell, Westinghouse Savannah River Company, Aiken, SC

J. T. Carter, Westinghouse Savannah River Company, Aiken, SC

S. Clifford, Westinghouse Savannah River Company, Aiken, SC

L. H. Delmau, Oak Ridge National Laboratory, Oak Ridge, TN

H. D. Harmon, Westinghouse Savannah River Company, Aiken, SC

R. T. Jubin, Oak Ridge National Laboratory, Oak Ridge, TN

J. D. Law, Idaho National Engineering and Environmental Laboratory, Idaho Falls, ID

R. Leugemors, Pacific Northwest National Laboratory, Richland, WA

G. J. Lumetta, Battelle, Pacific Northwest National Laboratory, Richland, WA

M. Maxted-Miles, DOE-SR, Aiken, SC

B. A. Moyer, Oak Ridge National Laboratory, Oak Ridge, TN

M. Norato, Westinghouse Savannah River Company, Aiken, SC

R. A. Pierce, Westinghouse Savannah River Company, Aiken, SC

P. C. Suggs, DOE-SR, Aiken, SC

M. C. Thompson, Westinghouse Savannah River Company, Aiken, SC

T. A. Todd, Idaho National Engineering and Environmental Laboratory, Idaho Falls, ID

D. D. Walker, Westinghouse Savannah River Company, Aiken, SC

V. Wheeler, DOE-SR, Aiken, SC

External (Printed Copy Only):

C. Conner, BWX Technologies, Inc., Lynchburg, VA

K. D. Gerdes, DOE-EM, Tanks Focus Area Headquarters, Germantown, MD

T. P. Pietrok, USDOE, Richland Operations Office, Richland, WA 
B. J. Williams, Pacific Northwest National Laboratory, Tanks Focus Area Technical Team, Richland, WA

External (Electronic Copy Only):

M. A. Buckley, ANL Library-E

E. Sackett, ANL Library-W

Chemical Technology Division Review Committee Members:

H. U. Anderson, University of Missouri-Rolla, Rolla, MO

R. A. Greenkorn, Purdue University, West Lafayette, IN

C. L. Hussey, University of Mississippi, University, MS

M. V. Koch, University of Washington, Seattle, WA

V. P. Roan, Jr., University of Florida, Gainesville, FL

J. R. Selman, Illinois Institute of Technology, Chicago, IL

J. S. Tulenko, University of Florida, Gainesville, FL

W. D. Clark, DOE-SR, Aiken, SC

S. M. Dinehart, Los Alamos National Laboratory, Los Alamos, NM

R. E. Edwards, Westinghouse Savannah River Company, Aiken, SC

S. D. Fink, Westinghouse Savannah River Company, Aiken, SC

D. Hobbs, Westinghouse Savannah River Company, Aiken, SC

L. N. Klatt, Oak Ridge National Laboratory, Oak Ridge, TN

D. E. Kurath, Pacific Northwest National Laboratory, Richland, WA

K. T. Lang, USDOE, Washington, DC

J. W. McCullough, USDOE, Aiken, SC

C. P. McGinnis, Oak Ridge National Laboratory, Oak Ridge, TN

A. L. Olson, Idaho National Engineering and Environmental Laboratory, Idaho Falls, ID

M. J. Palmer, Los Alamos National Laboratory, Los Alamos, NM

L. M. Papouchado, Westinghouse Savannah River Company, Aiken, SC

R. A. Peterson, Bechtel-Washington Process Technology, Richland, WA

B. M. Rapko, Pacific Northwest National Laboratory, Richland, WA

R. D. Rogers, University of Alabama, Department of Chemistry, Tuscaloosa, AL

K. J. Rueter, Bechtel-Washington Process Technology, Richland, WA

P. Rutland, Bechtel-Washington Process Technology, Richland, WA

S. Schlahta, Pacific Northwest National Laboratory, Richland, WA

J. L. Swanson, Richland, WA

W. L. Tamosaitis, Westinghouse Savannah River Company, Aiken, SC

L. L. Tavlarides, Syracuse University, Syracuse, NY

D. W. Tedder, Georgia Institute of Technology, Atlanta, GA

V. Van Brunt, University of South Carolina, Columbia, SC

J. F. Walker, Oak Ridge National Laboratory, Oak Ridge, TN

J. S. Watson, Oak Ridge National Laboratory, Oak Ridge, TN

R. M. Wham, Oak Ridge National Laboratory, Oak Ridge, TN

W. R. Wilmarth, Westinghouse Savannah River Company, Aiken, SC 